Universidad de Lima

Facultad de Ingeniería y Arquitectura

Carrera de Ingeniería Industrial

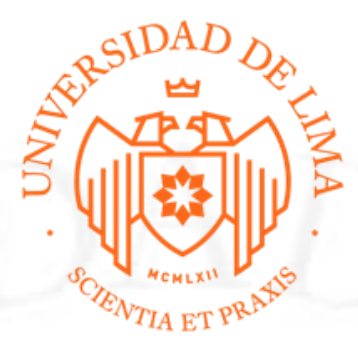

\title{
ESTUDIO DE PREFACTIBILIDAD PARA LA INSTALACIÓN DE UNA PLANTA DE NITRÓGENO PARA EL SERVICIO DE CONGELAMIENTO IQF PARA CONCHAS DE ABANICO
}

Trabajo de investigación para optar el Título Profesional de Ingeniero Industrial

\author{
Marcelo André Morán Gálvez \\ Código 20132040 \\ Alberto Enrique Carlos Cuadros
}

Código 20130241

\author{
Asesora \\ Inés Cristina Villafana Mego
}

Lima - Perú

Julio de 2019 


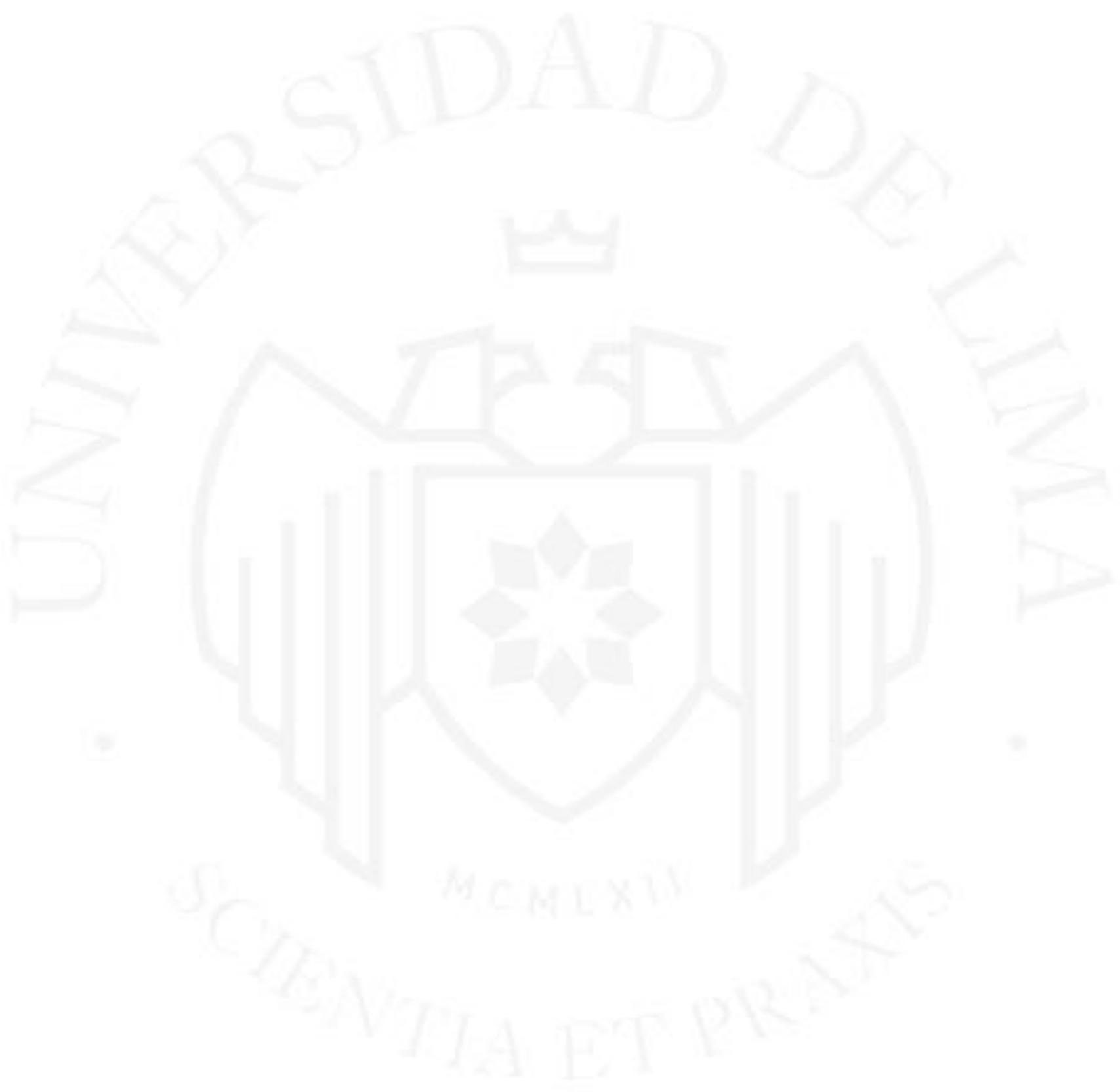




\section{PREFEASIBILITY STUDY FOR THE}

INSTALLATION OF AN INDUSTRIAL PLANT OF NITROGEN TO OFFERS FREEZING SERVICE OF PERUVIAN SCALLOPS USING THE IQF METHOD 


\section{TABLA DE CONTENIDO}

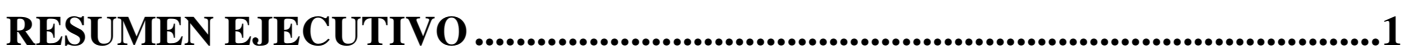

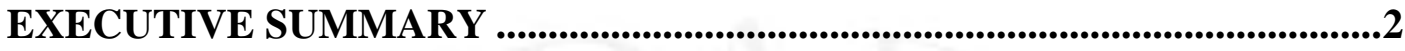

CAPÍTULO I. ASPECTOS GENERALES .............................................................3

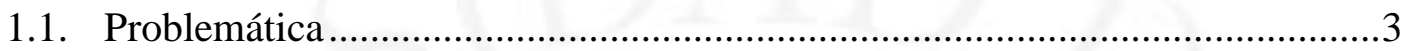

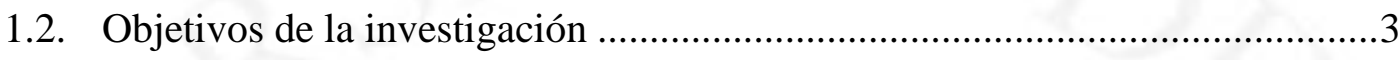

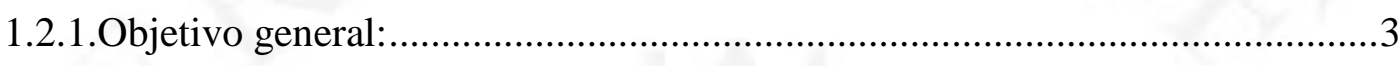

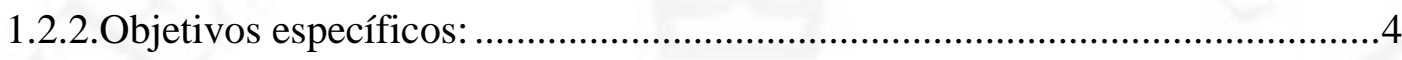

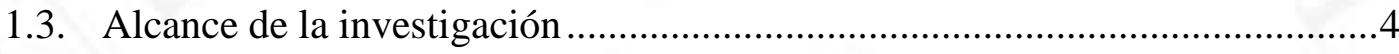

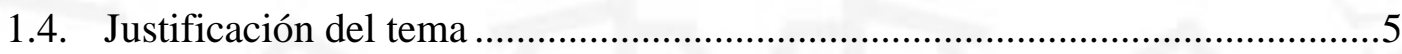

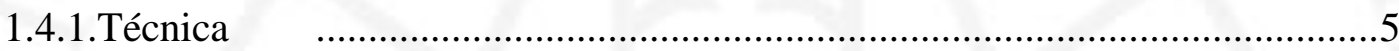

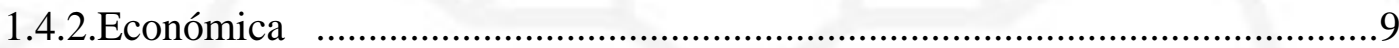

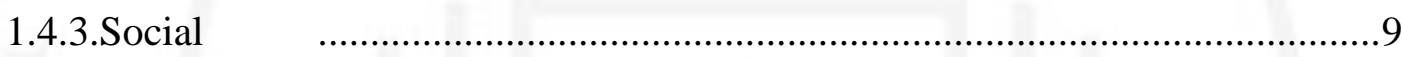

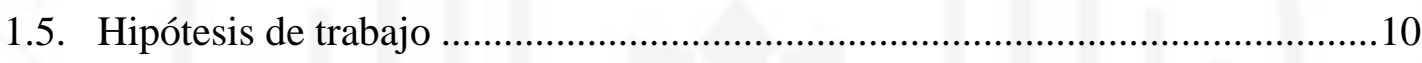

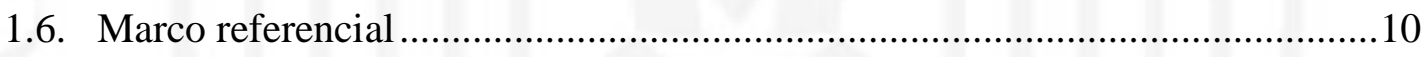

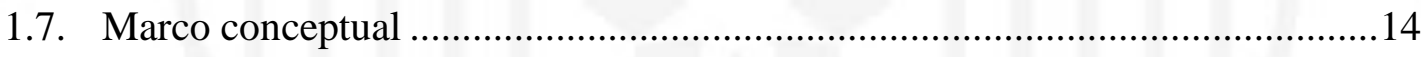

CAPÍTULO II: ESTUDIO DE MERCADO ...............................................................15

2.1. Aspectos generales del estudio de mercado ..................................................15

2.1.1.Definición del giro de negocio del servicio y tipo de servicio (profesionales,

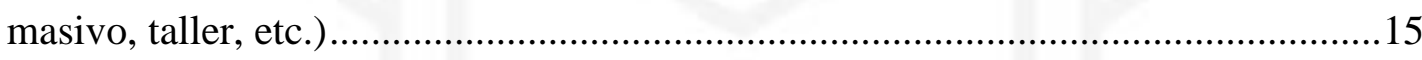

2.1.2.Principales beneficios del servicio (concepto del servicio) .............................15

2.1.3.Determinación de la metodología que se empleará en la investigación de mercado .16

2.1.4.Determinación del área geográfica que abarcará el estudio ............................17

2.1.5.Análisis del sector industrial (cinco fuerzas de PORTER) ..............................17

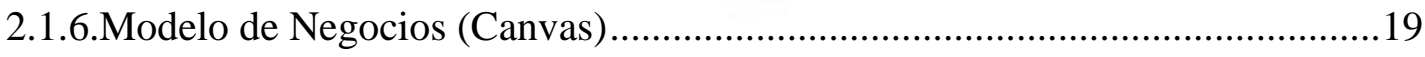

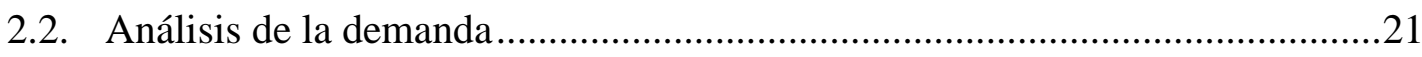

2.2.1.Data histórica del consumidor y sus patrones de consumo ............................21

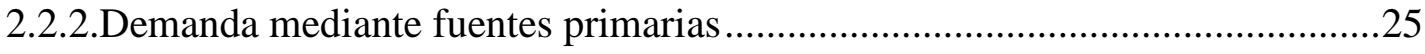

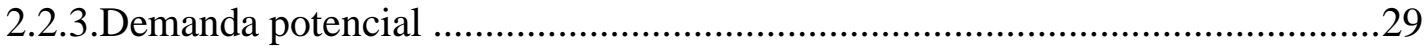


2.3. Análisis de la oferta .29

2.3.1.Análisis de la competencia. Competencia directa y sus ubicaciones. Participación de mercado (si aplica). .29

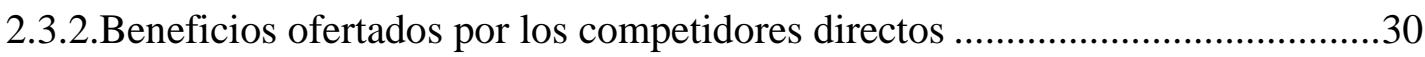

2.3.3.Análisis competitivo y comparativo (Matriz EFE) ...........................................30

2.4. Determinación Demanda para el proyecto .....................................................32

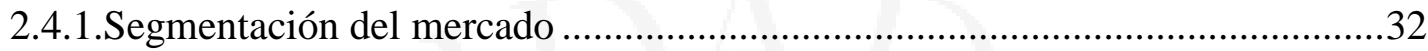

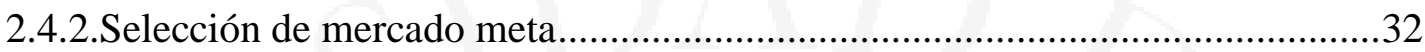

2.4.3.Determinación de la participación de mercado para el proyecto ........................33

2.5. Definición de la Estrategia de Comercialización ...............................................34

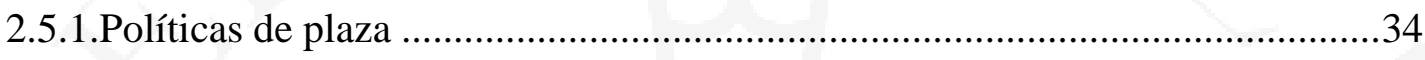

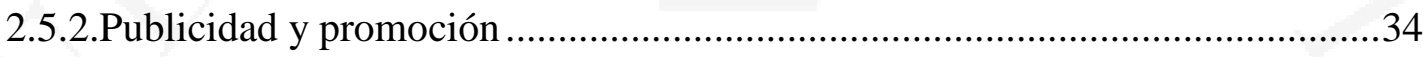

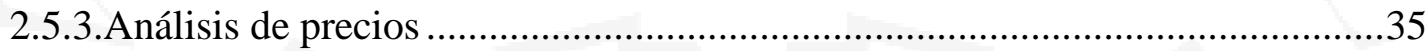

CAPÍTULO III: LOCALIZACIÓN DEL SERVICIO..............................................37

3.1. Identificación y análisis detallado de los factores de localización ....................37

3.2. Identificación y descripción de las alternativas de localización.........................38

3.3. Determinación del modelo de evaluación a emplear........................................38

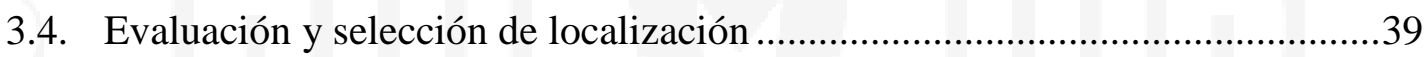

3.4.1.Evaluación y selección de la macro localización.............................................39

3.4.2.Evaluación y selección de la microlocalización ................................................43

CAPÍTULO IV. DIMENSIONAMIENTO DEL SERVICIO ................................48

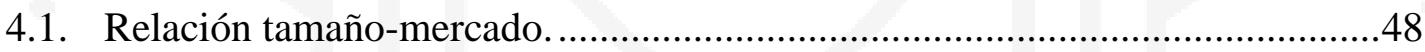

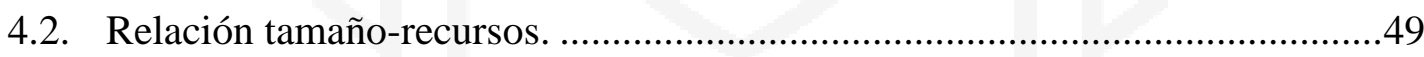

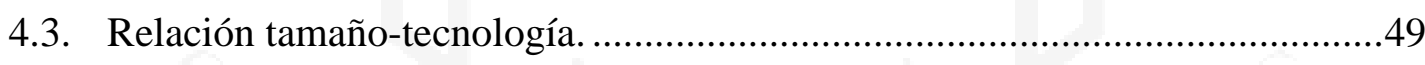

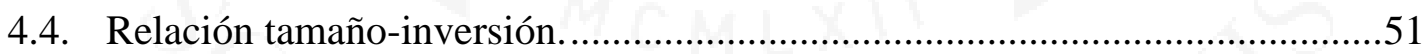

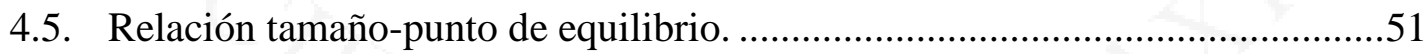

4.6. Selección de la dimensión del servicio............................................................52

CAPÍTULO V. INGENIERÍA DEL PROYECTO ..................................................53

5.1. Proceso para la realización del servicio. ..........................................................53

5.1.1.Descripción del proceso del servicio. ..........................................................53

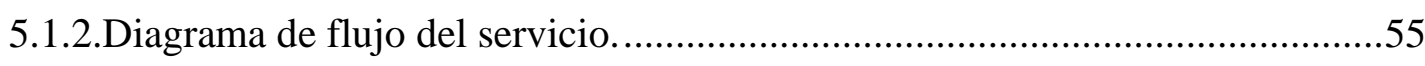

5.2. Descripción del tipo de tecnología a usarse en el servicio ...............................56

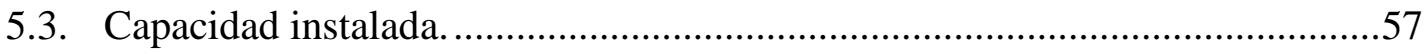


5.3.1.Identificación y descripción de los factores que intervienen en brindar el servicio .57

5.3.1.1.Factor Movimiento. .57

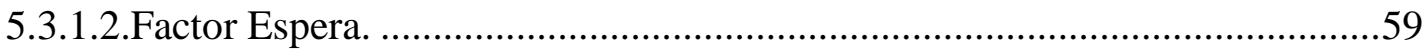

5.3.2.Determinación del factor limitante de la capacidad.......................................62

5.3.3.Determinación del número de recursos del factor limitante...........................63

5.3.4.Determinación del número de recursos de los demás factores. .......................63

5.3.5.Cálculo de la capacidad de atención. ...............................................................63

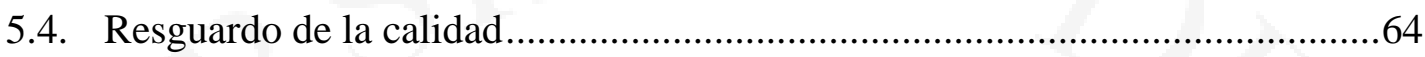

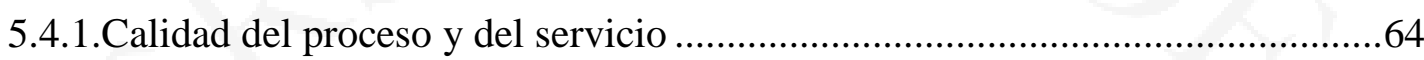

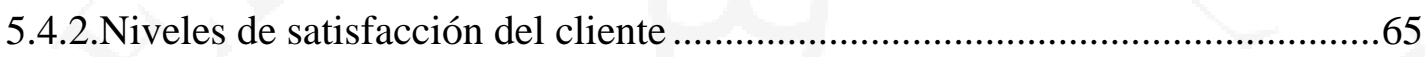

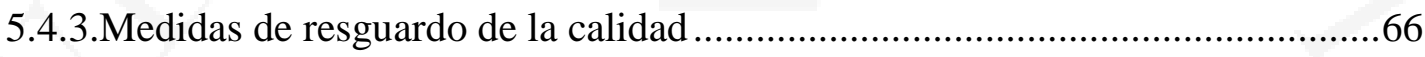

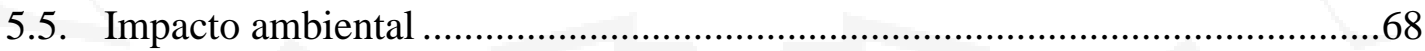

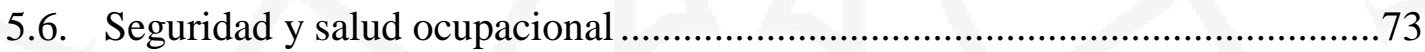

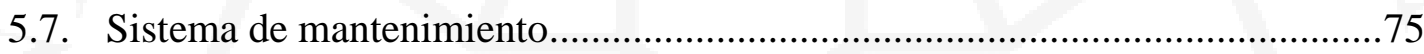

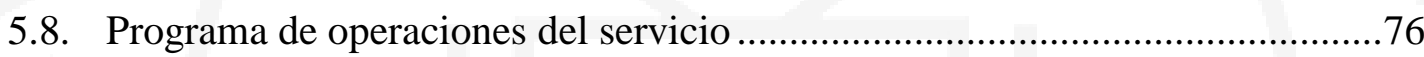

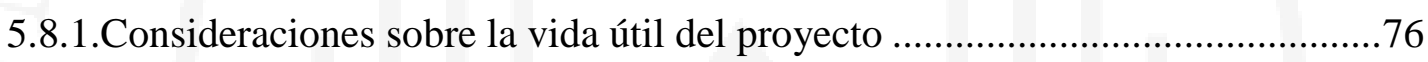

5.8.2.Programa de operaciones del servicio durante la vida útil del proyecto ...........76

5.9. Requerimiento de materiales, personal y servicio ..........................................77

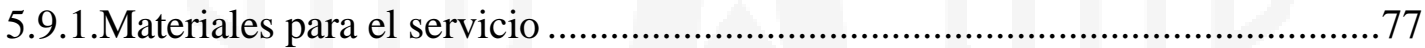

5.9.2.Determinación del requerimiento de personal de atención al cliente ...............78

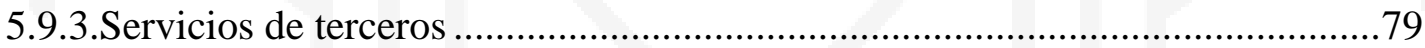

5.9.4.Otros: energía eléctrica, agua, transportes, etc. ............................................ 79

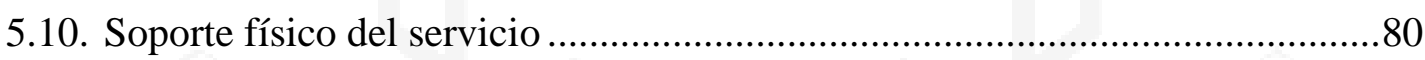

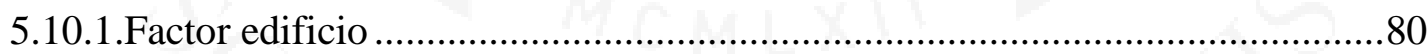

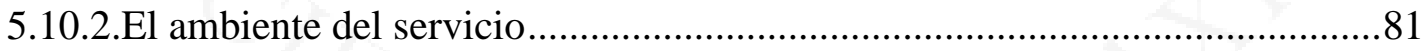

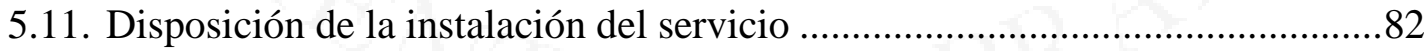

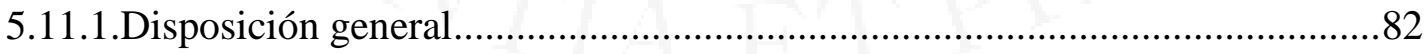

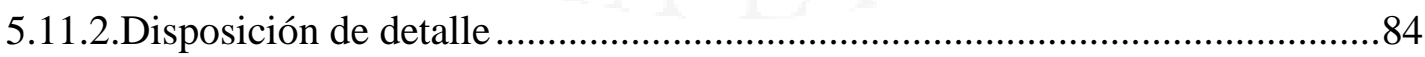

5.12. Cronograma de implementación del proyecto..............................................90

CAPÍTULO VI. ORGANIZACIÓN ADMINISTRATIVA ..............................92

6.1. Formación de la organización empresarial.................................................92

6.2. Requerimientos de personal directivo, administrativo y de servicios..............93 
6.3. Esquema de la estructura organizacional y funciones generales de los principales puestos.

CAPÍTULO VII: PRESUPUESTOS Y EVALUACIÓN DEL PROYECTO.....95

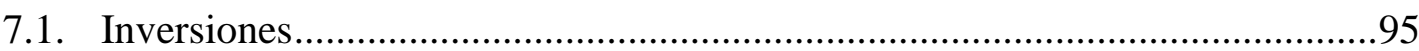

7.1.1.Estimación de las inversiones de largo plazo ...................................................95

7.1.2.Estimación de las inversiones de corto plazo ...................................................93

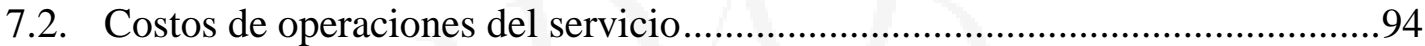

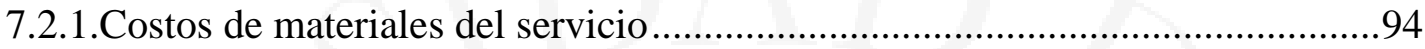

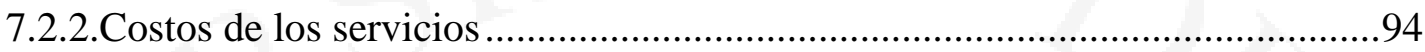

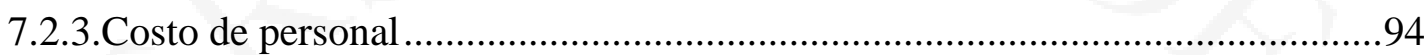

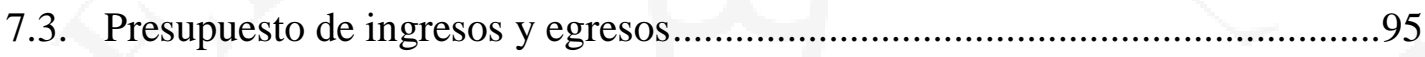

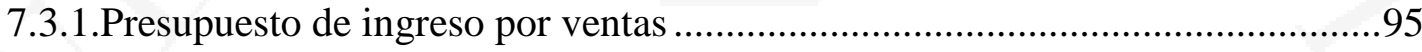

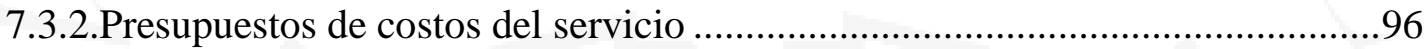

7.3.3.Presupuesto operativo de gastos administrativos..........................................97

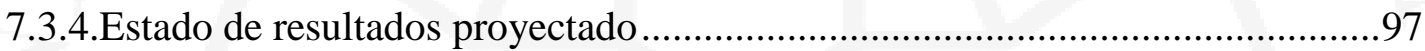

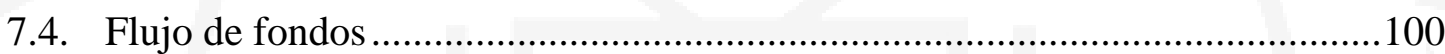

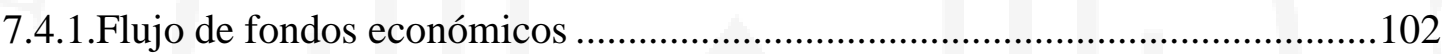

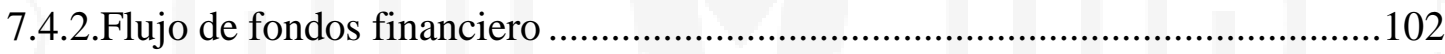

CAPÍTULO VIII: EVALUACIÓN ECONÓMICA Y FINANCIERA DEL PROYECTO

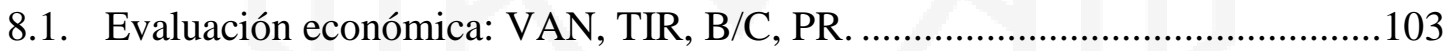

8.2. Evaluación financiera: VAN, TIR, B/C, PR ..................................................103

8.3. Análisis de los resultados económicos y financieros del proyecto ..................103

8.4. Análisis de sensibilidad del proyecto .............................................................104

CAPÍTULO IX: EVALUACIÓN SOCIAL DEL PROYECTO .............................108

9.1. Identificación de las zonas y comunidades de influencia del proyecto.............108

9.2. Impacto en la zona de influencia del proyecto .............................110

9.3. Impacto social del proyecto ...........................................110

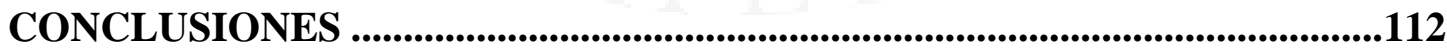

RECOMENDACIONES ….............................................................................113

REFERENCIAS

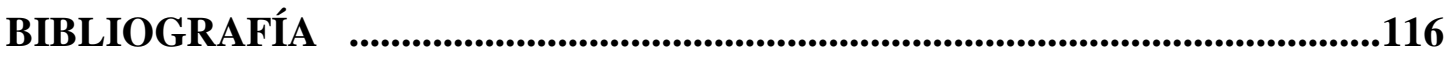

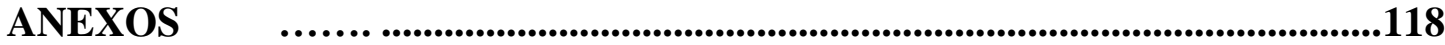




\section{ÍNDICE DE TABLAS}

Tabla 2.1 Modelo de Negocios del servicio de congelamiento de conchas de abanico

Tabla 2.2 Data histórica de la exportación de conchas de abanico por año. ............22

Tabla 2.3 Data histórica de consumo de conchas de abanico a nivel mundial..........23

Tabla 2.4 Importación de conchas de abanico a nivel mundial proyectada. ............23

Tabla 2.5 Consumo global y exportación proyectadas...........................................25

Tabla 2.6 Demanda de conchas de abanico a congelar...........................................25

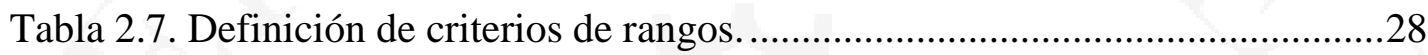

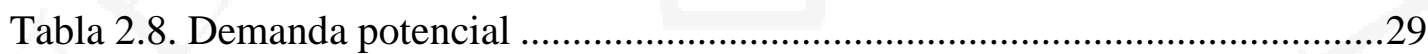

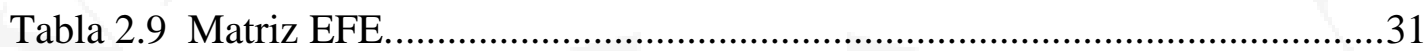

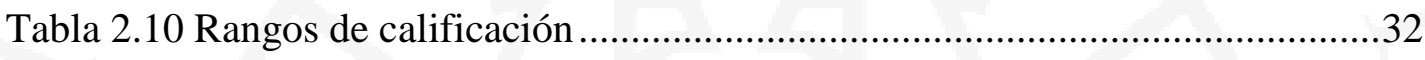

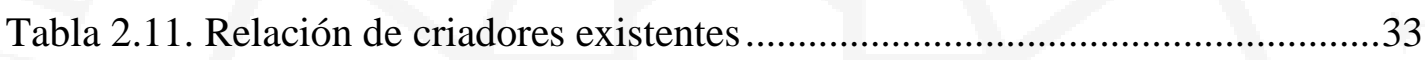

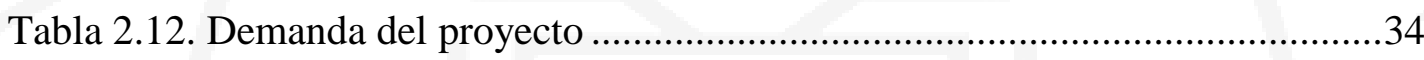

Tabla 3.1. Calificación de Macro y Micro localización ...........................................39

Tabla 3.2. Distancia al criadero mas cercano ........................................................40

Tabla 3.3. Población económicamente activa según departamento...........................40

Tabla 3.4. Red vial nacional pavimentada por departamento ...................................41

Tabla 3.5. Producción de energía eléctrica ( Gigawatts hora) ...................................41

Tabla 3.6. Inversion en infraestructura en telecomuniciones. ..................................42

Tabla 3.7. Enfrentamiento de factores de macro localización ..................................42

Tabla 3.8. Macro localización y selección de alternativas. .......................................43

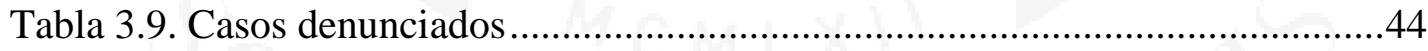

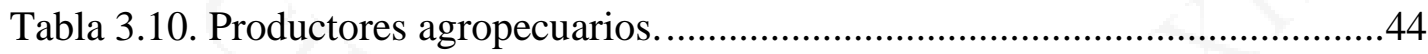

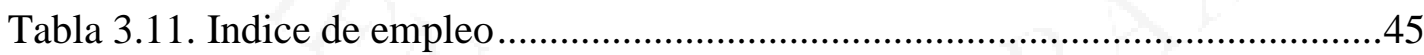

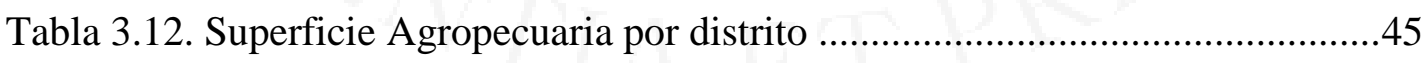

Tabla 3.13 Cálculo de ponderación de factores objetivos. .....................................46

Tabla 3.14. Tabla de enfrentamiento de factores subjetivos...................................46

Tabla 3.15. Cálculo de ponderación de factores de acuerdo a cada alternativa..........46

Tabla 3.16. Cálculo de factores subjetivos .............................................................47

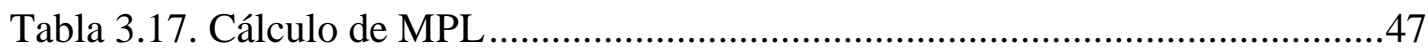

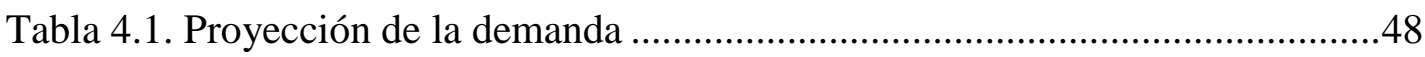




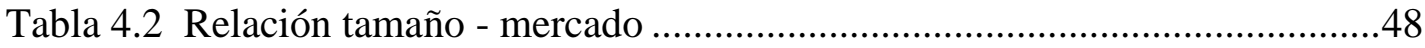

Tabla 4.3. Relación tamaño - Recursos..................................................................49

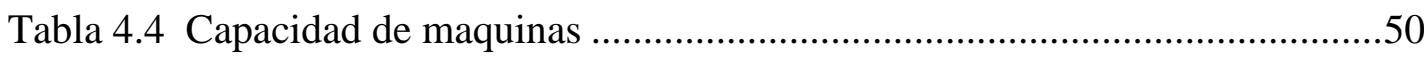

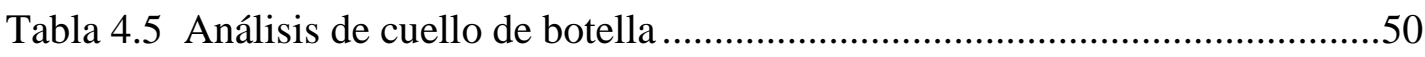

Tabla 4.6 Capacidad de producción en toneladas/año .............................................50

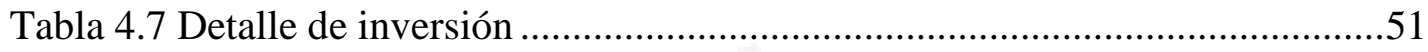

Tabla 4.8. Cálculo de punto de equilibrio............................................................52

Tabla 4.9 Selección de tamaño ...........................................................................52

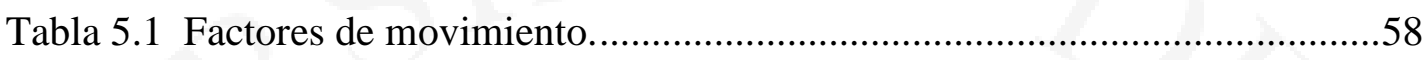

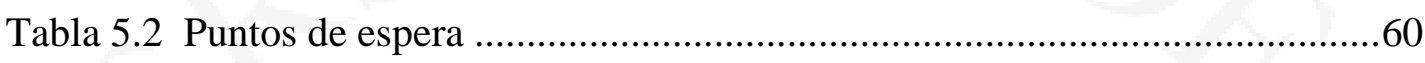

Tabla 5.3 Cálculo del cuello de botella en bolsas/sem. .........................................62

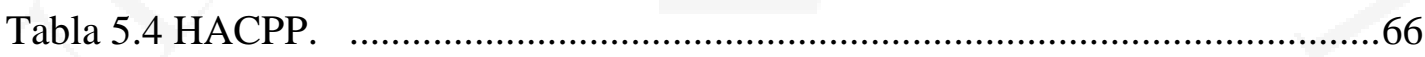

Tabla 5.5. Plan de monitoreo de los PCC para el congelamiento criogénico de las conchas

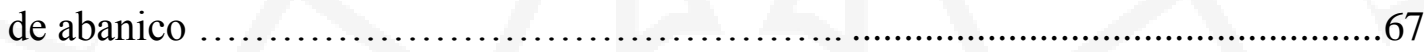

Tabla 5.6. Análisis ambiental de procesos................................................................68

Tabla 5.7. Matriz de aspectos ambientales ........................................................ 71

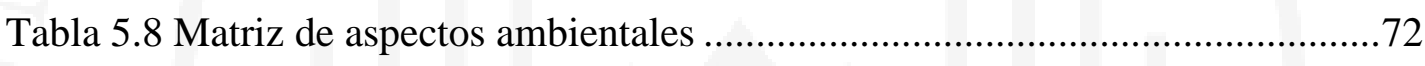

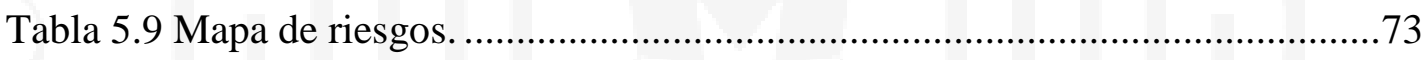

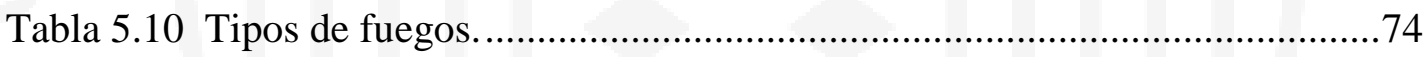

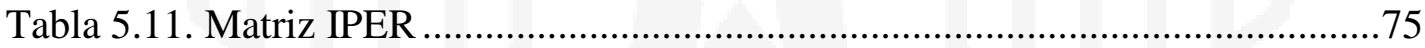

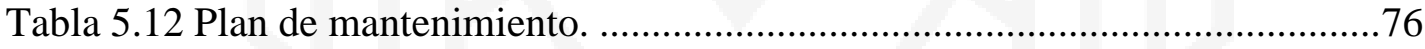

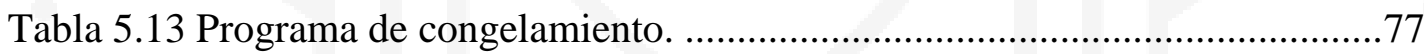

Tabla 5.14 Requerimiento de los principales insumos para el servicio de congelamiento

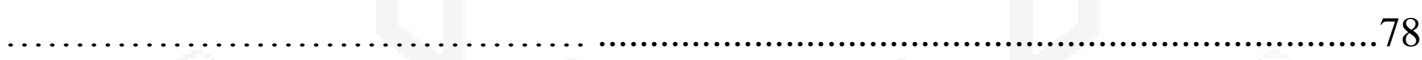

Tabla 5.15 Cálculo del número de operarios necesarios. ........................................79

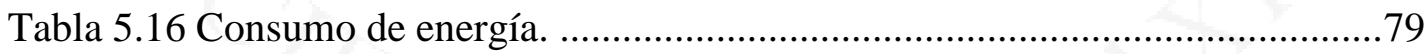

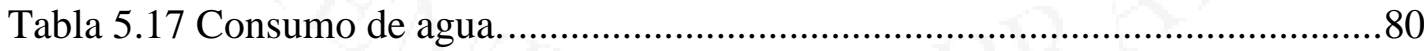

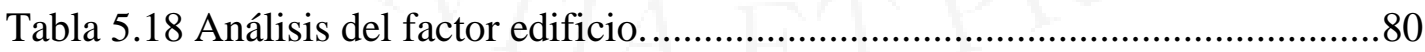

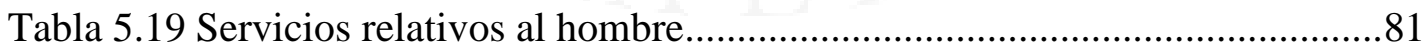

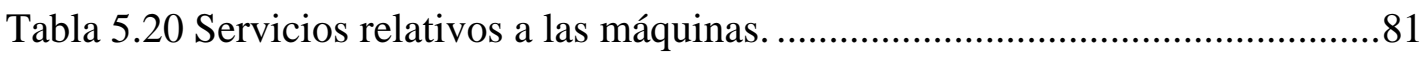

Tabla 5.21 Servicios relativos a las máquinas....................................................82

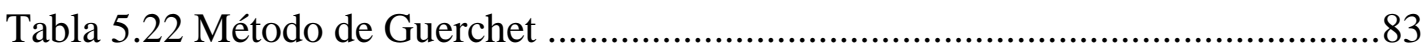

Tabla 5.23 Método de Guerchet, dimensiones ......................................................8

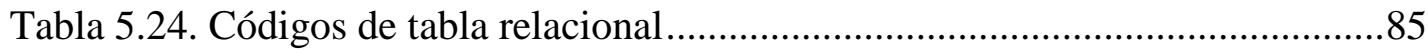




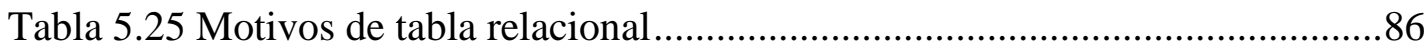

Tabla 5.26 Tabla relacional de actividades de las áreas ........................................87

Tabla 7.1. Costo total de intangibles y amortización..............................................96

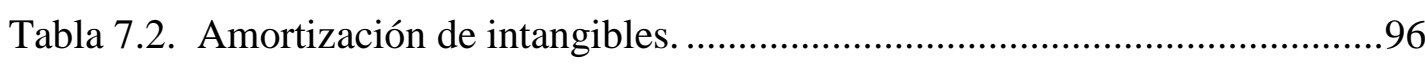

Tabla 7.3. Cálculo de egresos anuales. ..............................................................93

Tabla 7.4. Costos de materia prima o insumos para el servicio...............................94

Tabla 7.5. Costo total de los servicios identificados................................................94

Tabla 7.6. Costo total de mano de obra directa. .....................................................95

Tabla 7.7. Costo total de mano de obra indirecta. ..................................................95

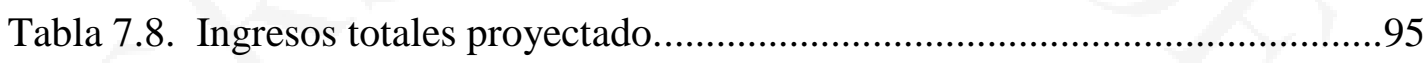

Tabla 7.9. Presupuesto de costos para el servicio de congelamiento .......................96

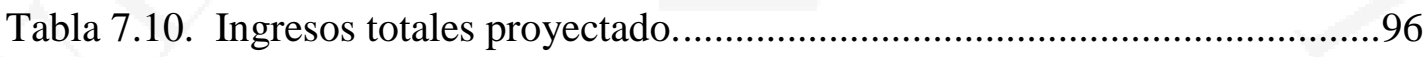

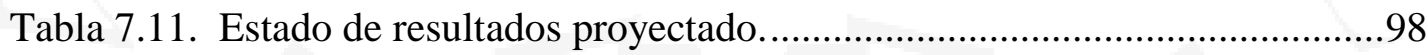

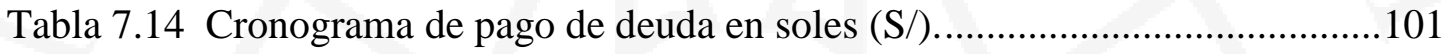

Tabla 7.15. Flujo económico del proyecto. ..........................................................102

Tabla 7.16. Flujo de financiero del proyecto. ¡Error! Marcador no definido.

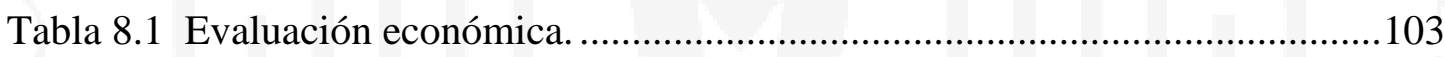

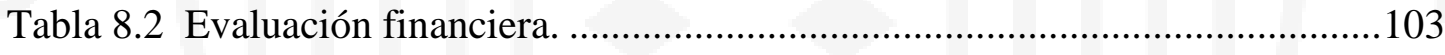

Tabla 8.3 Análisis de sensibilidad - Precio - Flujo Económico ................................104

Tabla 8.4 Análisis de sensibilidad - Precio - Flujo Financiero...................................105

Tabla 8.5 Análisis de sensibilidad - Volumen - Flujo Económico............................105

Tabla 8.6 Análisis de sensibilidad - Volumen - Flujo Financiero .............................106

Tabla 8.7 Análisis de sensibilidad - Aporte de deuda / Inversión total - Flujo Económico 106

Tabla 8.8 Análisis de sensibilidad - Financiamiento / Inversión total - Flujo Financiero 107

Tabla 9.1 Valor agregado 110 


\section{ÍNDICE DE FIGURAS}

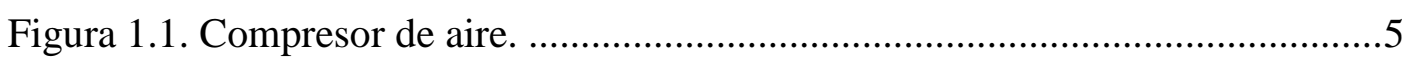

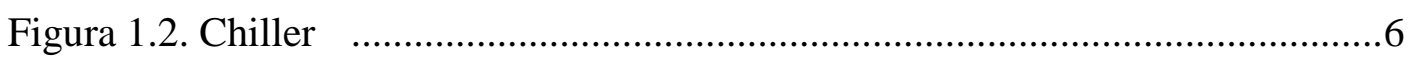

Figura 1.3. Secador de filtro molecular ........................................................6

Figura 1.4. Compresor de reciclo..................................................................

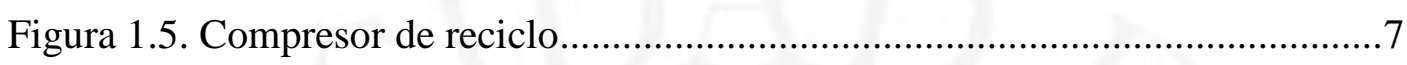

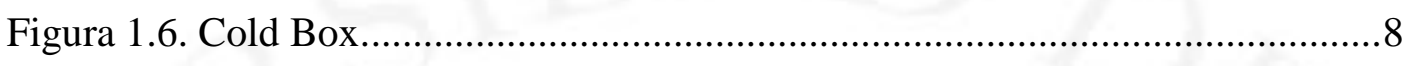

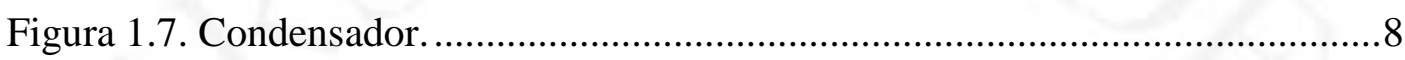

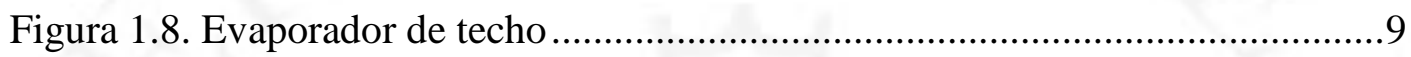

Figura 2.1 Tendencia de la producción.............................................................24

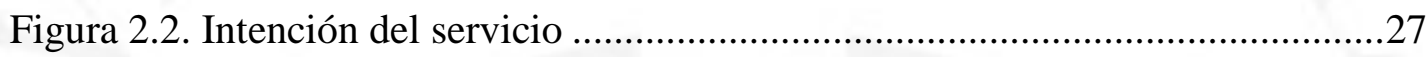

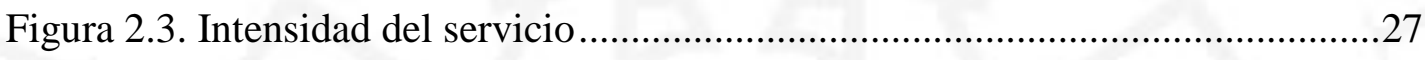

Figura 2.4. Producción diaria según encuestas. ....................................................28

Figura 2.5. Relación precio / tonelada según encuestas. .........................................36

Figura 5.1. Diagrama de operaciones para la producción de nitrógeno líquido ........54

Figura 5.2. Flujograma del servicio de congelamiento de conchas de abanico.........55

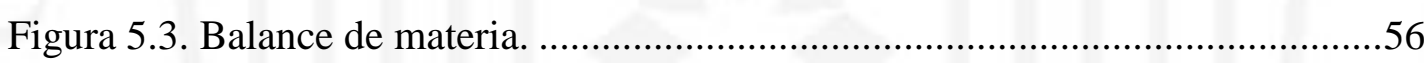

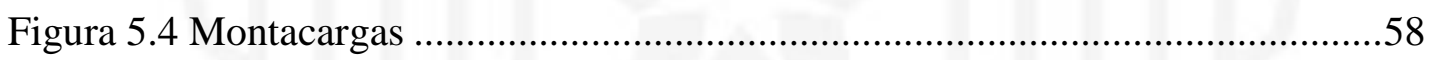

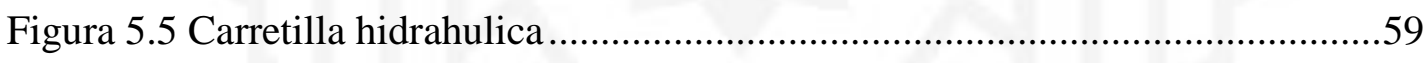

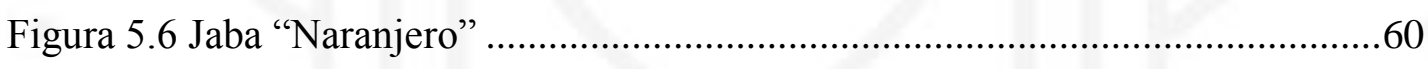

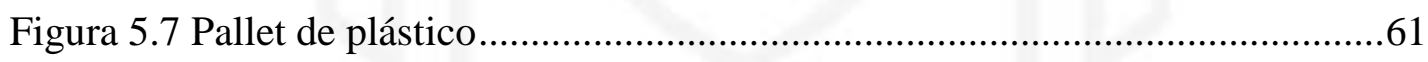

Figura 5.8. Análisis ambiental utilizando diagrama de flujo..................................70

Figura 5.9. Fórmula para el cálculo de número de operarios necesario. ....................78

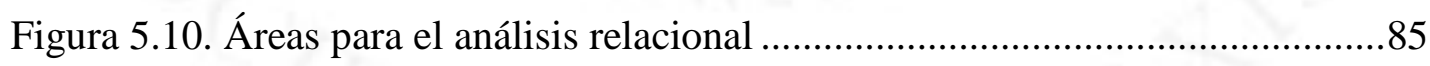

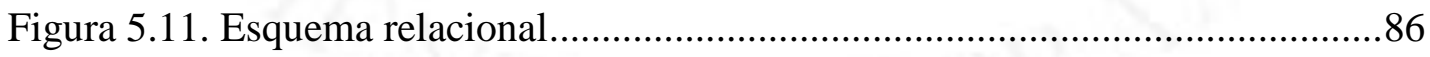

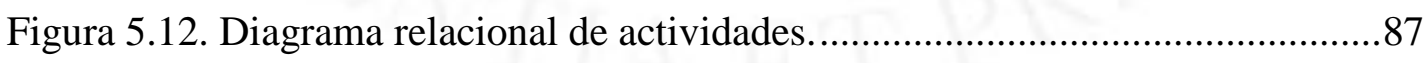

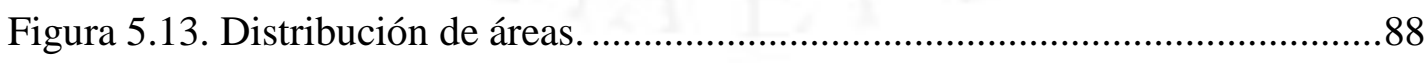

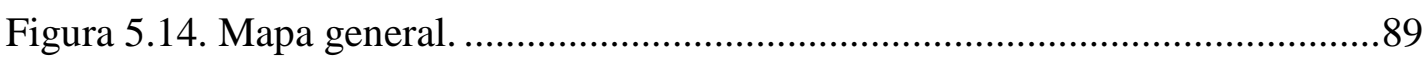

Figura 5.15. Cronograma de implementación del proyecto.....................................90

Figura 6.1. Esquema estructural de la organización ...............................................93

Figura 9.1 Identificación de las zonas y comunidades de influencia del proyecto...108 


\section{RESUMEN EJECUTIVO}

El presente trabajo plantea un estudio de prefactibilidad para la instalación de una planta que ofrecerá servicio de congelamiento de conchas de abanico, el método de congelamiento a utilizar es el IQF o congelación rápida de manera individual. El productor de conchas de abanico obtendrá las ventajas de ganar tiempo de vida del producto deteniendo su maduración en perfectas condiciones, conservando sus propiedades organolépticas, poder producir mayor volumen para finalmente exportar, obtener mayores ganancias y poder ofrecer más puestos de trabajo a las familias de la zona.

Se realizó un estudio de mercado, donde se encontró que la exportación de conchas de abanico tiene un crecimiento debido a que existe un aumento anual en la tendencia de consumo de productos acuicolas. Además, Sechura es el lugar con mayor producción para exportar de conchas de abanico en el país; por lo tanto, nuestra planta se ubicará cerca a los productores de Sechura.

Con la ayuda del balance general, se identificó la capacidad de nuestra planta, el número de equipos y personal que necesitaremos para porder atender la demanda del proyecto definida en el estudio de mercado. Esto nos facilitó la elaboración de nuestro requerimiento de materiales y otros insumos para la operación. De esta manera, calculamos nuestros ingresos y costos que habrán al ofrecer el servicio de congelamiento.

Finalmente, mediante el análisis de flujo económico, financiero y social determinamos la viabilidad del proyecto. Pues, se observó que es rentable al obtener VAN positivo, TIR mayor al costo de oportunidad esperado, relación de beficio - costo mayor a 1 y un rápido periodo de recupero.

Palabras clave: conchas de abanico, servicio de congelamiento, IQF, acuicultura, nitrogeno. 


\section{EXECUTIVE SUMMARY}

The present works shows a study of pre-feasibility for the installation of an industrial plant that offers freezing service of peruvian scallops using the IQF method or individual quick freezing. The advantages that the farmer will get using this method are keeping the properties of the product, gain time, producing higher volume and reducing the cost of transportation that will give them more earnings.

We made a market study, where we found that the peruvian scallop's exportation has a anual growth because of a trend of marine product's consuming. Also, Sechura is the place with the higher production of peruvian scallops, therefore, our plant will be located there.

With help of our material balance, we could indentify our plant's capcity, the number of our machines and workers that our plant need for work right and could attend the demand of the proyect that we determine in market study. Also it facilitated us for the elaboration of our requirements and could make our budget.

Finally, we made a social, economic and financial analysis and we determine the viability of the proyect. Because our VAN are possitive, our TIR are greater than the cost of opportunity, the $\mathrm{B} / \mathrm{C}$ are greater than one and we have a quick recovery period.

Keywords: peruvian scallops, freezing service, IQF, aquaculture, nitrogen. 


\section{CAPÍTULO I. ASPECTOS GENERALES}

\subsection{Problemática}

Según el diario Gestión (2017), las exportaciones nacionales de conchas de abanico están siendo subvaluadas debido a que no logran cumplir las exigencias de la Unión Europea. Pues, ciertas áreas de la bahía de Sechura han sido retiradas del Listado Oficial de Áreas de Producción de moluscos bivalvos autorizadas por la Unión Europea. Además, al ser perecibles, rápidamente tienden a ser enviados vía aérea, de lo contrario, lo acuicultores de conchas de abanico pierden su producción. Por ello, estas son congeladas por diferentes métodos como el de contacto indirecto que usa amoníaco o freón, que a lo largo se han visto que reducen la calidad de sus productos. Sin embargo, "el mismo insumo como lo es el amoníaco o el freón contaminan al medio ambiente” (Alvarado, 2014, párr.2).

Al ofrecer el nitrógeno como insumo para el método congelamiento IQF (Individual Quick Freezing) el productor de conchas de abanico "obtendrá las ventajas de ganar tiempo de vida del producto, deteniendo su maduración y mantener en perfectas condiciones" (Erazo, Loaiza, Velez, 2016, p.25). Por lo tanto, no perdería producción para exportar, le permitiría ofrecer al mercado un precio competitivo y poder exportarlo vía marítima ahorrando en el costo de transporte y volumen. Además, con este método podemos abarcar diferentes tipos de productos en un futuro, asegurando expandir nuestro mercado, nuestra capacidad de atención y por ende nuestras utilidades.

\subsection{Objetivos de la investigación}

\subsubsection{Objetivo general}

Determinar la viabilidad comercial, técnica, económica, social y medioambiental para la implementación de una planta de nitrógeno para el servicio de congelamiento IQF de conchas de abanico 


\subsubsection{Objetivos específicos:}

- Identificar y analizar las tecnologías existentes de congelamiento criogénico.

- Definir el mercado para ofrecer el servicio $\mathrm{IQF}^{1}$ usando nitrógeno.

- Diseñar la instalación de una planta de nitrógeno, analizando la óptima locación y reduciendo el menor impacto ambiental al momento de ofrecer nuestros servicios a los consumidores.

- Determinar la inversión necesaria, los costos del servicio y la viabilidad financiera con un VAN mayor a 1 y un TIR mayor al costo de oportunidad esperado.

\subsection{Alcance de la investigación}

- Unidad de análisis: Una tonelada de conchas de abanico, nitrógeno.

- Población: Se busca ofrecer el servicio a los criadores de conchas de abanico ubicados en la bahía de Sechura, Piura.

- Espacio: Nuestro estudio estará enfocado en el norte del Perú, en la bahía de Sechura. Se conoce que en el lugar hay cerca de 10 criadores de conchas de abanico actualmente en esa región y es la principal región productora de estas mismas (Aquahoy, 2014, párr.1).

- Tiempo: Se trabajará durante todo el año, con el objetivo de tener terminado todas las investigaciones necesarias en diciembre del presente año. Como meta se tiene poder llevar a cabo este proyecto a inicios del próximo año.

- Limitaciones de la investigación: Hay información que no se puede determinar con exactitud, como lo son la variación de producción, debido a que estas sufren con la presencia del fenómeno del Niño, pueden reducirse hasta en un $80 \%$ como lo ha sido en el presente año (El Tiempo, 2016, párr.2.)

- Nuestra investigación será de tipo correlacional, con la finalidad de conocer la relación que existe entre las exportaciones de conchas de abanico congeladas mandadas vía marítima y su aceptación en los mercados extranjeros

\footnotetext{
${ }^{1}$ Individual Quick Freezing
} 


\subsection{Justificación del tema}

\subsubsection{Técnica}

Las plantas productoras de nitrógeno si existen en la actualidad, "se han desarrollado diversos métodos de congelamiento como lo son el congelamiento por aire forzado, estos usan corrientes de aire a bajas temperaturas y a gran velocidad" (Ballesteros, 2017, p. 1); sin embargo, no se puede usar en todo tipo de productos; por otro lado, encontramos el método de contacto que usan amoníaco o freón. Según Barrera (2015), este método usa el calor del producto para dirigirlo a un refrigerante que está ubicado en paredes metálicas (p. 22). Sin embargo, contaminan al medio ambiente, son riesgosos para la salud y reducen la calidad del producto

Nosotros ofreceremos el método más actual que es el método IQF o congelación rápida de manera individual que consiste en usar nitrógeno en estado líquido para congelar las conchas de abanico. Al ofrecer el nitrógeno para el congelamiento de conchas de abanico brindamos una excelente calidad.

Para la obtención del nitrógeno líquido son necesarios los siguientes equipos:

- Compresor: Esta máquina absorbe aire a presión ambiental, estos pasan por un sistema de filtros de aire donde se retiene las partículas sólidas presentes en el aire (CarboSystem, 2013, párr. 2). Posteriormente al ya tener el aire filtrado empieza la compresión a presiones de 1, 3 y 5 bares. Llegando a una temperatura de 32 a $34{ }^{\circ} \mathrm{C}$. Al ser comprimido provoca su calentamiento y es enfriado en un radiador de aire propio. Al igual se trabajará con la marca Universal Boschi con capacidad de $387.5 \mathrm{~m} 3 / \mathrm{hr}$.

Figura 1.1.

Compresor de aire.

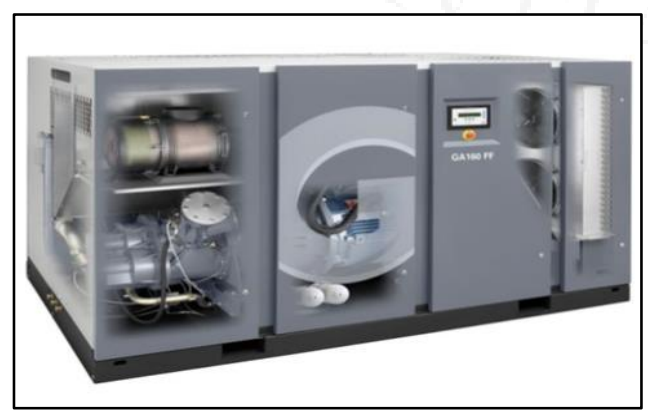

Fuente: Boschi (2017) 
- Chiller o pre enfriador: Para poder enfriar el aire usamos el chiller que es una unidad enfriadora de líquidos o más conocida como un condensador, se encarga de eliminar el calor residual del compresor (Quiminet, 2006, párr.2). De este mismo podemos tener el aire a una temperatura aproximada de 7 a $10^{\circ} \mathrm{C}$, usando refrigerantes. Para este proyecto se busca un Chiller con capacidad de $387.5 \mathrm{~m} 3 / \mathrm{hr}$.

Figura 1.2.

Chiller

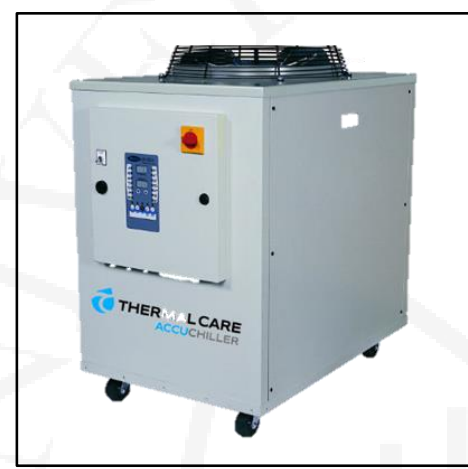

Fuente: Thermalcare (2017)

- Secador de filtro molecular: Esta máquina se encarga de separar el vapor residual por adsorción y además retiene gases. Este equipo tiene como insumos en la parte baja de la máquina aluminagel y en la parte superior un tamiz molecular. Estos son equipos paralelos para no tener que parar toda el proceso para su mantenimiento o limpieza.

Figura 1.3.

Secador de filtro molecular

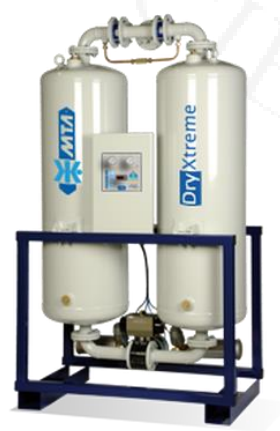

Fuente: Mta-it (2017) 
- Compresor de reciclo: El aire se conduce al compresor de reciclo o reflujo mayormente conocido que al salir de este proceso obtenemos el aire a $40^{\circ} \mathrm{C}$ con una presión de aproximadamente 28 bares. Donde posteriormente este es enfriado con la corriente proveniente de los compresores.

Figura 1.4.

Compresor de reciclo

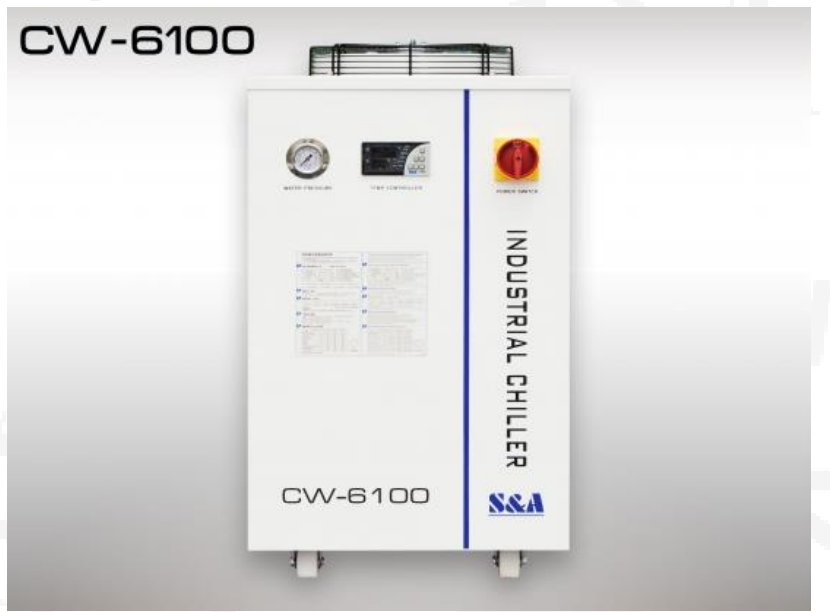

Fuente: teyuchiller (2017)

- Compresor de Booster: En este compresor se logra obtener el aire a una presión de 32 bares y por ende a una temperatura de $80^{\circ} \mathrm{C}$.

Figura 1.5.

Compresor de reciclo

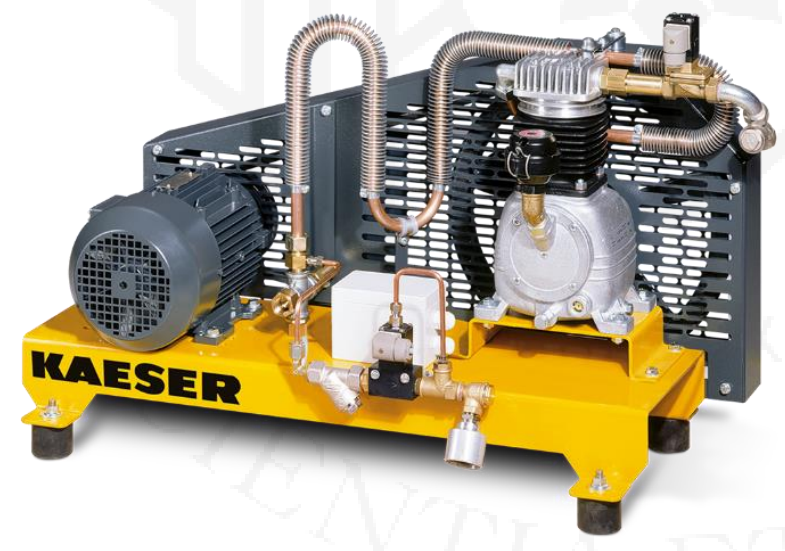

Fuente: Kaeser (2017) 
- Cold Box: La torre de enfriamiento está compuesta por 3 partes, la primera es la columna de destilación de platos a 5 bar, la segunda está a 0.5 a 0.7 bar y la última es una columna de expansión. El proceso inicia con el ingreso del aire líquido y aire gas criogénico en la primera columna, donde al expandirse se produce el cambio de fase a líquido del oxígeno y el argón, teniendo como resultado una corriente líquida con $40 \%$ de oxígeno. Por otro lado, el nitrógeno ingresa en la segunda columna bajando su temperatura para posteriormente ser enviada a la columna de expansión donde se reduce su presión a las presiones mencionadas anteriormente. (Tecnología Industrial, 2016, pág. 44-49).

Figura 1.6.

\section{Cold Box.}

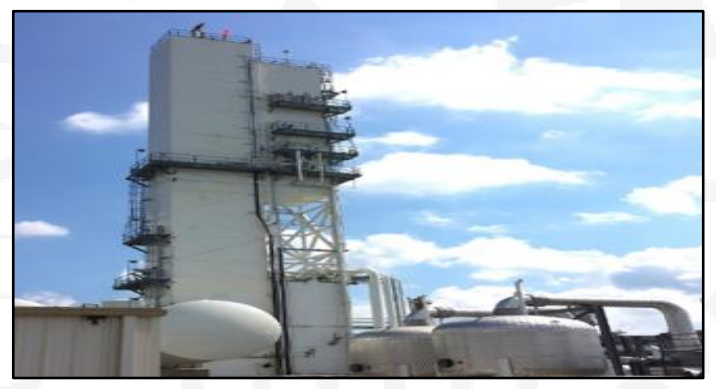

Fuente: MLEA INC. (2017)

Por otro lado, los equipos que se necesitarán para el almaecenamiento son los siguientes:

- Condensador: Ideales para el cambio de temperatura y cambio de fase. Es decir, su obejtivo será liberar el calor del refrigerante al ambiente y condensar el vapor proveniente del evaporador.

Figura 1.7.

Condensador.

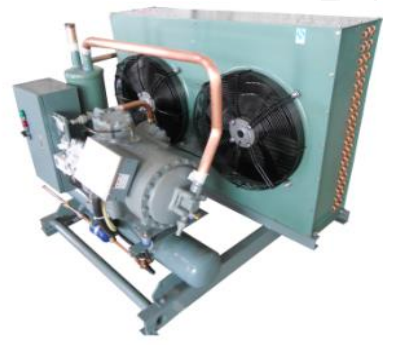

Fuente: Alibaba (2019) 
- Evaporador: Este equipo se encuentra al interior del almacén y será el encargado de realizar el intercambio de calor entre los fluidos refrigerantes (Bernad, 2019, párr. 3).

Figura 1.8.

Evaporador de techo

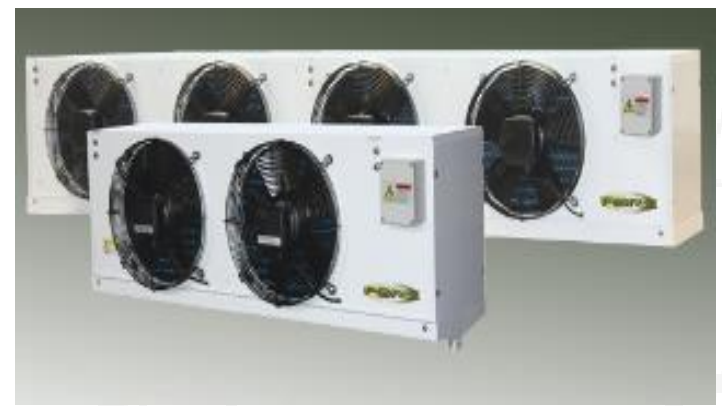

Fuente: Alibaba (2019)

\subsubsection{Económica}

El costo de implementar esta planta por tonelada se calcula en 660 soles, considerando variables como energía eléctrica, agua y mano de obra. Por otro lado, este servicio se vende al mercado a un precio variable de S/ 2722.6 a S/ 10890 por tonelada. Esta investigación busca incrementar sustancialmente las exportaciones de conchas de abanico del Perú usando el método de congelamiento criogénico, el cual consiste en introducir el producto en un baño de líquido refrigerante usando nitrógeno, esto da como resultado el congelamiento inmediato del producto a perfectas condiciones sin afectar la calidad del mismo. (Erazo, 2016).

Buscamos hacer un análisis de la capacidad de mercado dispuesto a contratar nuestros servicios y comprobar si el proyecto es altamente rentable, teniendo un margen de ganancias de $25 \%$ a $50 \%$ por encima de nuestros costos. Se busca tener un TIR mayor al costo de oportunidad y un VAN mayor a cero para demostrar financieramente que el proyecto es factible.

\subsubsection{Social}

Los acuicultores de conchas de abanico están siendo forzados a vender su producto a un bajo precio al mercado (La Hora, 2018, párr. 1), a muchos de ellos incluso les llegan a rechazar el pedido al momento de recibirlo por el estado en el que se encuentra. Por otro lado, al ser un producto de una corta duración, se ven obligados a acudir a transportar el 
pedido vía aérea, que tiene un costo más alto y menor volumen que el transporte por vía marítima.

Es por ello, que buscamos ofrecer trabajo a los habitantes de la zona en donde ubicaremos nuestra planta, además de incrementar los márgenes de exportaciones de nuestros clientes; de esta forma, colaborar en su crecimiento.

\subsubsection{Innovación:}

Por el lado de la innovación, podemos ofrecer un servicio de congelamiento instantáneo, en donde al realizar la operación preservamos las características organolépticas; es decir, mantenemos todas sus propiedades. Además, es una práctica menos contaminante y dañina para la salud que las actuales. Por último, la planta para producir nitrógeno solamente necesita aire y agua (García, R,. 2017).

\subsection{Hipótesis de trabajo}

La implementación de una planta criogénica para el servicio de congelamiento de conchas de abanico con la técnica de congelamiento rápida e individualizada (IQF) es factible económica y técnicamente porque existen criadores de conchas de abanico con la necesidad de vender sus productos en buena calidad.

\subsection{Marco referencial}

- Ortega-Villalba, K J; Vélez-Pasos, C A; Ayala-Aponte, A. (2016). Efecto De Las Condiciones De Operación Sobre La Calidad De Melon (Cucumis Melo) Congelado Por Iqf/Effect Of Operating Conditions On Quality Of Frozen Melon (Cucumis Melo) BY IQF. 23/04/2017: Recuperado de http://search.proquest.com/docview/1783661772/9B1BBEFA78C940E0PQ/ 4? accountid $=45277$

En este experimento, se halla que es un proceso que afecta en menor grado los cambios fisicoquímicos relacionados con la calidad del alimento congelado.

- Loaiza, Karen L; Erazo, Stephanía C; Velez, Carlos P. (2016). Congelación De Arveja Empleando Un Sistema De Congelación Individual, Iqf/Freezing Peas Using An Individual Freezing System, Iqf. 23/04/2017. Recuperado de 
http://search.proquest.com/docview/1783661210/9B1BBEFA78C940E0PQ/ 1 ? accountid $=45277$

En esta investigación se concluyó que en el congelamiento criogénico usando nitrógeno líquido como insumo, en un método el cual se usa la propiedad del nitrógeno, el cual al tenerlo en su punto de ebullición $\left(-196^{\circ} \mathrm{C}\right)$ puede llegar a congelar inmediatamente cualquier elemento perteneciente a la industria de alimentos. Sin embargo, el tiempo de congelamiento varía dependiendo del tamaño del producto a congelar. Además, que las variables de operación del sistema de congelación IQF analizadas presentan efectos significativos sobre el tiempo de congelación de las arvejas verdes, y entre ellas, el más notable es el tipo de lecho, pues los tiempos son en promedio $45.5 \%$ menores al utilizar lecho fluidizado en comparación con el lecho fijo y el fluidizado no se ve afectado significativamente al variar la altura.

- García, R. (Enero, 2017). Diseño de una estrategia de control difuso aplicada al proceso de ultra congelación de alimentos/Design of fuzzy control strategy applied to food process deep freeze. Mayo 2, 2017. Recuperado de http://search.proquest.com/docview/1879086954/7C2753EFB21E4125PQ/1 ?accountid $=45277$

En este paper científico podemos encontrar que el autor afirma que la ultra congelación, también conocida como sobre congelación o congelación rápida, es el proceso mediante el cual los alimentos son congelados en el menor tiempo posible ( 2 horas como máximo, dependiendo del tipo de producto), conllevando a que los mismos puedan conservar la mayor parte de sus cualidades, ya que su estructura celular se ve poco afectada por el menor tamaño de los cristales de hielo que se forman tanto en el interior de la célula como en los espacios entre células, durante el proceso en cuestión; por ello, al realizar la congelación criogénica con nitrógeno tenemos una velocidad de congelamiento sumamente rápida teniendo como consecuencia la conservación de la calidad del mismo.

- Dionicio, J. (2015). Efecto de la temperatura en respuestas fisiológicas de la concha de abanico- Argopecten purpuratus. Revista peruana de biología, 22, 329-334. Recuperado de http://dx.doi.org/10.15381/rpb.v22i3.11439 
En este paper se discutió la relación del efecto de la temperatura sobre la tasa de aclaramiento, ingestión y el consumo específico de las conchas de abanico en distintos grupos de tallas. Es decir, como la temperatura influye en la producción de las conchas de abanico. Concluyendo que un ascenso de temperatura incrementa la mayoría de los procesos fisiológicos que se mencionaron.

- Mendo, J. (2003). El Impacto del Niño sobre la Producción de Concha de Abanico En Bahía Independencia, Pisco, Perú. Ecología aplicada, 2(1), 5157. doi: 10.21704/rea.v2i1-2.247

Este paper discute los principales factores que afectan el auge de las conchas de abanico. En este informe se analizó varias variables como el crecimiento, reproducción, prelación, densidad media y condiciones de oxígeno. Concluyendo que la concha de abanico crece mejor bajo condiciones de calentamientos del mar.

- Sánchez Cuellar, L. (2017). Análisis De La Cadena De Valor De La Concha De Abanico En La Bahía De Sechura (tesis para optar el título de Ingeniero Pesquero) de Universidad Nacional Agraria La Molina.

En esta tesis, el autor Luis Sánchez, afirma que la demanda de la concha de abanico a nivel mundial influye en el cultivo de concha de abanico en la bahía de Sechura. Es decir que es una demanda fluctuante y nos vemos directamente beneficiados y/o afectados según la demanda a nivel mundial.

- Chambilla Tuyo, W. (2010). Efecto del método de congelación sobre las características fisicoquímicas y organolépticas de la carne de cuy (Cavia porcellus) (tesis para optar el título profesional de Ingeniero Agroindustrial). Recuperado de http://repositorio.unap.edu.pe/bitstream/handle/UNAP/3363/ Chambilla_Tuyo_Walter.pdf?sequence $=1 \&$ isAllowed $=y$

Esta tesis tenía como finalidad demostrar que una vez teniendo el producto listo para congelar y una vez congelado criogénicamente, este tiene mejores características fisicoquímicas y organolépticas de la carne de cuy, además hubo diferencia en la conservación de sus componentes entre el método criogénico, que presentó mejor su preservación de proteínas, grasa, capacidad de retención de agua, $\mathrm{pH}$ y la terneza, en placas solo presentó mejor jugosidad 
y por último el túnel, no afectó sobre las características físico químicas y organolépticas.

- Morales Landeo, R. (1986). Cálculo y diseño de un equipo experimental para la congelación de alimentos mediante nitrógeno líquido (tesis para optar el título profesional de Ingeniero Mecánico). Universidad Nacional de Ingeniería.

En esta tesis se da a conocer la justificación económica y social del uso de tecnología de congelamiento criogénico a partir del nitrógeno. Por el lado económico, se sustenta el costo bajo y además que con esto podemos lograr la disposición de crustáceos (langostino, langosta, etc.) en excelente condición y al alcance de las mayorías. Por el ámbito social, al no ofrecer el producto en óptimas condiciones, será difícil obtener su aceptación; por ello, al abrir la posibilidad de consumir diversos productos alimenticios, en óptimas condiciones de calidad a precios accesibles, se verá con gran aceptación en el mercado.

- Rudolph Delgado, F. (1989). Análisis tecnológico del congelamiento con nitrógeno de productos marinos de consumo humano (tesis para optar el título profesional de Ingeniero Industrial).Universidad de Lima.

En esta tesis se explica cuál es el papel que cumple el nitrógeno en la tecnología de congelación violenta o de choque, alternativa para conservar todas las características del pescado, ya que, con el método tradicional se forman hielos en la capa que dañan la estructura celular y pierden parte de sus propiedades y sabor. Además, explica todo el proceso que se realiza en el congelamiento.

- Ramos Gómez, G. (2013). Diseño de in Congelador continuo individual IQF on una Capacidad de $200 \mathrm{Kg} / \mathrm{Hr}$ de Espárragos (tesis para optar el título profesional de Ingeniero Mecánico). Pontificia Universidad Católica del Perú.

En esta tesis se tiene como objetivo diseñar un túnel de enfriamiento continuo IQF. Donde menciona, todos los tipos de congelamiento existentes, las consideraciones a tener en cuenta para el diseño IQF como la calidad del producto, la deshidratación en el proceso de congelación y la continuidad del 
funcionamiento. Además, realiza un análisis para la selección de refrigerante apropiado de acuerdo al producto que se necesita congelar.

\subsection{Marco conceptual}

Para el siguiente proyecto los siguientes términos se verán a lo largo de los capítulos:

- El congelamiento criogénico: Técnica utilizada para enfriar un cuerpo a partir de temperaturas muy bajas con el objetivo de conservarlo en condiciones óptimas.

- Individual Quick Freezing (IQF): Proceso de refrigeración que busca la conservación de las propiedades organolépticas (propiedades físicas de los alimentos, como son el sabor, el olor, la textura y el color) y las características nutritivas de los alimentos. Su particularidad radica en que $\mathrm{m}$ dad la rapidez de congelación, los cristales de hielo son de pequeños tamaños. ( Eduardo A. Muñoz, 2008, pp. 2)

- Punto de ebullición: Cambio de estado de una materia que pasa de líquido a gaseoso.

- Concha de Abanico - Argopecten purpuratus: Molusco bivalvo que habita en las zonas costeras. Y será el principal alimento que nuestro servicio de congelamiento congelará.

- Método de Brown y Gibson: Metodo de localización de planta, donde combina los factores cuantificables con los factores subjetivos.

- Hazard Analysis and Critical Control Points (HACPP): Sistema basado en la identificación de todos los peligros y medidas de control con el fin de garantizar la inocuidad de los alimentos, insumos a la salud humana. 


\section{CAPÍTULO II: ESTUDIO DE MERCADO}

\subsection{Aspectos generales del estudio de mercado}

\subsubsection{Definición del giro de negocio del servicio y tipo de servicio (profesionales, masivo, taller, etc.)}

El proyecto para implementar es un servicio de congelamiento criogénico para productos de exportación, con la finalidad de ofrecer los mejores productos preservando su calidad. Para el siguiente servicio, se necesita ingenieros industriales especializados en el sector de producción industrial de gases industriales. Para este proyecto necesitaremos 3 operarios de planta, 1 jefe en el área de congelados, 1 jefe en el área producción y 2 gerentes quienes se encargarán del área administrativa y operativa. Esto es debido a que las plantas productoras de nitrógeno, usando la última tecnología existente de la cual se planea invertir, son automatizadas; es decir, todo se controla por medio de computadoras. Los operarios trabajarán en 3 turnos de 8 horas cada uno, para no parar la atención. Se deja en claro, que este negocio solo es brindar el servicio de congelado. El lavado de los mismos insumos para el posterior congelado es realizado por los trabajadores de los criadores de conchas de abanico.

\subsubsection{Principales beneficios del servicio (concepto del servicio)}

- Servicios aumentados

En esta ocasión, ofreceremos el servicio de empaquetado del producto, con el fin de dejarlo listo para la exportación, cumpliendo parámetros de calidad. También, llevará una etiqueta con el nombre de la empresa o marca del cliente que contrate nuestro servicio.

- Servicios complementarios

Por otro lado, en los servicios complementarios, ofreceremos garantía, el cual aseguraremos a nuestros clientes en devolver su producto congelado a temperatura criogénica preservando su calidad y además asegurando disponibilidad de insumos. Además, ofreceremos créditos hasta que su 
producto sea exportado, para demostrar al cliente la calidad de nuestro servicio y lograr afianzar el negocio.

\subsubsection{Determinación de la metodología que se empleará en la investigación de mercado}

El proyecto se realizará con encuestas a los mismos criadores de conchas de abanico, a quienes se les ofrecerá el servicio. Además, se preguntará sobre el proceso en sí a expertos del tema. Tenemos el contacto directo con un ingeniero egresado de la Universidad de Lima, quien trabajó en 2 grandes empresas, levantó plantas de nitrógeno, oxígeno, argón, acetileno; quien nos ofreció brindar la información necesaria para poder llevar a cabo este proyecto. Por otro lado, se visitará la ciudad de Sechura, con el fin averiguar el costo de los terrenos y la factibilidad de desarrollar el proyecto.

Para poder determinar la información inicial para las bases de nuestra investigación se partirá con las entrevistas a los ingenieros especialistas en el tema de plantas productoras de gases industriales, además de consultar papers científicos encontrados en la base de datos "Proquest" de los autores: Pérez, Loaiza, Ortega, Alvarado, Acedo y García.

Para continuar, nuestro estudio de mercado se basará con entrevistas con los propietarios de las empresas productoras de conchas de abanico de la ciudad de Sechura con quienes abarcaremos temas de demanda y su propia capacidad y producción actual, estas empresas son:

- $\quad$ Piura Sea Food

- Viza

- $\quad$ Fimors

- Maria Luisa

- Acuiberlin

- Jehová es mi Proveedor

- Akayser

- $\quad$ Emox

- Seacorp 
Seguidamente, para abarcar los temas de localización se investigarán los factores más importantes que afectan directamente en su ubicación, como el agua, electricidad, disponibilidad de mano de obra, etc.

Luego, para abarcar los temas de financiamiento se averiguará en los bancos los requisitos y alternativas de financiamiento, así como las tasas que se ofrecen para financiar este proyecto.

\subsubsection{Determinación del área geográfica que abarcará el estudio}

El área que abarcará el estudio será el norte del Perú, se conoce que "en la bahía de Sechura (Piura) se produce un $80 \%$ de la producción total de conchas de abanico a nivel nacional; por otro lado, el 20\% restante es producido en Ancash" (El Comercio, 2017, párr. 2). Por ello, se ha elegido hacer el estudio en Sechura donde hay una mayor producción de conchas de abanico y donde se encuentran mayores nichos de criadores.

\subsubsection{Análisis del sector industrial (cinco fuerzas de PORTER)}

\section{Rivalidad entre competidores:}

En la actualidad la rivalidad entre los competidores es alta, debido a que el mercado está creciendo rápidamente y existen otras empresas en el giro. Además, existen barreras de salidas. Por ejemplo, los equipos tecnológicos que se usan difícilmente pueden ser usados en otras industrias y los altos costos por indemnización a empleados o proveedores que existen en el país.

Se puede observar que, las grandes empresas están centradas en los mercados de mayor volumen, muchos de estos centrados en la capital. Por ello, buscamos competir reduciendo precios, estos estarán compensados al instalar la planta en una región estratégica, cercana a los productores de conchas de abanico, con la finalidad de reducir los costos en transporte, además, poder atender toda su producción. Por otro lado, nuestro insumo no es dañino al medio ambiente (M. Morán, comunicación personal, 10 de junio, 2017), por lo que otras empresas usan amoniaco o freón como insumos, estos reducen la calidad del producto congelado. Tenemos competencia, pero de estas todas usan el método de contacto (Vidaurre, J), así tenemos una ligera ventaja ofreciendo el nitrógeno gracias a la preservación de la calidad y todas sus propiedades. 


\section{Amenaza de nuevos competidores:}

La amenaza de entrada de nuevos competidores es baja debido a que se necesita experiencia y capital. Para la entrada de nuevos competidores es difícil, ya que, para la implementación de esta planta es una inversión y mantenimiento alto, aproximadamente tener la planta de nitrógeno parada es de un millón y medio de dólares (Vidaurre, comunicación personal, 10 de junio, 2017). Además, buscaremos la lealtad de nuestros clientes ofreciendo precios bajos y calidad alta. Por último, nuestro producto es amigable con el medio ambiente, tema que hoy en día es muy discutido y que estamos en ventaja al ser la única tecnología ofreciendo el nitrógeno en el país.

\section{Amenaza de ingreso de productos sustitutos:}

El ingreso de productos sustitutos es bajo debido a que el nitrógeno es la última tecnología existente que cumple con todos los parámetros requeridos, como conservar la calidad, no contaminante, no dañino para la salud y facilitar el congelamiento rápido.

Como se mencionó anteriormente, la exposición al amoníaco es peligrosa para la salud humana al ser un elemento con la capacidad de irritar la piel, los ojos y hasta provocar la muerte. Por otro lado, se está prohibiendo la venta del freón, pues, al llegar a la atmósfera tiene la capacidad de destruir la capa de ozono.

\section{Poder de negociación de los proveedores:}

Al usar el nitrógeno líquido como fuente para congelar las conchas de abanico no se requiere ningún proveedor, debido a que para obtener este mismo la planta productora de nitrógeno cuenta con compresores de aire, estos comprimen el aire del entorno para empezar el proceso de producción del nitrógeno líquido.

\section{Poder de negociación de los compradores:}

El poder de negociación de los compradores es alto debido a que el cliente puede convertirse en su propio proveedor, es decir, pueden optar por adquirir su propio método de congelamiento de las conchas de abanico. Además, determinan el volumen de conchas de abanico a congelar y exigen que estos cumplan altos estándares de calidad. 


\subsubsection{Modelo de Negocios (Canvas)}

Tabla 2.1

Modelo de Negocios del servicio de congelamiento de conchas de abanico

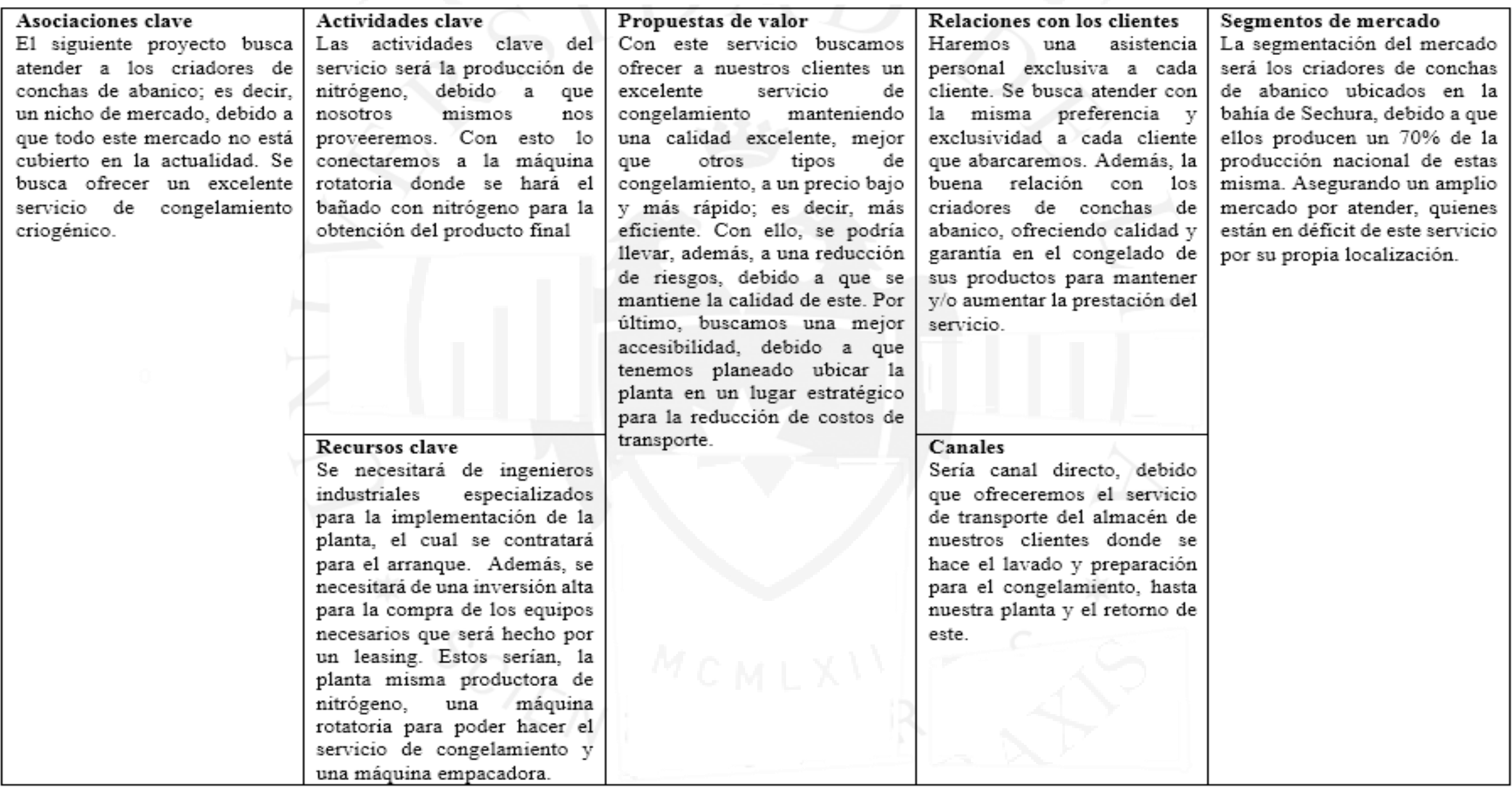


(continuación)

\begin{tabular}{|l|l|}
\hline $\begin{array}{l}\text { Estructura de costes } \\
\text { Por el lado de los costes, se calcula un gasto aproximado de } 150 \text { dólares por } \\
\text { tonelada, incluyendo el uso de la planta, el pago a los trabajadores, agua, luz y el }\end{array}$ & $\begin{array}{l}\text { Fuente de ingresos } \\
\text { Al ofrecer el servicio de congelamiento criogénico, se ganará por prestación del } \\
\text { servicio, se vende por toneladas de nitrógeno utilizado a un precio variable entre }\end{array}$ \\
$\begin{array}{l}\text { uso de nuestro medio de transporte. La planta que se planea comprar tiene una } \\
\text { capacidad de } 15 \text { toneladas diarias, en el cual se calcula que diariamente se hará un }\end{array}$ & $\begin{array}{l}\text { los } 300 \text { hasta los } 500 \text { dólares por tonelada. Sin embargo, para fidelizar al cliente, } \\
\text { se hará un arreglo en el precio final del servicio al comprar seguidamente. E1 cobro } \\
\text { ge realizará después de haber entregado el producto congelado. }\end{array}$
\end{tabular}

Elaboración propia. 


\subsection{Análisis de la demanda}

\subsubsection{Data histórica del consumidor y sus patrones de consumo}

\subsubsection{Patrones de consumo: incremento poblacional, consumo per cápita, estacionalidad}

Por el lado del incremento poblacional de las conchas de abanico, para este estudio se puede analizar que tienen como variable independiente su consumo nivel mundial. En los últimos años, ha sido afectado gravemente por el fenómeno del niño. Como comenta Carlos Posada al diario la Gestión (2017), esta ha disminuido en un 80\% en el 2017 (párr. 2) afectando la capacidad de atención de las exportaciones. Por otro lado, se ve que en años pasados como el 2013 ha sido un excelente año para la producción nacional de conchas de abanico, llegando a exportar hasta 15,121 toneladas, como se puede ver en la Tabla 2.2.

En el consumo per cápita, para este proyecto no se puede analizar a este nivel, debido que, en la actualidad los acuicultores de conchas de abanico usan otros métodos de congelamiento como lo son de contacto indirecto que usando freón o amoniaco como refrigerantes.

Finalmente, según el Banco Mundial (2013), la tendencia de consumo humano de la acuicultura tiene un crecimiento anual de $0.3 \%$ en promedio global (p. 45). Además:

La industria acuícola se está perfilando como una actividad con gran potencial de crecimiento a escala global. Existe un aumento en las inversiones para la acuicultura, sobre todo en tecnologías para mejorar la productividad, que incluyen el uso del agua de manera responsable, el mejoramiento genético en crías, las prácticas en los criaderos y la innovación en la alimentación de los peces. Todo esto debería incrementar la producción acuícola hasta un 4,14\% anual de aquí al año 2022, un crecimiento notablemente rápido. (Unión Industrial Bahía Blanca, 2017, párr. 10) 


\subsubsection{Demanda Interna Aparente Histórica tomando como fuente bases de datos de Producción, Importaciones y Exportaciones}

Se recopiló la data histórica de la exportación de conchas de abanico en el país, ya que todo lo que se exporta se tiene que congelar. De esta forma, obtendremos nuestra demanda que será considerada como la variable dependiente para su respectiva proyección.

\section{Tabla 2.2}

Data histórica de la exportación de conchas de abanico por año.

\begin{tabular}{c|c} 
AÑO & $\begin{array}{c}\text { EXPORTANCIÓN } \\
(\mathbf{t})\end{array}$ \\
\hline $\mathbf{2 0 0 8}$ & $6,924.00$ \\
$\mathbf{2 0 0 9}$ & $9,436.00$ \\
$\mathbf{2 0 1 0}$ & $12,612.00$ \\
$\mathbf{2 0 1 1}$ & $10,462.00$ \\
$\mathbf{2 0 1 2}$ & $5,820.00$ \\
$\mathbf{2 0 1 3}$ & $15,121.00$ \\
$\mathbf{2 0 1 4}$ & $12,332.00$ \\
$\mathbf{2 0 1 5}$ & $6,178.00$
\end{tabular}

Fuente: Organización de las Naciones

Unidas para la Alimentación, FAO. (2014)

No se consideran para la proyección el año 2012 ya que se presentó una alta tasa de mortalidad debido a la presencia de una marea roja (Gestión, 2014). Tampoco se consideraron los años 2014 al 2017 porque no existió un aprovisionamiento adecuado de semillas de conchas de abanico y la presencia del fenómeno del niño que afecta directamente a la vida de las conchas de abanico por las altas temperaturas, provocando un déficit de oxígeno en el mar (Gestión, 2018).

\subsubsection{Proyección de la demanda (serie de tiempo o asociativas)}

Para proyectar la demanda se utilizó el método de regresión, usando como variable independiente el consumo de conchas de abanico a nivel mundial, como se puede observar en la Tabla 2.3. 
Tabla 2.3

Data histórica de consumo de conchas de abanico a nivel mundial.

\begin{tabular}{l|l}
\multicolumn{1}{c}{ ÑNO } & CONSUMO GLOBAL $(\mathbf{t})$ \\
\hline & \\
\hline $\mathbf{2 0 0 8}$ & 116,793 \\
$\mathbf{2 0 0 9}$ & 122,649 \\
$\mathbf{2 0 1 0}$ & 132,078 \\
$\mathbf{2 0 1 1}$ & 136,065 \\
$\mathbf{2 0 1 2}$ & 124,091 \\
$\mathbf{2 0 1 3}$ & 154,820 \\
$\mathbf{2 0 1 4}$ & 158,884 \\
$\mathbf{2 0 1 5}$ & 173,752
\end{tabular}

Fuente: Banco Mundial (2015) y FAO (2015)

Elaboración propia.

Considerando que el consumo de productos marinos a nivel mundial viene incrementando en $0.3 \%$ anualmente, según la proyección del Banco Mundial, se tiene los siguientes resultados:

Tabla 2.4

Importación de conchas de abanico a nivel mundial proyectada.

\begin{tabular}{c|c} 
AÑO & $\begin{array}{c}\text { CONSUMO } \\
\text { GLOBAL } \\
\text { (t) }\end{array}$ \\
\hline $\mathbf{2 0 1 8}$ & 175,320 \\
$\mathbf{2 0 1 9}$ & 175,846 \\
$\mathbf{2 0 2 0}$ & 176,374 \\
$\mathbf{2 0 2 1}$ & 176,903 \\
$\mathbf{2 0 2 2}$ & 177,434 \\
$\mathbf{2 0 2 3}$ & 177,966 \\
$\mathbf{2 0 2 4}$ & 178,500 \\
\hline
\end{tabular}

Elaboración propia.

En consecuencia, la línea de tendencia de nuestra demanda se muestra en la figura 2.1. 
Figura 2.1

Tendencia de la producción.

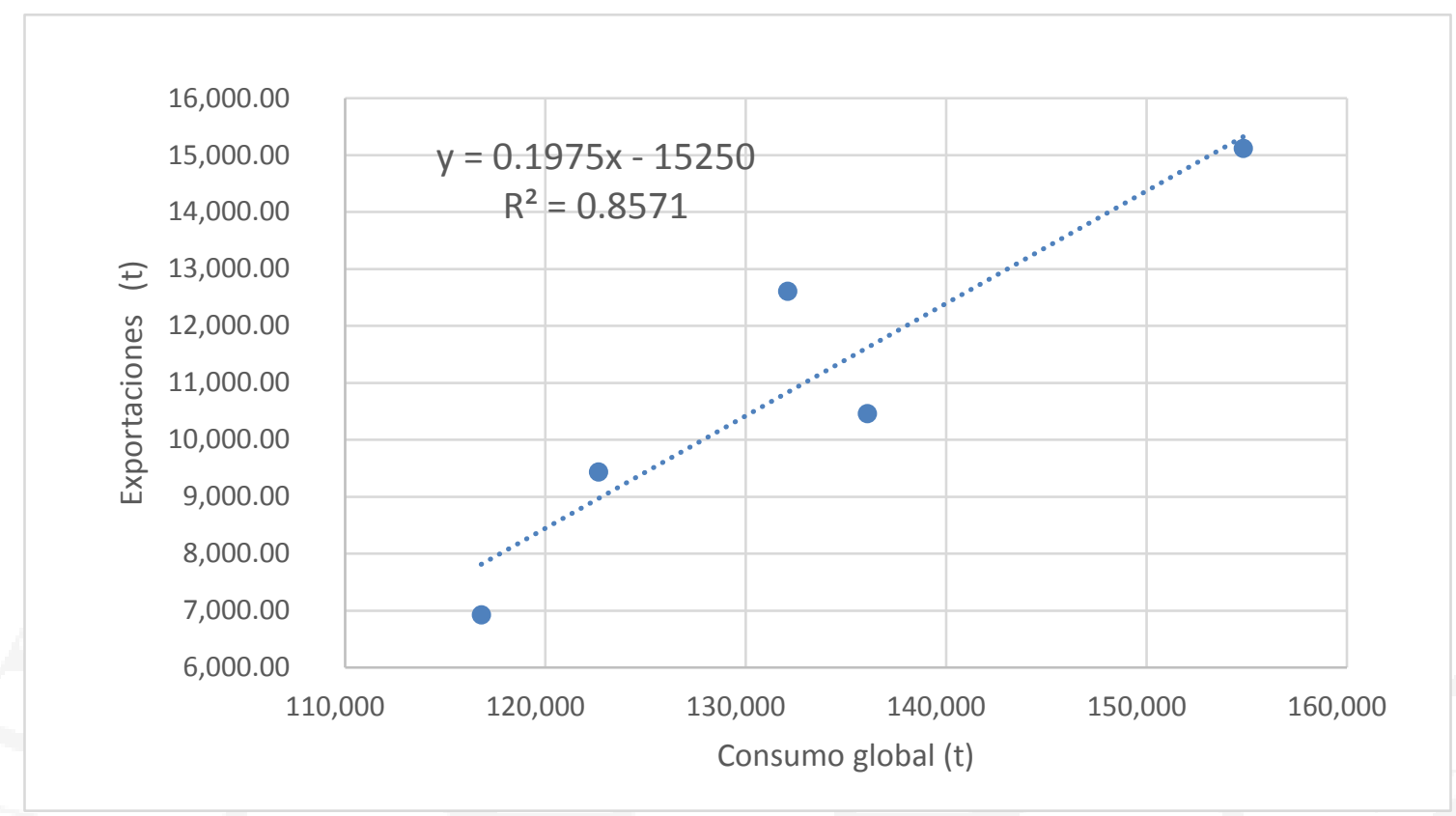

Elaboración propia.

Se consideró la regresión lineal, que es la que más se ajusta al comportamiento de los datos históricos obteniendo la siguiente ecuación y su coeficiente de determinación:

$$
\begin{aligned}
& Y=0.1975 X-15250 \\
& R^{2}=0,8571
\end{aligned}
$$

Dónde:

$\mathrm{Y}=$ Exportación proyectada.

$\mathrm{X}=$ Consumo global de conchas de abanico.

Esto significa que el $85.71 \%$ de la exportación de conchas de abanico esta explicado por el consumo global de conchas de abanico.

Con la ecuación hallada anteriormente se procede a proyectar la demanda hasta el año 2024 de conchas de abanico obteniendo los siguientes resultados: 
Tabla 2.5

Consumo global y exportación proyectadas.

\begin{tabular}{|l|cc} 
AÑO & $\begin{array}{c}\text { CONSUMO } \\
\text { GLOBAL (t) }\end{array}$ & EXPORTACIÓN (t) \\
\hline $\mathbf{2 0 1 8}$ & 175,320 & $19,375.79$ \\
$\mathbf{2 0 1 9}$ & 175,846 & $19,479.67$ \\
$\mathbf{2 0 2 0}$ & 176,374 & $19,583.86$ \\
$\mathbf{2 0 2 1}$ & 176,903 & $19,688.36$ \\
$\mathbf{2 0 2 2}$ & 177,434 & $19,793.17$ \\
$\mathbf{2 0 2 3}$ & 177,966 & $19,898.30$ \\
$\mathbf{2 0 2 4}$ & 178,500 & $20,003.75$ \\
\hline
\end{tabular}

Elaboración propia.

Como se mencionó anteriormente toda lo que se exporta necesita ser congelado; por lo tanto, nuestra demanda será la siguiente:

Tabla 2.6

Demanda de conchas de abanico a congelar.

\begin{tabular}{c|c} 
AÑO & $\begin{array}{c}\text { PRODUCCIÓN } \\
(\mathbf{t})\end{array}$ \\
\hline $\mathbf{2 0 1 8}$ & $19,375.79$ \\
$\mathbf{2 0 1 9}$ & $19,479.67$ \\
$\mathbf{2 0 2 0}$ & $19,583.86$ \\
$\mathbf{2 0 2 1}$ & $19,688.36$ \\
$\mathbf{2 0 2 2}$ & $19,793.17$ \\
$\mathbf{2 0 2 3}$ & $19,898.30$ \\
$\mathbf{2 0 2 4}$ & $20,003.75$ \\
\hline
\end{tabular}

Elaboración propia.

\subsubsection{Demanda mediante fuentes primarias}

\subsubsection{Diseño y aplicación de encuestas u otras técnicas}

Al contar solamente con 9 empresas dedicadas a la producción de conchas de abanico listas para la exportación, se ha hecho las encuestas a todas ellas debido a que nuestra población es muy limitada. 
Las empresas que producen conchas de abanico en la región de Sechura son:

1.Piura Sea Food

2.Viza

3.Fimors

4.Maria Luisa

5.Acuiberlin

6.Jehova es mi Proveedor

7.Akayser

8.Emox

9.Seacorp

A estas empresas se les realizó las siguientes preguntas:

1. ¿La ubicación de su criadero se encuentra en la bahía de Sechura? (si/no).

2. ¿Conoce el servicio de congelamiento criogénico que utiliza nitrógeno?

3. ¿Contrataría el servicio de congelamiento criogénico usando nitrógeno?

4. ¿Cuál es el grado de intensidad de su posible contratación de este servicio?

5. ¿Cuánto puede producir diariamente? (TON)

6. ¿Qué tecnología usa actualmente para este proceso?

7. ¿Cuánto estaría dispuesto a pagar por dicho servicio? (500-1000 dólares x tonelada).

8. ¿Cómo le gustaría que se le entregue el producto congelado?

Con los resultados obtenidos de la encuesta se calculó la intensión, intensidad y frecuencia de la adquisición del servicio de congelamiento.

a) Intención:

Según las encuestas realizadas a los criadores de conchas de abanico se obtuvieron los siguientes resultados: 
Figura 2.2.

Intención del servicio

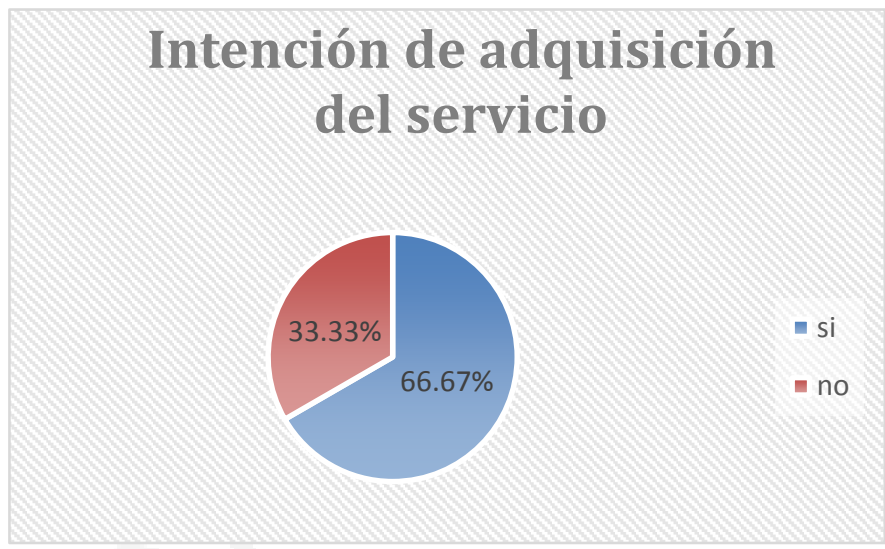

Elaboración propia.

Con las respuestas de las encuestas tenemos como resultado que el $66.67 \%$ de los productores de conchas de abanico estarían dispuestos a contratar el servicio de congelamiento criogénico usando nitrógeno como insumo.

b) Intensidad:

Según las encuestas realizadas a las empresas, se obtuvieron los siguientes resultados:

Figura 2.3.

Intensidad del servicio

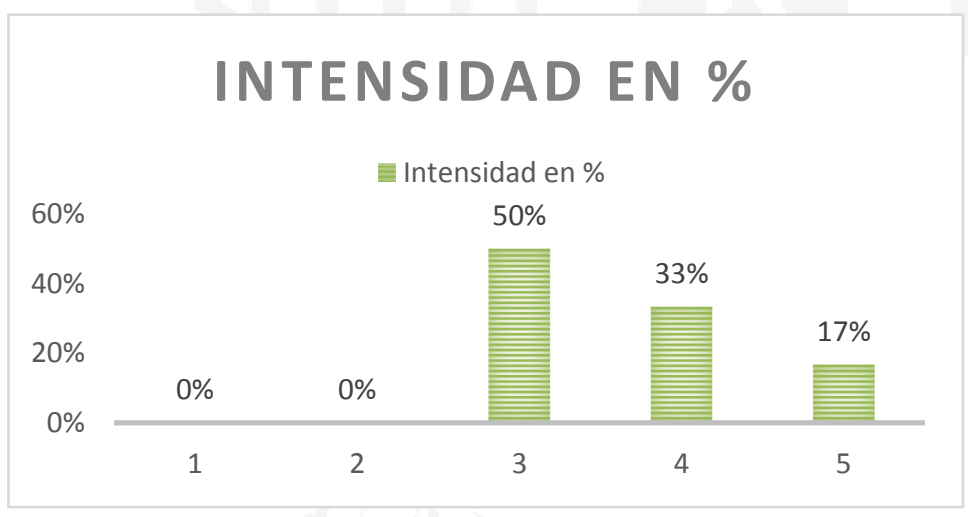

Elaboración propia.

Donde los criterios de rangos se muestran en la tabla 2.7 
Tabla 2.7.

Definición de criterios de rangos.

\section{RANGO DEFINICIÓN}

\begin{tabular}{l|l}
\hline $\mathbf{1}$ & No interesado \\
$\mathbf{2}$ & Sin mucho interés \\
$\mathbf{3}$ & Medianamente interesado \\
$\mathbf{4}$ & Por encima de la media interesado \\
$\mathbf{5}$ & Totalmente interesado
\end{tabular}

Elaboración propia.

Entonces, del porcentaje de las empresas que estarían dispuestos a adquirir el servicio, el $50 \%$ de los encuestados tienen mediano interés en adquirir el servicio, el $33 \%$ tienen un interés por encima de la media de adquirir el servicio y el $17 \%$ están totalmente interesados.

c) Frecuencia:

La producción de conchas de abanico que producen diariamente es de 12 a 18 toneladas. Según las encuestas realizadas tenemos los siguientes datos de las empresas que estarían dispuestos a adquirir el servicio, estas mismas serían congeladas al $100 \%$ debido a que las conchas de abanico son perecibles. Por lo tanto, nos interesa saber la capacidad de producción de cada uno de ellos ya que equivale a la cantidad que necesitan congelar.

Figura 2.4.

Producción diaria según encuestas.

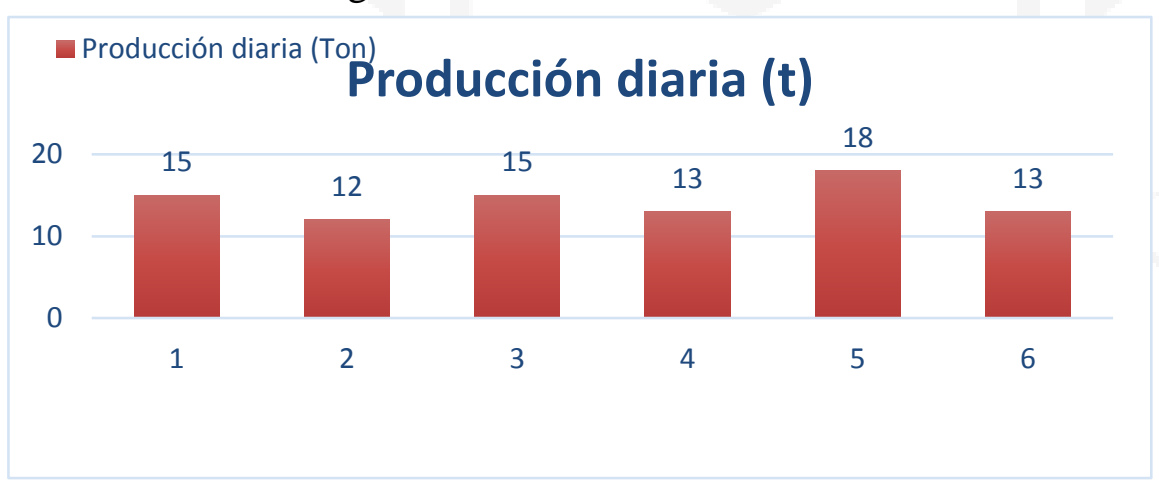

Elaboración propia. 


\subsubsection{Demanda potencial}

\subsubsection{Determinación de la demanda potencial}

La demanda potencial del proyecto al no tener el CPC, se ha establecido como demanda potencial la suma de toda la producción de cada empresa encuestada.

Tabla 2.8.

Demanda potencial

\begin{tabular}{l|c}
\multicolumn{1}{|c|}{ EMPRESA } & $\begin{array}{r}\text { PRODUCCIÓN } \\
\text { ANUAL }(\mathbf{t})\end{array}$ \\
\hline PIURA SEA FOOD & 5400 \\
VIZA & 4320 \\
MARIA LUISA & 5400 \\
JEHOVA ES MI & 4680 \\
PROVEEDOR & \\
AKAYSER & 6480 \\
SEACORP & 4680 \\
TOTAL & $\mathbf{3 0 9 6 0}$ \\
\hline
\end{tabular}

Elaboración propia.

\subsection{Análisis de la oferta}

\subsubsection{Análisis de la competencia. Competencia directa y sus ubicaciones. Participación de mercado (si aplica)}

Para realizar este análisis, se ha identificado cuatro empresas que utilizan otro tipo de tecnología, se conoce que solo dos tienen su propio congelado y las otras dos prestan servicio de congelamiento. Las dos empresas que tienen su propio congelado y su producción son IPRISCO S.A.C, que puede llegar a procesar hasta 60 toneladas por día y PERU PEZ S.A, ambos usan la tecnología de contacto directo usando amoniaco. Por otro lado, las otras dos empresas que serían denominadas como nuestra competencia directa, son GAM CORP y UNITED OCEANS S.A, quienes prestan el servicio de congelamiento usando freón y amoniaco respectivamente, demorando entre 3 a 5 horas para poder congelar. Finalmente, de las últimas tres empresas mencionadas, PERU PEZ S.A. Y GAM CORP tienen una capacidad de congelamiento de 15 toneladas diarias y 
UNITED OCEAN S.A. sólo 10 toneladas diarias. Por el lado de sus ubicaciones, todos se encuentran en Sechura. (J. Vidaurre, Comunicación personal, 13 de Mayo, 2017).

Es así, que IPRISCO S.A.C abarca un $60 \%$ del procesamiento actual de congelamiento, PERU PEZ S.A y GAM CORP un $15 \%$ cada uno y finalmente, UNITED OCEANS S.A un $10 \%$.

\subsubsection{Beneficios ofertados por los competidores directos}

El beneficio es que usando los métodos convencionales ya es conocido por los criadores de conchas de abanico, de esta forma optarían por utilizar esos métodos. Además de la cantidad que puede procesar IPRISCO (60TPD), quien puede asegurar el servicio a sus clientes.

\subsubsection{Análisis competitivo y comparativo (Matriz EFE).}

Para poder realizar el análisis competitivo y comparativo de los factores externos es necesario describir el nivel importancia de cada uno. Como se mencionó en la descripción del problema la existencia de un rechazo de la producción de conchas de abanico al momento de exportar ya que estos son perecibles, existe la necesidad de poder alargar su tiempo de vida. Nosotros al ofrecer el servicio de congelamiento IQF que permitiría satisfacer la necesidad, consideramos el factor más importante, asignándole un peso de 0.16, el siguiente factor más importante es el crecimiento de demanda del exterior, pues, nos permitiría tener mayor producción de conchas de abanico para congelar y tener mayor utilidad, por lo tanto obtiene un peso de 0.13 . El tercer factor a tener en consideración es la falta de agua y desagüe en algunas zonas, ya que el agua es utilizada como refrigerante en nuestra planta, es esencial su disponibilidad, si no la planta no podría producir nitrógeno, por eso le ponemos un peso de 0.11 . Los siguientes factores como política de sanidad, golpe del fenómeno del niño a la producción y falta de energía eléctrica tienen un peso de 0.1 , mientras que el factor de mayor costo de servicio, rivalidad de competidores, concientización del cuidado del medio ambiente tienen un peso de 0.09 y 0.08 respectivamente ya que hay une menor probabilidad de ocurrencia. Finalmente, el factor de nuevos mercados del servicio tiene un puntaje de 0.05 ya que nos enfocaremos inicialmente solo en el servicio del congelamiento de conchas de abanico. 
Tabla 2.9

Matriz EFE.

\begin{tabular}{|c|c|c|c|}
\hline FACTORES DETERMINANTES DEL ÉXITO & PESO & CALIFICACIÓN & $\begin{array}{c}\text { PESO } \\
\text { PONDERADO }\end{array}$ \\
\hline \multicolumn{4}{|l|}{ OPORTUNIDADES } \\
\hline $\begin{array}{l}\text { 1. CRECIMIENTO DE DEMANDA DEL } \\
\text { EXTERIOR. }\end{array}$ & 0.13 & 2 & 0.26 \\
\hline 2. POLÍTICAS DE SANIDAD. & 0.1 & 4 & 0.4 \\
\hline 3. NUEVOS MERCADOS DEL SERVICIO & 0.05 & 3 & 0.15 \\
\hline $\begin{array}{l}\text { 4. CONCIENTIZACIÓN DEL CUIDADO DEL } \\
\text { MEDIO AMBIENTE. }\end{array}$ & 0.08 & 4 & 0.32 \\
\hline $\begin{array}{l}\text { 5. NECESIDAD DE ALARGAR EL TIEMPO DE } \\
\text { VIDA DEL PRODUCTO }\end{array}$ & 0.16 & 2 & 0.32 \\
\hline \multicolumn{4}{|l|}{ AMENAZAS } \\
\hline $\begin{array}{l}\text { 1. GOLPE DEL FENÓMENO DEL NIÑO A LA } \\
\text { PRODUCCIÓN. }\end{array}$ & 0.1 & 4 & 0.4 \\
\hline 2. MAYOR COSTO DEL SERVICIO. & 0.09 & 2 & 0.18 \\
\hline 3. RIVALIDAD DE COMPETIDORES & 0.08 & 2 & 0.16 \\
\hline $\begin{array}{l}\text { 4. FALTA DE INSTALACIÓN DE ENERGÍA } \\
\text { ELÉCTRICA EN ALGUNAS ZONAS }\end{array}$ & 0.1 & 3 & 0.3 \\
\hline $\begin{array}{l}\text { 5. FALTA DE AGUA Y DESAGÜE EN ALGUNAS } \\
\text { ZONAS }\end{array}$ & 0.11 & 3 & 0.33 \\
\hline TOTAL & 1 & & 2.82 \\
\hline
\end{tabular}

Elaboración propia. 
Tabla 2.10

Rangos de calificación

DONDE:

$1 \quad$ Respuesta es mala

2 Respuesta es la media

3 Respuesta por arriba de la media

4 Respuesta superior

Elaboración propia.

Se tiene que el peso ponderado es 2.82 y se encuentra por encima de la media. Por lo tanto, se encuentra con capacidad de éxito por el lado de oportunidades y amenazas. Además, tenemos como oportunidades una calificación de 1.45 versus 1.37 de amenazas, lo cual establece que el medio es favorable a la organización.

\subsection{Determinación Demanda para el proyecto}

\subsubsection{Segmentación del mercado}

Para esta investigación, se tendrá en cuenta a los criadores de conchas de abanico de Sechura-Piura, quienes tienen una producción del 80\% de la producción nacional (El Tiempo, 2018, párr. 4), considerando como información de fuentes primarias que sólo hay 4 empresas de congelamiento que prestan servicio en esta zona del país.

\subsubsection{Selección de mercado meta}

El mercado meta para la investigación presente está dedicado a las empresas productoras de conchas de abanico de la región de Sechura ubicado en el departamento de Piura. De acuerdo al criterio de segmentación del mercado definido, se ha podido identificar a las siguientes empresas ubicadas en esta región: 
Tabla 2.11.

Relación de criadores existentes

INTERESADOS EN LA

EMPRESA

ADQUISICIÓN DEL SERVICIO

\begin{tabular}{c|c|}
\hline PIURA SEA FOOD & $\mathrm{Si}$ \\
VIZA & $\mathrm{Si}$ \\
FIMORS & no \\
MARIA LUISA & $\mathrm{si}$ \\
ACUIBERLIN & no \\
JEHOVA ES MI & $\mathrm{si}$ \\
PROVEEDOR & \\
AKAYSER & $\mathrm{si}$ \\
EMOX & no \\
SEACORP & si \\
\hline
\end{tabular}

Elaboración propia.

\subsubsection{Determinación de la participación de mercado para el proyecto}

Basándonos en el análisis realizado en el subcapítulo del análisis de la competencia, la empresa UNITED OCEANS S.A tiene la menor participación del mercado, $10 \%$ del procesamiento actual de congelado para conchas de abanico (J. Vidaurre, comunicación personal, 13 de Mayo, 2017.). Por lo tanto, al considerar que nuestra empresa recién se ha formado, la participación en el mercado que alcanzara será 10\%, la menor participación identificada en el análisis de la competencia.

Entonces, la participación en toneladas para los siguientes cinco años, teniendo en cuenta la demanda proyectada de conchas de abanico y el resultado de nuestras encuestas, donde calculamos un factor de corrección de 0.49 (Intensidad* Intensión), tenemos como resultado: 
Tabla 2.12.

Demanda del proyecto

\begin{tabular}{|l|c|c|c|c|c|c|}
\hline Año & $\begin{array}{c}\text { Producción } \\
\text { de nitrógeno } \\
(\mathbf{t})\end{array}$ & $\begin{array}{c}\text { Segmentación } \\
\text { (Sechura 80\%) }\end{array}$ & $\begin{array}{c}\text { Factor de } \\
\text { corrección } \\
\text { (Intención x } \\
\text { Intensidad) }\end{array}$ & $\begin{array}{c}\text { Demanda } \\
\text { Objetivo } \\
(\mathbf{t})\end{array}$ & $\begin{array}{c}\text { Participación } \\
\mathbf{( 1 0 \% )}\end{array}$ & $\begin{array}{c}\text { Demanda } \\
\text { del } \\
\text { proyecto (t) }\end{array}$ \\
\hline $\mathbf{2 0 1 8}$ & $19,375.79$ & $80.00 \%$ & 0.49 & $7,595.31$ & 0.10 & 759.53 \\
\hline $\mathbf{2 0 1 9}$ & $19,479.67$ & $80.00 \%$ & 0.49 & $7,636.03$ & 0.10 & 763.60 \\
\hline $\mathbf{2 0 2 0}$ & $19,583.86$ & $80.00 \%$ & 0.49 & $7,676.87$ & 0.10 & 767.69 \\
\hline $\mathbf{2 0 2 1}$ & $19,688.36$ & $80.00 \%$ & 0.49 & $7,717.84$ & 0.10 & 771.78 \\
\hline $\mathbf{2 0 2 2}$ & $19,793.17$ & $80.00 \%$ & 0.49 & $7,758.92$ & 0.10 & 775.89 \\
\hline $\mathbf{2 0 2 3}$ & $19,898.30$ & $80.00 \%$ & 0.49 & $7,800.14$ & 0.10 & 780.01 \\
\hline $\mathbf{2 0 2 4}$ & $20,003.75$ & $80.00 \%$ & 0.49 & $7,841.47$ & 0.10 & 784.15 \\
\hline
\end{tabular}

Elaboración propia.

Se debe tener en cuenta además que se están realizando proyectos para poder incrementar la producción de las conchas de abanico a nivel municipal. (Vidaurre, J).

\subsection{Definición de la estrategia de comercialización}

\subsubsection{Políticas de plaza}

Para la planta necesitaremos un espacio aproximado entre 800 y 1,500 $\mathrm{m}^{2}$, el cálculo de este se detallará en el capítulo V, para poder levantar nuestras instalaciones contando con nuestro edificio de control donde se manipulará la máquina automatizada y donde se encontrarán las oficinas de los 2 gerentes. La planta estará ubicada lo más cercado posible al taller de las empresas acuicultoras para disminuir el tiempo de espera en el transporte del producto por congelar y del producto congelado, así tendremos una respuesta más rápida a nuestra demanda. Se tiene pensado en localizar la planta en un punto común de dos o tres productores, debido a que cada uno está produciendo en promedio 17 toneladas diarias.

\subsubsection{Publicidad y promoción}

Por el lado de la publicidad y promoción, se enfocará en mostrar las ventajas de nuestro producto y resaltar las desventajas de los otros métodos, con la finalidad de acoger a los clientes. Se buscará resaltar la principal ventaja que mantenemos que es conservar la calidad el cual incurre en una menor deshidratación (5 a $10 \%$ tradicional vs $0.25 \%$ 
criogénico) y, por último, bajos costos de operación, mantenimiento y limpieza. (M. Morán, comunicación personal, 10 de junio, 2017).

Por el lado de promoción con el cliente, ofreceremos el empacado y congelado de su producto, listo para poner la marca del cliente, acceso a las unidades de transporte para poder llevar el producto del cliente y por último un crédito bimensual (se cobra cada 60 días).

\subsubsection{Análisis de precios}

\subsubsection{Tendencia histórica de los precios}

Según las encuestas realizadas, ver Anexo $\mathrm{N}^{\circ} 1$ - pregunta 7 , los precios que se pagan por el servicio de congelamiento de conchas de abanico varían entre 800 y 1000 dólares por tonelada, es decir considerando un tipo de cambio de 3.3 según la Sunat (2019), los precios en soles son aproximadamente entre 2640 soles y 3300 soles por tonelada

\subsubsection{Estrategia de precios (precio Inicial)}

Por lanzamiento se cobrará 2600 soles la tonelada, aplicaremos una estrategia de liderazgo de costos para tener una mayor penetracion de mercado, ya que nos permitiría atraer a los clientes de la competencia y aumentar la cantidad promedio de la contratación de nuestro servicio, además, se tiene la finalidad de solidificar la empresa y buscar el crecimiento en términos de capacidad en los próximos años con ampliación de las instalaciones.

La estrategia de comercialización, consistirá en realizar contratos con los dueños de las piscinas de conchas de abanico; es decir, nos encargaremos de atender a solamente una porción de la producción. Respecto al cobro del servicio de congelamietno, se realizará después de haber congelado y devuelto el producto terminado, firmando previamente un contrato, de esta manera se fidelizará al cliente demostrando la garantía del servicio.

Según las encuestas realizadas, los productores de conchas de abanico que se encuentran interesados en adquirir el servicio pagarían los siguientes montos por tonelada. 
Figura 2.5.

Relación precio / tonelada según encuestas.

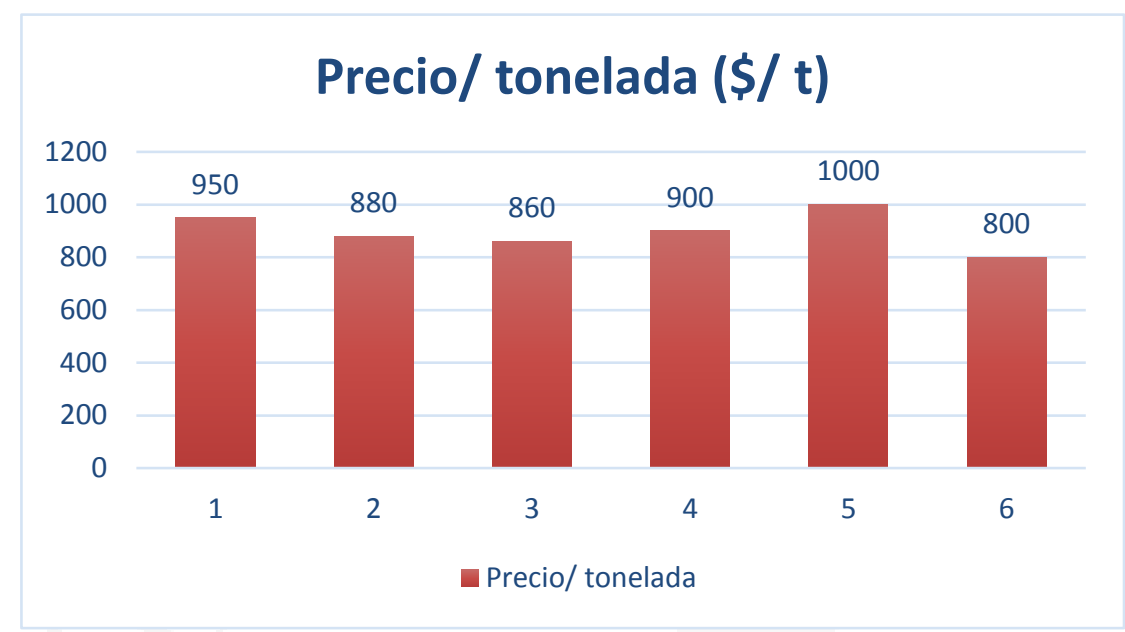

Elaboración propia.

El precio promedio que pagarían los productores de conchas de abanico está en 899 dólares por tonelada, es decir 2966,70 soles. 


\section{CAPÍTULO III: LOCALIZACIÓN DEL SERVICIO}

\subsection{Identificación y análisis detallado de los factores de localización}

Los factores de localización más importantes para este estudio son los siguientes:

- Cercanía de mercado: Este factor es de vital importancia debido a que el transporte que se realizará del taller de producción de conchas de abanico a nuestra planta de congelamiento criogénico y viceversa se hará diariamente. Por lo tanto, mientras más cercano sea el trayecto del transporte, habrá mayor atención al cliente. Además, se debe considerar que el producto antes de ser congelado es muy susceptible a perder debido a que es un producto fresco. Para poder evaluar este punto consideraremos las distancias entre las zonas de producción y de nuestra posible locación.

- Calidad de agua: Al ser el agua potable un servicio básico para las personas es necesario tener en cuenta que debe haber acceso de agua por red pública y que este bien tratada para que exista comodidad en el centro laboral.

- Infraestructura vial: Para poder trasladar nuestros equipos a nuestra planta y que los clientes accedan a ella, es necesario tener en cuenta si los camiones pueden tener un fácil acceso a dichas zonas, ya que las conchas de abanico al ser un producto altamente perecible, se necesita de un transporte rápido y sin obstáculos. En la evaluación se considerará el estado de las carreteras y la cantidad de estas mismas.

- Disponibilidad de energía eléctrica: Esta planta productora de nitrógeno demanda una alta cantidad de energía eléctrica; por ello, es necesario tener una disponibilidad de energía de alta tensión. Se evaluara de acuerdo a la cantidad producida de energía por lugar.

- Costo de terreno: Esta planta nos demanda tener un terreno que puede variar entre $800 \mathrm{~m}^{2}$ y $1500 \mathrm{~m}^{2}$; es por ello, que el factor del costo de terreno es muy importante, se debe comprar un terreno amplio y que esté categorizado como un terreno industrial. El criterio para esta calificación es el costo por metro cuadrado. 
- Infraestructura en las telecomunicaciones: Es necesario considerar este factor para la instalación de una planta, pues, que exista infraestructura en las telecomunicaciones significa que los clientes puedan mantenerse siempre en contacto con nosotros, además, nos da la oportunidad de manejar un excelente plan de logística y coordinaciones dentro de la planta.

- Población Económicamente Activa: Este factor corresponde a la fuerza laboral efectiva del país, ya que en este grupo forman parte las personas que están en edad de trabajar y están laborando o buscando trabajo.

\subsection{Identificación y descripción de las alternativas de localización}

Para la evaluación de las alternativas de localización, tenemos en primer lugar el lado de macro localización; en el cual, se hará a nivel departamental, considerando los departamentos de Piura, Tumbes y Lima, ya que son departamentos que vienen convirtiéndose en las principales zonas de producción acuícola en el país.

Seguidamente, se evaluará a nivel de ciudades, teniendo las siguientes alternativas: Sechura, Sullana y Talara que son las regiones que más desarrollo han tenido en los últimos años. Pues, las principales actividades que destacan en Talara son el refinamiento del crudo y la pesca. Por otro lado, Sechura, conocida como tierra de pescadores, destaca la pesca principalmente en la producción de conchas de abanico. Finalmente, Sullana posee una ubicación estratégica que lo convierte en el eje de comunicación entre las provincias de Piura.

\subsection{Determinación del modelo de evaluación a emplear}

En este capítulo se recurrirá a un ranking de factores, método semi cualitativo en el cual enfrentará los siete factores más importantes que hemos considerado para este proyecto.

Una vez definido los factores a enfrentar, previamente se ha otorgado una escala de puntaje para este mismo. De la cual serán: 
Tabla 3.1.

Calificación de Macro y Micro localización

\section{CALIFICACIÓN PUNTAJE}

\begin{tabular}{l|c}
\hline MUY MALO & 1 \\
MALO & 3 \\
DEFICIENTE & 5 \\
BUENO & 7 \\
EXCELENTE & 10
\end{tabular}

Elaboración propia.

Valorados estos factores, se evaluará por 3 departamentos del Perú mencionados previamente. De lo cual, la alternativa ganadora se evaluará a nivel provincial. Los factores considerados son Cercanía de Mercado, Calidad de Agua, Población Económica Activa, Acceso a la Infraestructura Vial, Disponibilidad de Energía Eléctrica, Costo de Terreno e Infraestructura de Comunicaciones.

\subsection{Evaluación y selección de localización}

\subsubsection{Evaluación y selección de la macro localización}

1. Cercanía de mercado: Como mencionamos anteriormente, la distancia a los criaderos de conchas de abanico es importante, la ubicación principal de los productos de conchas de abanico se encuentra en la bahía de Sechura, dentro del departamento de Piura. Poniendo como localización excelente a este departamento, seguidamente por Tumbes y finalmente por Lima. Por ello, Piura se lleva una calificación de excelente, Tumbes una calificación de bueno y finalmente Lima con una calificación de malo. A continuación, se muestra la distancia que existe entre las alternativas y los criaderos de conchas de abanico más cercana. 
Tabla 3.2.

Distancia al criadero más cercano

\section{DISTANCIA AL}

\section{CRIADERO MAS}

\section{DEPARTAMENTO CERCANO (KM)}

\begin{tabular}{c|c}
\hline PIURA & $52,5 \mathrm{~km}$ \\
TUMBES & $80,0 \mathrm{~km}$ \\
LIMA & $287 \mathrm{~km}$ \\
\hline
\end{tabular}

Fuente: Google Maps (2018)

2. Calidad de agua: Según el INEI (2015), la población que accede a agua potable en Lima es de 90,4\%, mientras que en Tumbes es de 75,7\% y Piura es de 62,3\%. Por ello Piura tiene una calificación de deficiente, Tumbes una de bueno y Lima una excelente calificación.

3. Población Económica Activa: Según el INEI, obtenemos que Lima tiene la ventaja principal en este factor y Tumbes es el departamento quien tiene menor cantidad de población económicamente activa. Se muestra el siguiente cuadro donde se señala el departamento evaluado y su población económicamente activa:

\section{Tabla 3.3.}

Población económicamente activa según departamento

\begin{tabular}{c|c} 
& $\begin{array}{c}\text { POBLACIÓN } \\
\text { ECONÓMICAMENTE } \\
\text { DEPARTAMENTO }\end{array}$ \\
\hline TUMBES & $0,6 \%$ \\
PIURA & $1,1 \%$ \\
LIMA & $2,1 \%$
\end{tabular}

Fuente: INEI. (2016)

Por ello, Lima tiene una calificación de excelente, Piura una calificación de bueno y finalmente Tumbes una calificación de deficiente.

4. Acceso a la infraestructura vial: En el departamento de Lima podemos observar una gran cantidad de redes de carreteras y pistas, ofreciendo un fácil acceso a cualquier lugar deseado; por lo tanto tiene una calificación excelente. Por otro lado, en el departamento de Piura en se está inaugurando una carretera doble vía, que facilita el acceso a Paita, donde se encuentra el puerto, y la cercanía entre mercados, por ello tiene una calificación 
de bueno. Por último, Tumbes, se viene perjudicado por la poca inversión de carreteras, teniendo como calificación deficiente. A continuación, se muestra una tabla de redes viales $(\mathrm{km})$ existentes.

Tabla 3.4.

Red vial nacional pavimentada por departamento

\begin{tabular}{c|c} 
DEPARTAMENTO & RED VIAL \\
& PAVIMENTADA (KM) \\
\hline LIMA & $1054,02 \mathrm{~km}$ \\
PIURA & $936,03 \mathrm{~km}$ \\
TUMBES & $138,15 \mathrm{~km}$
\end{tabular}

Fuente: Ministerio de Transportes y Comunicaciones (2012)

5. Disponibilidad de energía eléctrica: Para poder evaluar la disponibilidad de energía eléctrica se recopiló de Instituto Nacional de Estadística e Informática la producción de energía eléctrica por departamento y se obtuvo el siguiente cuadro.

Tabla 3.5.

Producción de energía eléctrica ( Gigawatts hora)

\begin{tabular}{c|c} 
& \multicolumn{1}{c}{$\begin{array}{c}\text { PRODUCCIÓN DE } \\
\text { ENERGÍA }\end{array}$} \\
DEPARTAMENTO & \multicolumn{1}{c|}{ ELÉCTRICA(GW-H) } \\
\hline LIMA & 24143,4 \\
PIURA & 1279,0 \\
TUMBES & 16,4 \\
\hline
\end{tabular}

Fuente: INEI (2017)

Por lo tanto, Lima tiene una calificación excelente, Piura bueno y tumbes malo.

6. Costo de terreno: Según el diario Gestión (2017), el precio de valor de la tierra se ha triplicado alcanza un precio entre 1000 y 2500 dólares por metro cuadrado. Mientras que en Piura, según el diario el Tiempo (2017), el precio por metro cuadrado esta entre los 500 y 1000 dólares. Por otro lado en Tumbes, según el diario Gestión (2017), se encuentran metros cuadrados con precios desde 120 hasta 1000 dólares. Por lo tanto, se considera que Lima tiene una calificación mala, por su alto costo, Piura una calificación buena y Tumbes una calificación excelente. 
7. Infraestructura en las telecomunicaciones: Para este último punto, se considera la inversión en infraestructura en las telecomunicaciones, el detalle se puede ver en la Tabla 3.6 .

\section{Tabla 3.6.}

Inversion en infraestructura en telecomuniciones.

\begin{tabular}{c|c} 
& \multicolumn{1}{c}{ INVERSIÓN(MILES DE } \\
SOLES)
\end{tabular}

Fuente: INEI (2016)

Como se puede ver, Lima tiene una mejor infraestructura en telecomunicaciones, por lo tanto tendría una calificación de excelente, Piura una calificación de bueno y Tumbes una valoración de malo.

Para poder evaluar las alternativas de macro localización, primero tenemos que evaluar los factores a considerar para poder asignar la ponderación correspondiente. Entonces tenemos lo siguiente:

Tabla 3.7.

Enfrentamiento de factores de macro localización

\begin{tabular}{|c|c|c|c|c|c|c|c|c|c|}
\hline \multicolumn{8}{|c|}{ Factores de la macro localización } & \multirow[b]{2}{*}{ Total } & \multirow[b]{2}{*}{ Ponderación } \\
\hline & 1 & 2 & 3 & 4 & 5 & 6 & 7 & & \\
\hline 1 & $\mathrm{x}$ & 1 & 1 & 1 & 1 & 1 & 1 & 6 & $25.00 \%$ \\
\hline 2 & 0 & $\mathrm{x}$ & 1 & 0 & 0 & 1 & 1 & 3 & $12.50 \%$ \\
\hline 3 & 0 & 1 & $\mathrm{x}$ & 0 & 0 & 0 & 0 & 1 & $4.17 \%$ \\
\hline 4 & 0 & 1 & 1 & $\mathrm{x}$ & 1 & 1 & 1 & 5 & $20.83 \%$ \\
\hline 5 & 0 & 1 & 1 & 0 & $\mathrm{x}$ & 1 & 1 & 4 & $16.67 \%$ \\
\hline 6 & 0 & 1 & 1 & 0 & 1 & $\mathrm{X}$ & 1 & 4 & $16.67 \%$ \\
\hline 7 & 0 & 1 & 0 & 0 & 0 & 0 & $\mathrm{x}$ & 1 & $4.16 \%$ \\
\hline & & & & & & & Total & 24 & \\
\hline
\end{tabular}

Elaboración propia.

Una vez obtenido estas ponderaciones, podemos enfrentar ahora sí las posibles macro localizaciones, teniendo lo siguiente: 
Tabla 3.8.

Macro localización y selección de alternativas.

\begin{tabular}{|c|c|c|c|c|c|c|c|c|c|}
\hline \multirow{3}{*}{ Alternativas } & Factor & $\mathbf{1}$ & $\mathbf{2}$ & $\mathbf{3}$ & $\mathbf{4}$ & $\mathbf{5}$ & $\mathbf{6}$ & $\mathbf{7}$ & Total \\
\cline { 2 - 11 } & Ponderación & $\mathbf{2 5 , 0 0 \%}$ & $\mathbf{1 2 , 5 0 \%}$ & $\mathbf{4 , 1 7 \%}$ & $\mathbf{2 0 , 8 3 \%}$ & $\mathbf{1 6 , 6 7 \%}$ & $\mathbf{1 6 , 6 7 \%}$ & $\mathbf{4 , 1 6 \%}$ & $\mathbf{1 0 0 . 0 0 \%}$ \\
\hline \multirow{3}{*}{ Piura } & Calificación & 10 & 5 & 7 & 7 & 7 & 7 & 7 & \multirow{2}{*}{$\mathbf{7 , 5 0 0}$} \\
\cline { 2 - 11 } & Puntaje & 2,5 & 0,625 & 0,2919 & 1,4581 & 1,1669 & 1,1669 & 0,2912 & \\
\hline \multirow{2}{*}{ Tumbes } & Calificación & 7 & 7 & 5 & 5 & 3 & 10 & 3 & \multirow{2}{*}{$\mathbf{6 , 1 6 7}$} \\
\cline { 2 - 11 } & Puntaje & 1,75 & 0,875 & 0,2085 & 1,0415 & 0,5001 & 1,667 & 0,1248 & \\
\hline \multirow{2}{*}{ Lima } & Calificación & 3 & 10 & 10 & 10 & 10 & 3 & 10 & \multirow{2}{*}{$\mathbf{7 , 0 8 3}$} \\
\cline { 2 - 10 } & Puntaje & 0,75 & 1,25 & 0,417 & 2,083 & 1,667 & 0,5001 & 0,416 & \\
\hline
\end{tabular}

Elaboración propia.

Teniendo como ganador la ciudad de Piura con una calificación de 7,5, por encima de las otras dos alternativas evaluadas.

\subsubsection{Evaluación y selección de la microlocalización}

Para selección del lugar donde se realizará la implementación de la planta se utilizará el método de Brown y Gibson. Seguidamente, identificamos siete factores, los cuales tres son factores objetivos y los otros cuatro son factores subjetivos.

A continuación, se describirán y analizarán los factores para los distritos de Sechura, Talara y Sullana.

1. Costo de Arbitrios: El costo de arbitrios por mes en Sechura, según la ordenanza municipal $N^{\circ} 513$, es de $\mathrm{S} / 65,00$ por mes, mientras que en Sullana asciende a S/ 131,78 por mes, de acuerdo a la ordenanza municipal $\mathrm{N}^{\circ} 26$. Y el costo de arbitrio en Talara es de $\mathrm{S} / 129,30$ por mes, de acuerdo a la ordenanza municipal $\mathrm{N}^{\circ} 16$.

2. Costo de Agua: Para evaluar este factor se utilizó como criterio el costo en soles por metro cubico. Esta información es recopilada de la entidad encargada de la distribución de agua en el departamento de Piura, E.P.S GRAU. Según la estructura tarifaria vigente los costos en la categoría industrial en Sechura son de $\mathrm{S} / 2.9752 / \mathrm{m}^{3}$, en Talara es de $\mathrm{S} / 3.039 / \mathrm{m}^{3}$ y en Sullana es de $\mathrm{S} / 2.7540 / \mathrm{m}^{3}$.

3. Costo de energía: Para el cálculo de este costo se tomaron como base las tarifas aprobadas por OSINERGMIN. De esta forma, los costos en Sechura, Talara, Sullana son S/ 23,67/Kw.h, S/ 23,40/Kw.h, S/ 23,67/Kw.h respectivamente. En este caso, el menor costo lo tiene Talara, mientras que Sechura y Sullana tienen el mismo costo. 
4. Seguridad y orden público: La seguridad es un factor que se tiene que considerar para la evaluación de localización pues, un lugar inseguro generaría varios obstáculos a una planta, principalmente porque su producción seria interrumpida constantemente. A continuación mostraremos un cuadro que indica el número de casos denunciados por comisión de delitos en el año 2016.

Tabla 3.9.

Casos denunciados

\section{DEPARTAMENTO CASOS DENUNCIADOS}

\begin{tabular}{l|c}
\hline SECHURA & 75 \\
TALARA & 223 \\
SULLANA & 157 \\
\hline
\end{tabular}

Fuente: Ministerio del Interior (2016)

Se puede concluir que Sechura es el lugar más seguro, a comparación de las otras opciones, pues tiene el menor número de casos denunciados, por ende, tiene una calificación de excelente, luego Talara, con una calificación buena y Sullana una calificación deficiente.

5. Productores Agropecuarios: Es necesario evaluar la existencia de los productores agropecuarios en cada alternativa propuesta, ya que de ellos depende la producción de las especies acuícolas. A mayor número de productores mayor oportunidad de ingresos para nuestro servicio, porque se obtendría mayor producción. En la siguiente tabla mostramos la cantidad de productores existente en cada alternativa propuesta. Y se puede observar que Sullana tiene mayor cantidad de productores acuícolas; por lo tanto, tiene una calificación de excelente. Luego le sigue Sechura obteniendo una calificación de bueno y finalmente se encuentra Talara con una calificación deficiente.

Tabla 3.10.

Productores agropecuarios.

\begin{tabular}{l|c}
\multicolumn{1}{c}{ DEPARTAMENTO } & $\begin{array}{c}\text { PRODUCTORES } \\
\text { AGROPECUARIOS }\end{array}$ \\
\hline SECHURA & 8713 \\
TALARA & 121 \\
SULLANA & 16496
\end{tabular}

Fuente: INEI-IV Censo Nacional Agropecuario (2017) 
6. Índice de empleo en empresas formales: Este factor nos permitirá evaluar la estabilidad laboral en cada distrito de Piura y el grado de la fuerza laboral que existe para la producción. Pues, cuando hay mejor estabilidad la producción en una industria aumenta.

Tabla 3.11

Indice de empleo

\begin{tabular}{|l|c|}
\multicolumn{2}{|c|}{ DEPARTAMENTO } \\
\multicolumn{2}{l}{ ÍNDICE } \\
\hline SECHURA & 83,7 \\
TALARA & 72,6 \\
SULLANA & 140,6 \\
\hline
\end{tabular}

Fuente: Ministerio de Trabajo y Promoción Social (2016).

Elaboración propia.

Por ello otorgamos la calificación de excelente a Sullana, bueno a Sechura y deficiente a Talara.

7. Superficie Agropecuaria: Este factor es muy importante para considerar en la evaluación de la localización de la planta. Pues, que exista una mayor superficie agropecuaria significa que hay mayor posibilidad de desarrollar la producción de conchas de abanico y otras especies marinas. Lo que permitiría mayores ingresos a nuestro servicio al existir mayor demanda. Según el Instituto Nacional de Estadística e Informática tenemos:

Tabla 3.12.

Superficie Agropecuaria por distrito

\begin{tabular}{l|c}
\multicolumn{1}{c|}{ DEPARTAMENTO } & $\begin{array}{c}\text { SUPERFICIE } \\
\text { AGROPECUARIA } \\
\text { (hectárea) }\end{array}$ \\
\hline SECHURA & 579403 \\
TALARA & 3316 \\
SULLANA & 73061 \\
\hline
\end{tabular}

Fuente: INEI-IV Censo Nacional Agropecuario (2017)

Como se puede observar, Sechura tiene mayor superficie; por lo tanto, tiene una calificación excelente, luego le sigue Sullana con una calificación buena y deficiente a Talara.

De acuerdo a la descripción de cada factor mencionada, se procederá al cálculo de los factores objetivos. 
Tabla 3.13

Cálculo de ponderación de factores objetivos.

\begin{tabular}{ccccccc} 
LUGARES & $\begin{array}{c}\text { COSTO DE } \\
\text { ARBITRIOS } \\
\text { MUNICIPALES } \\
(\text { S/) }\end{array}$ & $\begin{array}{c}\text { COSTO } \\
\text { DE } \\
\text { AGUA } \\
(\text { S/ } /)\end{array}$ & $\begin{array}{c}\text { COSTO } \\
\text { DE } \\
\text { ENERGÍA } \\
(\text { S/) }\end{array}$ & TOTAL & RECİPROCO & FO \\
\hline SECHURA & 65,00 & 2,9752 & 23,67 & 91,65 & 0,010911646 & $\mathbf{0 , 4 4 1}$ \\
TALARA & 129,30 & 3,039 & 23,40 & 155,74 & 0,006420999 & $\mathbf{0 , 2 5 9}$ \\
SULLANA & 131,78 & 2,754 & 23,67 & 134,53 & 0,007433065 & $\mathbf{0 , 3 0 0}$
\end{tabular}

Elaboración propia.

Luego se procederá a calcular las ponderaciones respectivas para los factores subjetivos identificados.

Tabla 3.14.

Tabla de enfrentamiento de factores subjetivos.

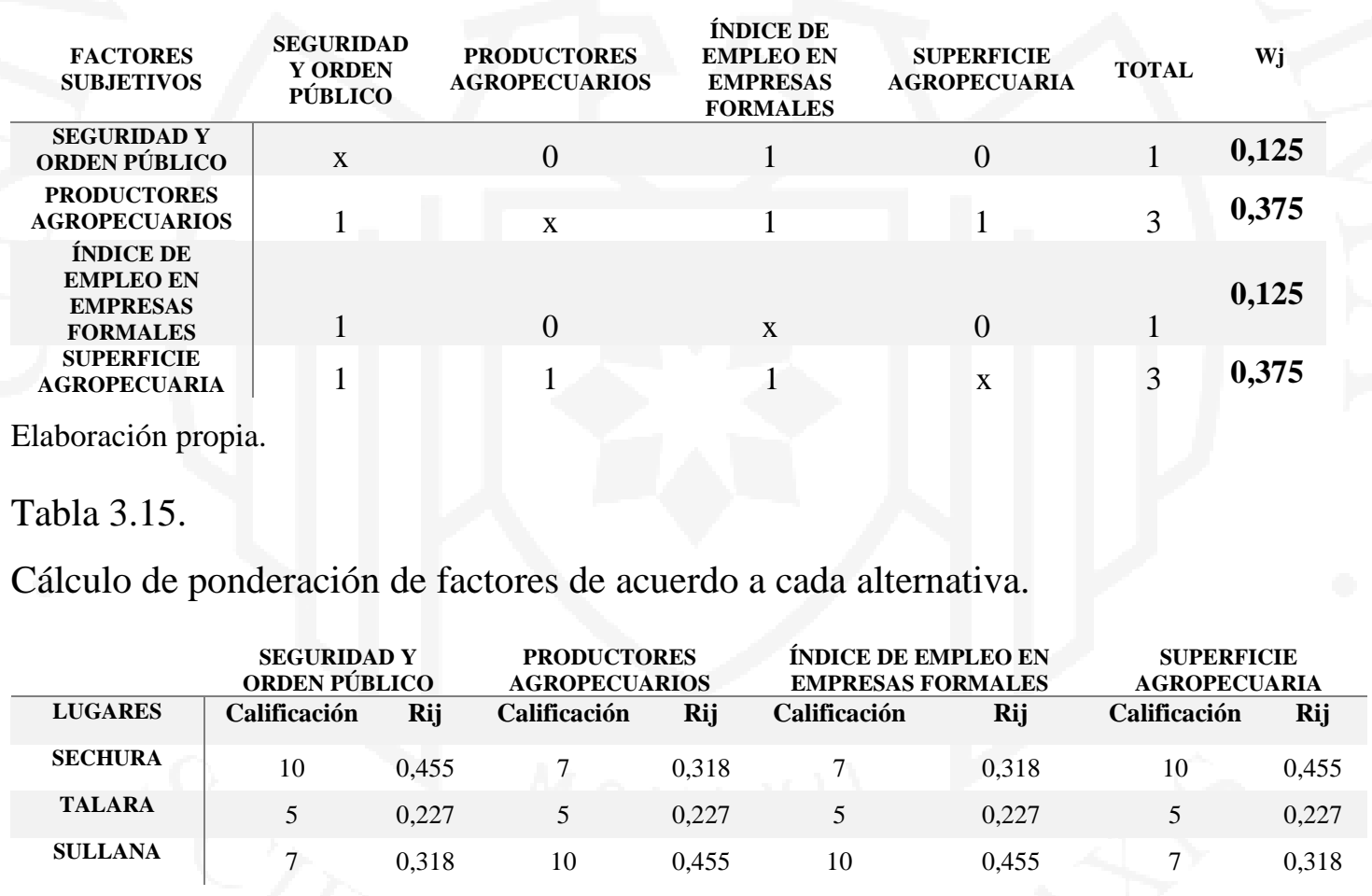

Elaboración propia. 
Tabla 3.16.

Cálculo de factores

\section{FACTORES SUBJETIVOS}

\begin{tabular}{l|c}
\hline LUGARES & Suma $\mathbf{W j * R i}$ \\
SECHURA & 0.387 \\
TALARA & 0.227 \\
SULLANA & 0.386
\end{tabular}

Elaboración propia.

Para el cálculo de la medida de preferencia de localizacion (MPL), cuya fórmula es $\mathrm{K}^{*}$ Factor Objetivo+(1-K)*(Factor Subjetivo), se consideró que los factores objetivos dos veces mas importantes que los factores subjetivos. Ya que, al ser una empresa que recién esta comenzando, no se cuenta con un alto capital de trabajo. De esta forma, nuestro factor $\mathrm{K}$ tendrá un valor de 0.67 .

Tabla 3.17.

Cálculo de MPL

\begin{tabular}{l|c|} 
LUGARES & MPL \\
\hline SECHURA & 0.42270 \\
TALARA & 0.24871 \\
SULLANA & 0.32859
\end{tabular}

Elaboración propia.

La mejor alternativa para la implementación de una planta es Sechura ya que tiene el mayor MPL, según el método de Brown y Gibson. 


\section{CAPÍTULO IV. DIMENSIONAMIENTO DEL SERVICIO}

\subsection{Relación tamaño-mercado.}

Nuestra relación tamaño - mercado se determina por la demanda del proyecto. En el Subcapítulo 2.2 “Análisis de la Demanda" se determinó la proyección de la demanda, obteniendo el siguiente resultado:

Tabla 4.1.

Proyección de la demanda

\begin{tabular}{l|l}
\multicolumn{1}{l}{ A N } & DEMANDA (t) \\
\hline $\mathbf{2 0 1 8}$ & 19375,79 \\
$\mathbf{2 0 1 9}$ & 19479,67 \\
$\mathbf{2 0 2 0}$ & 19583,86 \\
$\mathbf{2 0 2 1}$ & 19688,36 \\
$\mathbf{2 0 2 2}$ & 19793,17 \\
$\mathbf{2 0 2 3}$ & 19898,30 \\
$\mathbf{2 0 2 4}$ & 20003,75
\end{tabular}

Elaboración propia.

Como se mencionó en el subcapítulo 2.4. "Determinación de la demanda para el proyecto". Se consideró una participación en el mercado del 10\%, el porcentaje de producción de conchas de abanico en Sechura y un factor de corrección, derivado de las encuestas, de 0,49. De esta forma se obtuvo la demanda del proyecto, como se puede ver en la Tabla 4.2.

Tabla 4.2

Relación tamaño - mercado

\begin{tabular}{c|ccccc} 
AÑ & $\begin{array}{c}\text { Demanda } \\
(\mathbf{t})\end{array}$ & $\begin{array}{c}\text { \% Producción en } \\
\text { Sechura }\end{array}$ & Participación & $\begin{array}{c}\text { Factor de } \\
\text { corrección }\end{array}$ & $\begin{array}{c}\text { Demanda del } \\
\text { proyecto (t) }\end{array}$ \\
\hline $\mathbf{2 0 1 8}$ & 19375,79 & 0,80 & 0,10 & 0,49 & 759,53 \\
$\mathbf{2 0 1 9}$ & 19479,67 & 0,80 & 0,10 & 0,49 & 763,60 \\
$\mathbf{2 0 2 0}$ & 19583,86 & 0,80 & 0,10 & 0,49 & 767,69 \\
$\mathbf{2 0 2 1}$ & 19688,36 & 0,80 & 0,10 & 0,49 & 771,78 \\
$\mathbf{2 0 2 2}$ & 19793,17 & 0,80 & 0,10 & 0,49 & 775,89 \\
$\mathbf{2 0 2 3}$ & 19898,30 & 0,80 & 0,10 & 0,49 & 780,01 \\
$\mathbf{2 0 2 4}$ & 20003,75 & 0,80 & 0,10 & 0,49 & 784,15
\end{tabular}

Elaboración propia 
Además, se observa que la mayor demanda obtenida será en el año 2024, esta cifra representa el límite máximo del proyecto.

\subsection{Relación tamaño-recursos.}

Nuestro servicio al tratarse de congelamiento usando nitrógeno, nuestra materia prima para el funcionamiento es nuestra producción de nitrógeno. Según Miguel Morán, ex gerente de operaciones de Praxair Perú S.R.L e Indura Perú, se necesita entre 1 a 1,2 kilogramos de nitrógeno para cada kilogramo de conchas de abanico a congelar. Es decir, se necesita una tonelada de nitrógeno líquido para congelar una tonelada de conchas de abanico aproximadamente. Por lo tanto, la proyección del nitrógeno a utilizar en el proyecto es el siguiente:

Tabla 4.3.

Relación tamaño - Recursos.

AÑO NITRÓGENO (t)

\begin{tabular}{l|l}
$\mathbf{2 0 1 8}$ & 759,53 \\
$\mathbf{2 0 1 9}$ & 763,60 \\
$\mathbf{2 0 2 0}$ & 767,69 \\
$\mathbf{2 0 2 1}$ & 771,78 \\
$\mathbf{2 0 2 2}$ & 775,89 \\
$\mathbf{2 0 2 3}$ & 780,01 \\
$\mathbf{2 0 2 4}$ & 784,15
\end{tabular}

Elaboración propia.

En la siguiente tabla se puede observar que el límite máximo se da en el año 2024

\subsection{Relación tamaño-tecnología.}

Las principales máquinas requeridas para el servicio son la planta de nitrógeno, la máquina rotatoria y la estampadora, que son las evaluadas para determinar la capacidad de la planta en Capítulo V. A continuación se mostrará su capacidad en planta: 
Tabla 4.4

Capacidad de máquinas

\begin{tabular}{|c|c|}
\hline Nombre & Capacidad de producción \\
\hline Planta de nitrógeno & $465 \mathrm{~kg} / \mathrm{h}$ \\
\hline Maquina rotatoria & $300 \mathrm{~kg} / \mathrm{h}$ \\
\hline Estampadora & $290 \mathrm{bls} / \mathrm{h}$ \\
\hline
\end{tabular}

Fuente: Alibaba (2017)

Para poder determinar si existen limitaciones, se procederá a identificar el cuello de botella.

Tabla 4.5

Análisis de cuello de botella

\begin{tabular}{|c|c|c|c|c|c|c|c|c|c|c|c|}
\hline OPERACIÓN & $\begin{array}{c}\text { Qs } \\
\text { (und/sem) }\end{array}$ & $\begin{array}{c}\mathbf{P} \\
(\operatorname{prod} / h)\end{array}$ & $\mathbf{M}$ & $\mathrm{D} / \mathrm{S}$ & H/T & $\mathbf{T}$ & $\mathbf{U}$ & $\mathbf{E}$ & $\mathrm{CO}$ & FC & COPT \\
\hline $\begin{array}{c}\text { Producción de } \\
\text { nitrógeno }\end{array}$ & $\begin{array}{c}15701,53 \\
\text { Kilogramos } \\
\end{array}$ & $\begin{array}{c}465 \\
\mathrm{Kg} / \mathrm{h} \\
\end{array}$ & 1 & & 8 & 3 & 0,75 & 0,83 & 48825.00 & 0,48 & $\begin{array}{l}23443 \\
\text { bolsas }\end{array}$ \\
\hline Congelamiento & $\begin{array}{c}15387,50 \\
\text { Kilogramos }\end{array}$ & $\begin{array}{c}300 \\
\mathrm{Kg} / \mathrm{h}\end{array}$ & 1 & 7 & 8 & 3 & 0,75 & 0,83 & 31500.00 & 0,49 & $\begin{array}{l}15433 \\
\text { bolsas }\end{array}$ \\
\hline Estampado & $\begin{array}{c}7693,00 \\
\text { bolsas }\end{array}$ & $\begin{array}{r}290 \\
\text { bls/h }\end{array}$ & 1 & 7 & 8 & 3 & 0,75 & 0,83 & 30450.00 & 0.98 & $\begin{array}{l}29840 \\
\text { bolsas }\end{array}$ \\
\hline $\begin{array}{l}\text { Producto } \\
\text { terminado }\end{array}$ & $\begin{array}{c}7539,00 \\
\text { bolsas }\end{array}$ & & & & & & & & & & \\
\hline
\end{tabular}

Fuente: Alibaba (2017)

Elaboración propia.

Tabla 4.6

Capacidad de producción en toneladas/año

\begin{tabular}{|l|c|c|c|c|c|}
\hline OPERACIÓN & $\begin{array}{c}\text { COPT } \\
\text { (bls/sem) }\end{array}$ & Sem/año & Kg/bls & t/kg & COPT (t/año) \\
\hline $\begin{array}{l}\text { Producción de } \\
\text { nitrógeno }\end{array}$ & 23443 & 52 & 2 & 1000 & 2438,07 \\
\hline Congelamiento & 15433 & 52 & 2 & 1000 & 1605,03 \\
\hline $\begin{array}{l}\text { Producto } \\
\text { terminado }\end{array}$ & 29840 & 52 & 2 & 1000 & 3103,36 \\
\hline
\end{tabular}

Elaboración propia.

Como se puede observar en la Tabla 4.6, existe cuello de botella en la operación de congelamiento, donde se encuentra la maquina rotatoria. Por lo tanto, al tener una capacidad de producción de 1,605.03 t/año, menor que las otras máquinas, se tendría una limitación respecto al tamaño-tecnología. 


\subsection{Relación tamaño-inversión.}

Se ha establecido que la compra de maquinaria y la remodelación terreno va a ser financiado en un $60 \%$. La diferencia, el $40 \%$, será financiada con capital propio. La empresa cuenta con S/ 601 214,27de aporte.

Tabla 4.7

Detalle de inversión

\begin{tabular}{|c|c|c|c|}
\hline INVERSIÓN & $\begin{array}{l}\text { MONTO TOTAL } \\
\text { (S/.) }\end{array}$ & $\begin{array}{c}\text { FINANCIAMIENTO } \\
(60 \%)(\mathrm{S} / .)\end{array}$ & CAPITAL PROPIO (S/.) \\
\hline MAQUINARIA & 1022930,32 & 613758,19 & 409172,13 \\
\hline $\begin{array}{l}\text { PLANTA DE } \\
\text { NITRÓGENO }\end{array}$ & 984000,00 & 590400,00 & 393600,00 \\
\hline $\begin{array}{l}\text { TANQUE DE } \\
\text { ALMACÉN DE } \\
\text { NITRÓGENO }\end{array}$ & 11480,00 & 6888,00 & 4592,00 \\
\hline $\begin{array}{c}\text { MÁQUINA } \\
\text { ROTATORIA }\end{array}$ & 16400,00 & 9840,00 & 6560,00 \\
\hline ESTAMPADORA & 554,32 & 332,59 & 221,73 \\
\hline APILADOR & 1968,00 & 1180,80 & 787,20 \\
\hline CONDENSADORES & 3280,00 & 1968,00 & 1312,00 \\
\hline EVAPORADORES & 5248,00 & 3148,80 & 2099,20 \\
\hline $\begin{array}{l}\text { REMODELACIÓN } \\
\text { DE TERRENO }\end{array}$ & $480,105.36$ & $480,105.36$ & $480,105.36$ \\
\hline $\begin{array}{l}\text { TOTAL } \\
\text { Fuente: Alibaba (2017) } \\
\text { Elaboración propia. }\end{array}$ & 1503035,68 & 901821,41 & 601214,27 \\
\hline
\end{tabular}

Para la obtención del punto de equilibrios tendremos en cuenta el margen de contribución y los costos fijos anuales aproximados. Para el cálculo de este, se utilizará la siguiente fórmula:

$\mathrm{Q} \min =$ Costos fijo total/ (precio unitario-costo unitario variable)

Como se puede ver en el Capítulo VII: "Presupuesto y evaluación del proyecto" se obtiene el detalle del costo fijo total que tiene un valor de S/ 264179,95 , el costo variable total es de S/ 15762,92 y el precio de venta es de S/ 2 600, como se mencionó en el subcapítulo 2.5. "Definición de la estrategia de Comercialización".

El costo variable unitario se determina por la siguiente fórmula:

C. V. U. $=\frac{\text { COSTO VARIABLE TOTAL }}{\text { CONCHAS DE ABANICO CONGELADAS(t) }}=\frac{15,762.92}{784.15}=20,10$ 
Con todos los datos mencionados, se aplica la fórmula para hallar el punto de equilibrio. El resultado se puede ver en la siguiente tabla:

Tabla 4.8

Cálculo de punto de equilibrio

\begin{tabular}{|c|c|c|c|}
\hline \multicolumn{2}{|c|}{ Costos fijos anuales } & \multicolumn{2}{c|}{ Precios y costos variables unitarios } \\
\hline \multirow{2}{*}{ TOTAL } & S/ 264 179,95 & Precio venta (S/) & 2600 \\
\cline { 3 - 4 } & & Costo variable unitario (S/) & 20,10 \\
\cline { 3 - 4 } Punto de equilibrio (ton) & \multicolumn{2}{|c|}{102,39 toneladas } \\
\hline
\end{tabular}

Elaboración propia.

A partir de esta tabla se puede concluir que la cantidad mínima a atender en el congelado de conchas de abanico son 102,39 toneladas

\subsection{Selección de la dimensión del servicio}

Tabla 4.9

Selección de tamaño

TIPO

MERCADO

MATERIA PRIMA

TECNOLOGÍA

PUNTO DE

EQUILIBRIO
TAMAÑO(t)

784,15

784,15

1605,03

102,39

Elaboración propia.

De la siguiente tabla se puede observar que el tamaño máximo será el referido a la tecnología, el tamaño mínimo será el de punto de equilibrio y el tamaño óptimo el que esta asociado al mercado. 


\section{CAPÍTULO V. INGENIERÍA DEL PROYECTO}

\subsection{Proceso para la realización del servicio}

\subsubsection{Descripción del proceso del servicio}

Para el servicio descrito, en primer lugar, se necesitará la producción de nitrógeno líquido, mediante el método de destilación que se detallará a continuación.

De acuerdo a Cerrada (2017):

El aire atmosférico pasa por una filtración preliminar para eliminar las partículas para eliminar todas las partículas gruesas, como el polvo, que puedan poner en riesgo la integridad de los compresores. Luego, el aire se comprime hasta una presión de 5 bares, donde el aire se calentara y deberá ser enfriado hasta una temperatura de $20^{\circ} \mathrm{C}$, el aire luego, se pre-enfría en un chiller y se vuelve a condensar en un tanque de aire. A continuación pasa a un tanque purificador donde se desecha el nitrógeno húmedo, posteriormente la corriente de aire pasa a la torre de destilación, ahí, el proceso continúa primero por la columna inferior que consiste en la rectificación de la temperatura y masa, en esta el nitrógeno con alto punto de ebullición se evapora y el oxígeno con bajo punto de ebullición se condensa; por otro lado, en la columna superior se obtendrá el nitrógeno después de calentarse a través del intercambiador de calor del subenfriador, obteniendo así nitrógeno con pureza de $98 \%$ hasta un $99.9 \%$. Cabe resaltar que, durante todo el proceso, la mezcla es enfriada mediante intercambiadores de calor usando agua como medio refrigerante. (p. 2233)

Una vez producido el nitrógeno líquido, este pasará a una máquina rotatoria, el cual se encargará de bañar a las conchas de abanico con nitrógeno líquido produciendo su congelamiento inmediato mediante el proceso IQF. Después, pasarán a una máquina de empaquetado, que se encargará de embolsar las conchas congeladas en bolsas de $2 \mathrm{~kg}$. Finalmente a cada bolsa se estampará la marca deseada y se entregará al contratista. 
Figura 5.1.

Diagrama de operaciones para la producción de nitrógeno líquido

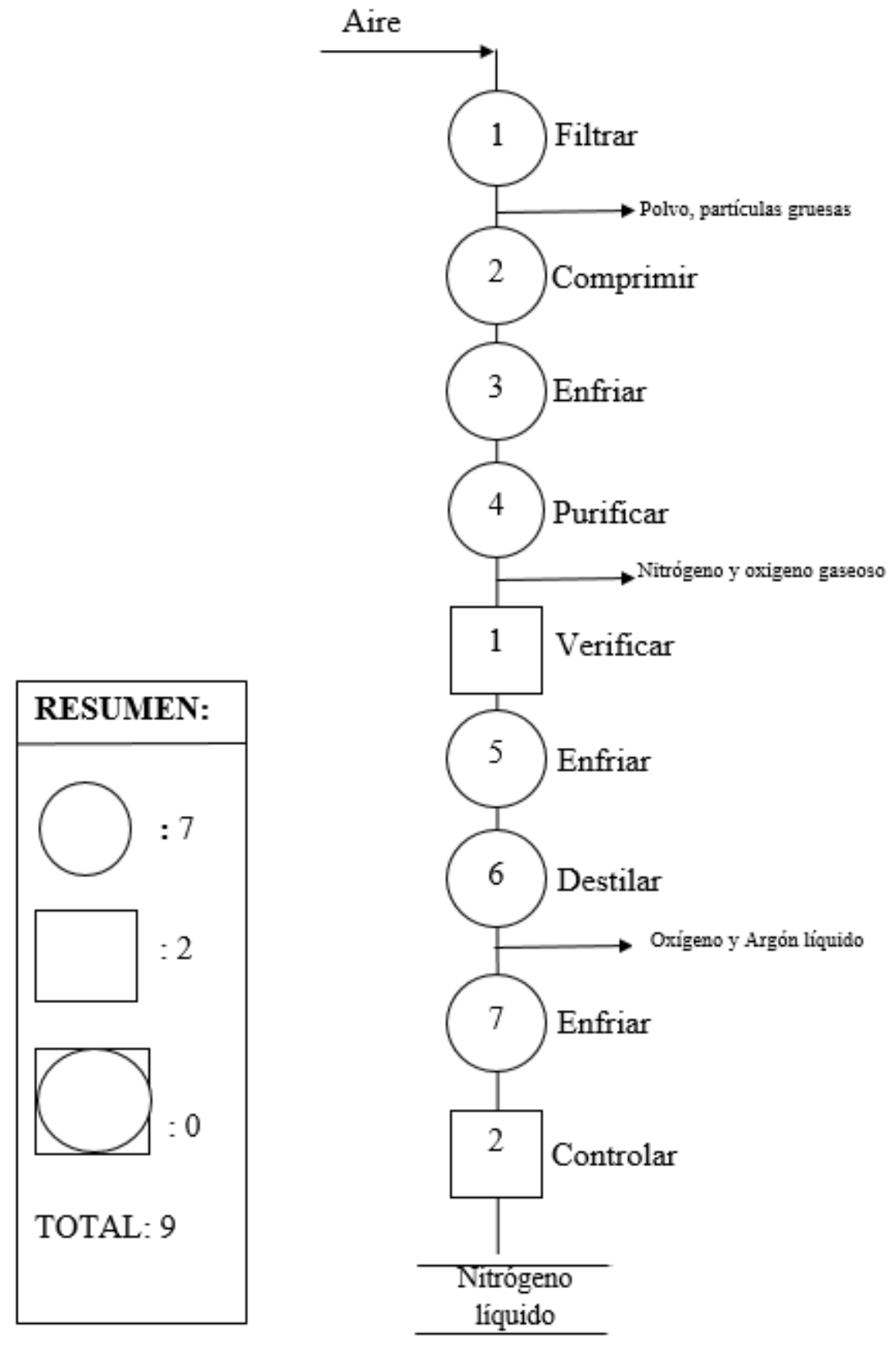

Elaboración propia. 


\subsubsection{Diagrama de flujo del servicio.}

Figura 5.2.

Flujograma del servicio de congelamiento de conchas de abanico.

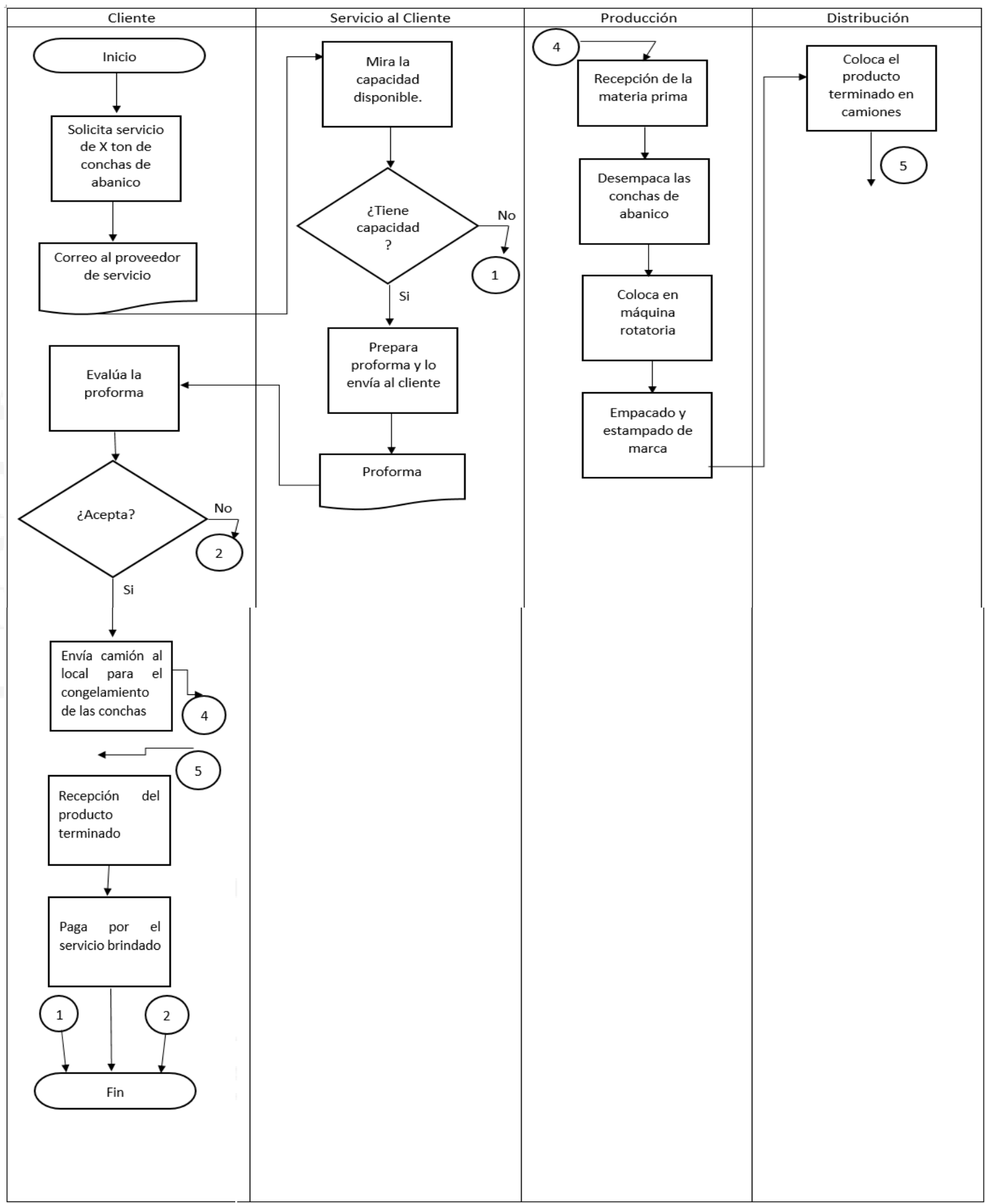

Elaboración propia. 


\subsection{Descripción del tipo de tecnología a usarse en el servicio}

La tecnología que se usará en el servicio será la propia planta productora de nitrógeno, entre sus principales componentes encontramos el chiller, la compresora de aire y el cold box. En esta oportunidad compraremos una planta de marca Hang Tong, de origen Chino. El cual es una máquina automatizada con pantallas touch screen, con certificación ISO9001. Esta tiene una capacidad de producción de $465 \mathrm{~kg} / \mathrm{h}$. Entre sus equipos se encuentran: compresores de aire, secadora, aumentador de presión, estación de servicio (en donde se encuentran las pantallas de manejo automatizado), filtros de aire, tanque de aire, compresor de alta presión, analizador de punto de rocío, entre otros. Además, esta misma se conectará a una máquina rotatoria.

A continuación, se muestra el balance de materia de nuestra planta de congelamiento.

Figura 5.3.

Balance de materia.

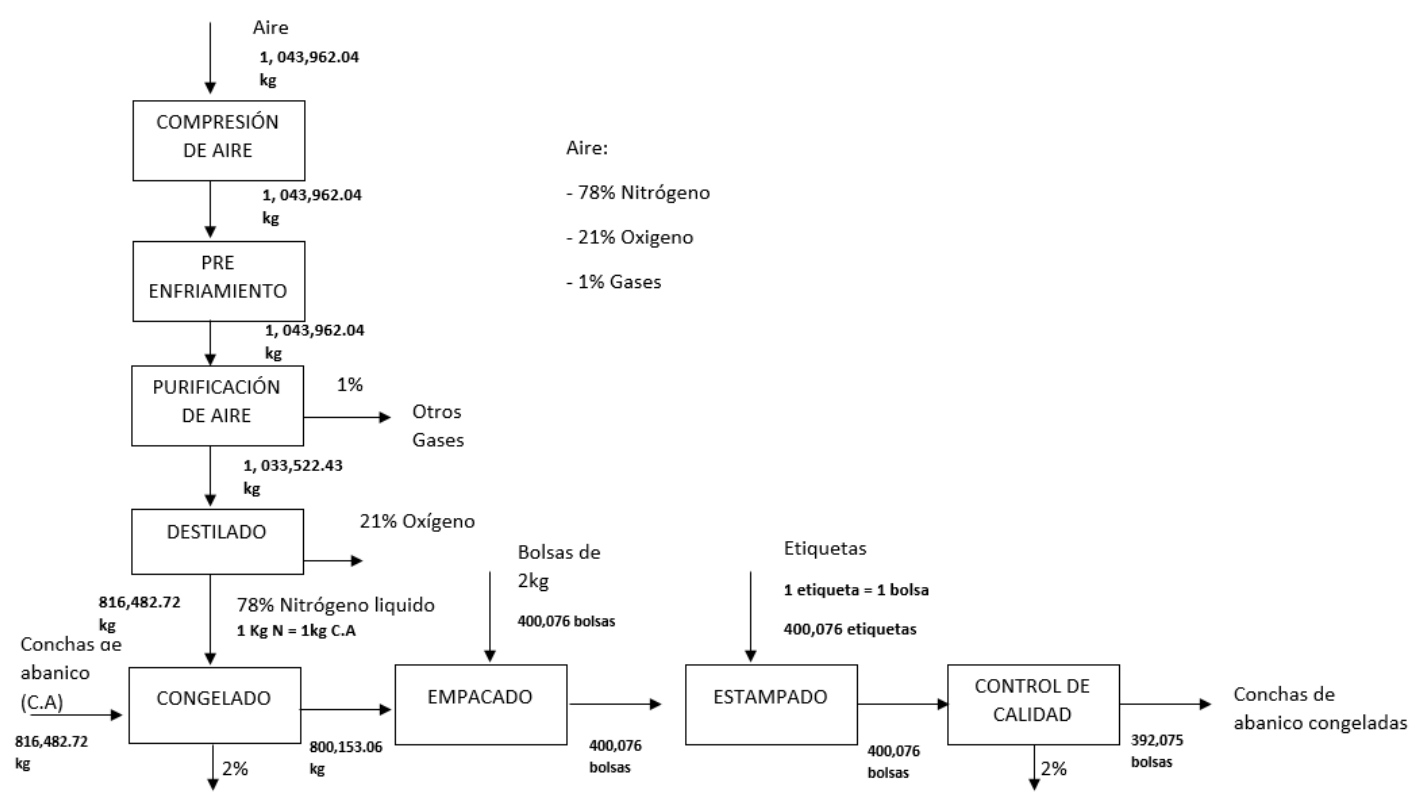

Elaboración propia. 


\subsection{Capacidad instalada.}

\subsubsection{Identificación y descripción de los factores que intervienen en brindar el servicio.}

La planta que se instalará, como se mencionó anteriormente, será automatizada. Por ello sólo se necesitarán de dos jefes quienes estarán encargados del buen funcionamiento de la planta productora de nitrógeno y de la máquina rotatoria. Por otro lado, un operario más para el uso de la estampadora por turno.

Por el lado de los equipos y tecnologías, se comprará una planta productora de nitrógeno de marca Wuhan Hengyetong Gas Equipment CO., LTD, de origen chino, esta tiene pantallas touch screen para su manejo. Además, se adquirirá un tanque de almacenamiento de nitrógeno de capacidad de $25 \mathrm{~m}^{3}$ que se conectará con la máquina rotatoria que tiene una capacidad de $300 \mathrm{~kg} / \mathrm{h}$, que son las menores capacidades existentes en el mercado, y finalmente para poder hacer el empacado y estampado de la marca, se hará mediante una estampadora manual.

A continuación, se describirá los factores que se identificaron para brindar el servicio.

\subsubsection{Factor Movimiento.}

Para realizar al factor movimiento es necesario evaluar el principio de manejo de materiales, desde la recepción hasta el despacho del producto. A continuación se mostrará el cuadro de análisis de movimiento. 


\section{Tabla 5.1}

Factores de movimiento.

\begin{tabular}{|l|c|c|c|c|l|}
\cline { 2 - 5 } \multicolumn{1}{c|}{} & \multicolumn{2}{c|}{\begin{tabular}{c}
\multicolumn{2}{c|}{ UNIDAD DE } \\
TRANSPRTE
\end{tabular}} & $\begin{array}{c}\text { PUNTO DE } \\
\text { INICIO }\end{array}$ & $\begin{array}{c}\text { PUNTO DE } \\
\text { LLEGADA }\end{array}$ & MEDIO \\
\hline $\begin{array}{l}\text { Concha de } \\
\text { abanico lavada }\end{array}$ & POBRE & PESO (kg) & $\begin{array}{c}\text { Almacén } \\
\text { inicial o de MP }\end{array}$ & $\begin{array}{c}\text { Maquina } \\
\text { Rotatoria }\end{array}$ & Montacargas \\
\hline $\begin{array}{l}\text { Rollos de } \\
\text { Etiquetas }\end{array}$ & Parihuelas & $36,61 \mathrm{~kg}$ & $\begin{array}{c}\text { Almacén de } \\
\text { inicial o de MP }\end{array}$ & Estampadora & $\begin{array}{l}\text { Carretilla } \\
\text { hidráulica }\end{array}$ \\
\hline $\begin{array}{l}\text { Impurezas menores } \\
\text { Área de control } \\
\text { de calidad }\end{array}$ & $\begin{array}{c}\text { Depósito de la } \\
\text { planta }\end{array}$ & $\begin{array}{l}\text { Carretilla } \\
\text { hidráulica }\end{array}$ \\
\hline $\begin{array}{l}\text { Rollos de } \\
\text { Bolsas de plástico }\end{array}$ & Parihuelas & $16003,04 \mathrm{~kg}$ & $\begin{array}{c}\text { Almacén de } \\
\text { inicial o de MP }\end{array}$ & $\begin{array}{c}\text { Empaquetadora } \\
\text { Carretilla } \\
\text { hidráulica }\end{array}$ \\
\hline $\begin{array}{l}\text { Bolsas de concha } \\
\text { congelanico }\end{array}$ & Parihuelas & $784150 \mathrm{~kg}$ & Empaquetadora & $\begin{array}{l}\text { Almacén final o } \\
\text { de producto } \\
\text { terminado }\end{array}$ & Montacargas \\
\hline
\end{tabular}

Elaboración propia.

Seguidamente realizaremos el análisis de la necesidad de medios de acarreos.

El equipo para el movimiento de las javas es el montacargas de marca Crown modelo Extensión Simple RR. Este montacargas tiene una capacidad de carga de $1,600 \mathrm{~kg}-2,000 \mathrm{~kg}$ será utilizado para llevar con facilidad las parihuelas al área de congelado y descargar y cargar los camiones.

Figura 5.4

Montacargas

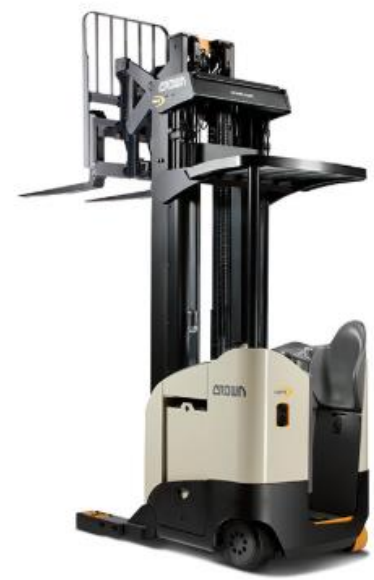

Fuente: Crown (2018) 
El equipo para transportar los Rollos de plástico para el área de embolsado, los Rollos de etiquetas para la estampadora y las impurezas menores encontradas en el área de calidad será la carretilla hidráhulica. Su tamaño permite que se tranporte con facilidad dentro del área de congelado.

\section{Figura 5.5}

Carretilla hidrahulica

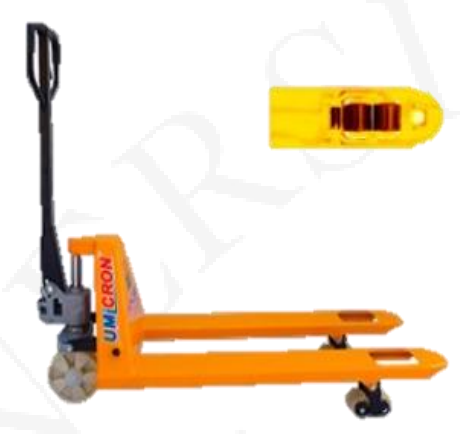

Fuente: Mecalux (2018)

\subsubsection{Factor Espera.}

\subsubsection{Puntos de espera requeridos. Determinación del espacio requerido.}

Para el proceso se ha identificado un punto de espera en el embolsado o empacado y uno en el área de congelado. Donde en el área de embolsado se tendrá en espera un rollo de bolsas plástico que estará en un porta rollos circular de pie, junto a la mesa de trabajo, cuyo diámetro es de $0,5 \mathrm{~m}^{2}$. En cuanto el rollo se termine se repondrá en el porta rollo, entonces el área del punto de espera será de $0.196 \mathrm{~m}^{2}$. Por otro lado, en el área de congelado, el punto de espera consistirá en dos parihuelas, ubicadas junto a la maquina rotatoria, de tamaño 1,2 m x 1,2 m x 0,15 m, donde se pondrán las javas para las conchas de abanico, en cuanto una de las parihuelas se quede vacía se repondrán las javas a esa misma mientras que usan la otra parihuela con javas. Entonces el área para el punto de espera en la actividad de congelado es de $2,88 \mathrm{~m}^{2}$ 


\section{Tabla 5.2}

Puntos de espera

\begin{tabular}{|l|c|c|}
\hline \multicolumn{1}{|c|}{ ACTIVIDAD } & UNIDAD DE ESPERA & PUNTO DE ESPERA \\
\hline Embolsado o empacado & Rollo de bolsa de plástico & Un porta rollo de diámetro de $0,5 \mathrm{~m}$ \\
\hline Congelado & Javas & Dos parihuelas de $1,2 \mathrm{~m} \times 1,2 \mathrm{~m}$ \\
\hline
\end{tabular}

Elaboración propia.

\subsubsection{Almacenes requeridos. Determinación del espacio.}

El material adecuado a utilizar en el almacenamiento son las javas, debido a que podemos almacenar correctamente las conchas de abanico sin maltratarlas, además existen javas con resistencia al almacenamiento de productos congelados, conocido como java "Naranjero", las especificaciones son de 499 mm x $351 \mathrm{~mm}$ x 313mm. La condición que indican es material muy resistente y apto para cámaras frigoríficas.

Para calcular la cantidad de javas a utilizar, nuestros almacenes de materias primas y de productos terminados tendrán una capacidad de una semana de almacenamiento.

- Cantidad de bolsas de $2 \mathrm{~kg}$ a congelar por semana: 7539 bolsas $=15078 \mathrm{~kg}$

- Una jaba puede soportar $25 \mathrm{~kg}$ como máximo y sus dimensiones son:

○ $0,499 \mathrm{~m} \times 0,351 \mathrm{~m} \times 0,313 \mathrm{~m}$

Figura 5.6

Jaba "Naranjero"

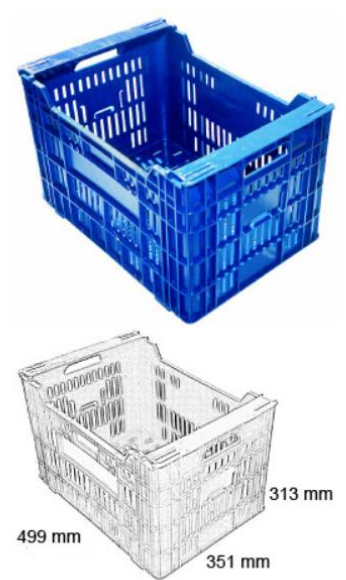

Fuente: Daplast (2018) 
- Cubicando las bolsas en una jaba tenemos:

o 1 bolsa $=2 \mathrm{~kg}$

o 1 jaba $=25 \mathrm{~kg}$

o 12 bolsas $=1$ jaba

- Necesitamos para almacenar por una semana por lo menos:

o $7539 / 12=629$ jabas

o $629 \times 2$ (almacenes) $=1258$ javas

Así mismo, estos serán acumulados en pallets, pero serán de plásticos para facilitar la eliminación de bacterias, estas tendrán las siguientes características:

- Dimensiones: $1.2 \mathrm{~m} \mathrm{x} 1.2 \mathrm{~m}$

- Peso: $17.5 \mathrm{~kg}$

- Carga: 5Ton

- Material: Polietileno y polipropileno

Figura 5.7

Pallet de plástico

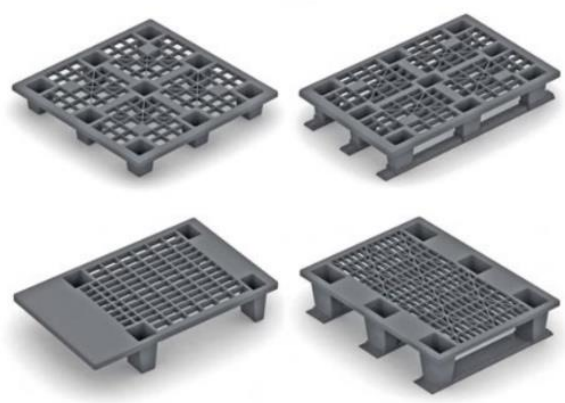

Fuente: Mecalux (2018)

Las dimensiones de nuestros almacenes serán similares; sin embargo, en el almacén de materias primas será solamente refrigerado con la finalidad de preservar momentáneamente el producto, mientras que el almacén de productos terminados tendrá un ambiente en frío, dónde se conservará el congelado. Cabe resaltar que nuestros almacénes estaran cubiertos con paneles de polyuretano ya que son excelentes aislantes térmicos. 
A continuación detallaremos el cálculo de las dimensiones:

- 1 java $=0.499 \mathrm{~m} \times 0.351 \mathrm{~m}=0.15 \mathrm{~m}^{2}$

- 1 pallet $=1.2 \mathrm{~m} \times 1.2 \mathrm{~m}=1.44 \mathrm{~m}^{2}$

- 1 pallet $=6$ javas en base y de alto 5 pisos; es decir, 30 javas por pallet.

- $629 / 30=20.96=21$ pallets por almacén.

Sin embargo, debemos considerar un espacio de $0.5 \mathrm{~m}$ entre cada torre entre lados y de 1.5 metros entre cada fila con la finalidad de poder movilizarse con la carretilla hidráulica. Construyendo 5 filas y 5 columnas, en total requerimos de $102 \mathrm{~m}^{2}$ por cada almacén.

\subsubsection{Determinación del factor limitante de la capacidad.}

Para determinar el factor limitante de la capacidad, se considerará que de la jornada de 8 horas se pierden 2 horas por diversos motivos por lo tanto nuestro factor de utilización (U) sería igual a:

$$
\mathrm{U}=\frac{8-2 \text { horas }}{8 \text { horas }}=0.75
$$

Además, respecto a la eficiencia, de las 6 horas productivas en una jornada el número de horas estándar es 5 horas. Por lo tanto, nuestro factor de eficiencia sería igual a:

$$
\mathrm{E}=\frac{5 \text { horas }}{6 \text { horas }}=0.83
$$

Por lo tanto, nuestro cálculo de capacidad mínima será la siguiente:

\section{Tabla 5.3}

\begin{tabular}{|c|c|c|c|c|c|c|c|c|c|c|c|}
\hline OPERACIÓN & Qs (und/ sem) & P (prod/h) & M & $D / S$ & $H / T$ & $T$ & $\mathrm{U}$ & $E$ & $\mathrm{CO}$ & FC & COPT \\
\hline \multirow{2}{*}{$\begin{array}{l}\text { Producción de } \\
\text { nitrógeno }\end{array}$} & 15701,53 & 465 & \multirow{2}{*}{1} & \multirow{2}{*}{7} & \multirow{2}{*}{8} & \multirow{2}{*}{3} & \multirow{2}{*}{0,75} & \multirow{2}{*}{0,83} & \multirow{2}{*}{48825,00} & \multirow{2}{*}{0,48} & 23443 \\
\hline & Kilogramos & $\mathrm{Kg} / \mathrm{h}$ & & & & & & & & & bolsas \\
\hline \multirow{2}{*}{ Congelamiento } & 15387,50 & 300 & \multirow{2}{*}{1} & \multirow{2}{*}{7} & \multirow{2}{*}{8} & \multirow{2}{*}{3} & \multirow{2}{*}{0,75} & \multirow{2}{*}{0,83} & \multirow{2}{*}{31500,00} & \multirow{2}{*}{0,49} & 15433 \\
\hline & Kilogramos & $\mathrm{Kg} / \mathrm{h}$ & & & & & & & & & bolsas \\
\hline \multirow{2}{*}{ Estampado } & 7693,00 & 290 & \multirow{2}{*}{1} & \multirow{2}{*}{7} & \multirow{2}{*}{8} & \multirow{2}{*}{3} & \multirow{2}{*}{0,75} & \multirow{2}{*}{0,83} & \multirow{2}{*}{30450,00} & \multirow{2}{*}{0,980} & 29840 \\
\hline & bolsas & $\mathrm{bls} / \mathrm{h}$ & & & & & & & & & bolsas \\
\hline $\begin{array}{l}\text { Producto } \\
\text { terminado }\end{array}$ & $\begin{array}{l}7539,00 \\
\text { bolsas }\end{array}$ & & & & & & & & & & \\
\hline
\end{tabular}

Cálculo del cuello de botella en bolsas/sem.

Fuente: Alibaba (2017)

Elaboración propia.

De acuerdo a esta tabla el factor limitante sería la operación de congelamiento, ya que, tiene la menor capacidad de producción en unidades de producto terminado. 


\subsubsection{Determinación del número de recursos del factor limitante.}

El factor limitante en esta oportunidad es la máquina rotatoria donde se hace el congelamiento IQF y es el centro de nuestro servicio. Esta tiene una capacidad de procesamiento de $300 \mathrm{~kg} / \mathrm{h}$. Para determinar el número de máquinas de la estación de congelamiento se considerará 7 horas efectivas por turno, tres turnos por día, 52 semanas al año y 7 días a la semana

$$
\begin{aligned}
H= & 8 \frac{\text { Horas }}{\text { Turno }} * 3 \frac{\text { Turno }}{\text { Dia }} * 7 \frac{\text { Dias }}{\text { Semana }} * 52 \frac{\text { Semanas }}{A \tilde{n} o}=8736 \frac{\text { Horas }}{A \tilde{n} o} \\
& \frac{1 \mathrm{HM}}{300 \mathrm{~kg}} * 816,482.72 \frac{\mathrm{kg}}{\mathrm{An \tilde { } o}} \\
8736 \frac{\text { Horas }}{\text { Añ } o} & =0.200=1 \text { maquina rotatoria }
\end{aligned}
$$

\subsubsection{Determinación del número de recursos de los demás factores.}

Por el lado de los factores no limitantes, encontramos la planta productora de nitrógeno, con una capacidad de producción de $465 \mathrm{~kg} / \mathrm{h}$ y estampadora de 290 bolsas/hora. Para el cálculo del número de máquinas, se considera el mismo escenario de horas al año que se halló en el apéndice 5.3.3.

$$
\begin{gathered}
H=8 \frac{\text { Horas }}{\text { Turno }} * 3 \frac{\text { Turno }}{\text { Dia }} * 7 \frac{\text { Dias }}{\text { semana }} * 52 \frac{\text { Semanas }}{A \tilde{n} o}=8736 \frac{\text { Horas }}{A \tilde{n} o} \\
\frac{\frac{1 H M}{465 \mathrm{~kg}} * 1,043,962.04 \frac{\mathrm{kg}}{A \tilde{\mathrm{n}} o}}{8736 \frac{\text { Horas }}{A \tilde{n} o}}=0.3983=1 \text { planta de nitrógeno } \\
\frac{\frac{1 \mathrm{HM}}{290 \text { bolsas }} * 400,076.00 \frac{\text { bolsas }}{\text { Año }}}{8736 \frac{\text { Horas }}{A \tilde{n} o}}=0.1579=1 \text { estampadora }
\end{gathered}
$$

\subsubsection{Cálculo de la capacidad de atención.}

Como se vió en la Tabla 4.6, nuestro cuello de botella se encuentra en el proceso de congelamiento con una capacidad de 1 605,03 toneladas al año. Por otro lado, tenemos que la máxima demanda, 2024, es de 784,15 toneladas. Por lo tanto, al ser la capacidad 
del cuello de botella mayor que la capacidad del mercado, nuestra capacidad de atención es la del mercado.

\subsection{Resguardo de la calidad}

\subsubsection{Calidad del proceso y del servicio}

Nuestro servicio consta de la congelación criogénica de conchas de abanico usando nitrógeno. Según la agropecuaria Esmeralda S.A se define a las conchas de abanico como perteneciente a la familia Pectinidae, son moluscos marinos cuya concha bivalva protege la parte blanda, está articulada dorsalmente por una charnela. Los tallos y los scallops con gónadas son las que se consumen en el mercado. Para el congelado criogénico es necesario sustraer el calor del producto por contacto directo con un gas o vapor licuefacto, como es el nitrógeno líquido (Ravina Gomez, Hung, Astete León, \& Soria, 2000).

Nuestros procesos estarán basados mediante la ISO 9001 y el HACCP-P-01 "Plan HACCP para Conchas de Abanico". Según la agropecuaria Esmeralda, quienes hacen un proceso similar, "el proceso consiste en la recepción de la materia prima, esta es registrada en cantidad y condiciones según el artículo AP-R-04 "Guía de Recepción”, se verifica que llegue refrigerada, en bolsas de polietileno con una cantidad de $2 \mathrm{~kg}$ cada una, estas deben llegar codificadas según el AP-I-03 “Lista de códigos”. Posteriormente, se extrae una muestra para hacer el plan de muestreo 001AC que se encuentra en el procedimiento AC-P-001 "Inspección y ensayo", donde el técnico lo registrará y cumplirá con el control de recepción HACCP 001. En nuestro caso se asegura que el producto esté previamente lavado por el mismo contratista. Al hacer el procedimiento de congelado, donde se realiza a una temperatura de $-60^{\circ} \mathrm{C}$ mediante la máquina rotatoria, donde es bañada uniformemente, cumpliendo la instrucción AP-I-02 "Manejo del túnel criogénico". Para el posterior proceso que es el empacado, esta es previamente sumergido en una tina de agua clorada a $20-25$ ppm con hielo, para proteger el congelado, textura y apariencia. Ya en el proceso de embolsado, el producto es colocado en bolsas de polietileno cumpliendo el control de empaque HACCP \#003, donde es controlado cada 20 minutos. Seguidamente, las bolsas son selladas y colocadas en cajas de $20 \mathrm{~kg}$ para su almacenamiento. Finalmente, en la etapa del almacenamiento las cajas son apiladas en parihuelas donde son llevadas a cámaras de frío donde se almacenan a $-22^{\circ} \mathrm{C}$, donde reciben la parte de empaque del registro AC-R-003, donde el jefe de empaque indica el 
código, cantidad y cajas de producto. El jefe registra la cantidad en la guía de recepción (registro AP-R-04). Para la salida del producto; es decir, para la entrega, esta se registra en la guía de salida AP-R-05."

\subsubsection{Niveles de satisfacción del cliente}

Se busca tener lealtad del cliente y determinada participación del mercado, debido a que, al ofrecer el servicio de congelamiento, cumpliendo la normativa y procesos necesarios para obtener el producto final en perfectas condiciones, buscamos que el cliente confíe en nuestro servicio. Además, centrar la participación del mercado, solidificar la empresa y en un futuro ampliarla para tratar de llegar a nuestra demanda potencial. 


\subsubsection{Medidas de resguardo de la calidad}

Tabla 5.4

HACPP.

\begin{tabular}{|c|c|c|c|c|c|}
\hline $\begin{array}{l}\text { Etapa del } \\
\text { proceso }\end{array}$ & Peligros & \begin{tabular}{|l} 
¿Es \\
significativo?
\end{tabular} & $\begin{array}{l}\text { Justificar } \\
\text { decisión }\end{array}$ & $\begin{array}{l}\text { ¿Qué medidas } \\
\text { preventivas } \\
\text { puede ser } \\
\text { aplicada? }\end{array}$ & $\begin{array}{l}\text { ¿Es } \\
\text { etapa } \\
\text { un } \\
\text { PPC? }\end{array}$ \\
\hline $\begin{array}{l}\text { Compresión de } \\
\text { aire }\end{array}$ & $\begin{array}{l}\text { Físico: } \\
\text { Contaminación } \\
\text { de filtros }\end{array}$ & No & $\begin{array}{l}\text { Los filtros se } \\
\text { cambian en } \\
\text { mantenimientos. }\end{array}$ & $\begin{array}{l}\text { Mantenimiento } \\
\text { preventivo } \\
\text { trimestral }\end{array}$ & No \\
\hline $\begin{array}{l}\text { Pre enfriamiento } \\
\text { de aire }\end{array}$ & $\begin{array}{l}\text { Química: } \\
\text { Contaminación } \\
\text { por el aceite }\end{array}$ & No & $\begin{array}{l}\text { Se hace } \\
\text { tratamiento de } \\
\text { residuos } \\
\text { industriales }\end{array}$ & $\begin{array}{l}\text { Mantenimiento } \\
\text { preventivo } \\
\text { trimestral }\end{array}$ & No \\
\hline $\begin{array}{l}\text { Purificación de } \\
\text { aire }\end{array}$ & $\begin{array}{l}\text { Físico: } \\
\text { Contaminación } \\
\text { de filtros }\end{array}$ & No & $\begin{array}{l}\text { Los filtros se } \\
\text { cambian en } \\
\text { mantenimientos. }\end{array}$ & $\begin{array}{l}\text { Mantenimiento } \\
\text { preventivo } \\
\text { trimestral }\end{array}$ & No \\
\hline $\begin{array}{l}\text { Intercambio de } \\
\text { calor }\end{array}$ & $\begin{array}{l}\text { Biológico: } \\
\text { Contaminación } \\
\text { del agua }\end{array}$ & No & $\begin{array}{l}\text { Se usa agua de } \\
\text { adecuada }\end{array}$ & $\begin{array}{l}\text { Mantenimiento } \\
\text { preventivo } \\
\text { trimestral }\end{array}$ & No \\
\hline Destilación & $\begin{array}{l}\text { Biológico: } \\
\text { Contaminación } \\
\text { por gases }\end{array}$ & No & $\begin{array}{l}\text { Correcto sistema } \\
\text { de } \\
\text { mantenimientos }\end{array}$ & $\begin{array}{l}\text { Mantenimiento } \\
\text { preventivo } \\
\text { trimestral }\end{array}$ & No \\
\hline Congelamiento & $\begin{array}{l}\text { Químico: } \\
\text { Pureza del } \\
\text { nitrógeno }\end{array}$ & No & $\begin{array}{l}\text { Para conservar la } \\
\text { calidad se necesita } \\
\text { nitrógeno a una } \\
\text { pureza de } 98 \% \text { en } \\
\text { adelante }\end{array}$ & $\begin{array}{l}\text { Mantenimiento } \\
\text { preventivo } \\
\text { trimestral }\end{array}$ & No \\
\hline Empacado & $\begin{array}{l}\text { Físico: } \\
\text { Contaminación } \\
\text { por residuos } \\
\text { plásticos }\end{array}$ & $\mathrm{Si}$ & $\begin{array}{l}\text { Reciclaje de } \\
\text { plásticos }\end{array}$ & $\begin{array}{l}\text { Juntar todas las } \\
\text { mermas para su } \\
\text { reciclaje masivo }\end{array}$ & $\mathrm{Si}$ \\
\hline Estampado & $\begin{array}{l}\text { Físico: } \\
\text { Contaminación } \\
\text { por residuos de } \\
\text { etiquetas }\end{array}$ & No & $\begin{array}{l}\text { Reciclaje de } \\
\text { papeles }\end{array}$ & $\begin{array}{l}\text { Juntar todas las } \\
\text { mermas para su } \\
\text { reciclaje masivo }\end{array}$ & No \\
\hline
\end{tabular}

Elaboración propia. 
Tabla 5.5.

Plan de monitoreo de los PCC para el congelamiento criogénico de las conchas de abanico.

\begin{tabular}{|c|c|c|c|c|c|c|c|c|c|}
\hline \multirow[b]{2}{*}{$\begin{array}{l}\text { Puntos de } \\
\text { control } \\
\text { críticos }\end{array}$} & \multirow[b]{2}{*}{$\begin{array}{c}\text { Peligros } \\
\text { significativos }\end{array}$} & \multirow{2}{*}{$\begin{array}{c}\text { Limites } \\
\text { críticos } \\
\text { para cada } \\
\text { medida } \\
\text { preventiva }\end{array}$} & \multicolumn{4}{|c|}{ Monitoreo } & \multirow[b]{2}{*}{$\begin{array}{l}\text { Acciones } \\
\text { correctorias }\end{array}$} & \multirow[b]{2}{*}{ Registros } & \multirow[b]{2}{*}{ Verificación } \\
\hline & & & Qué & Cómo & Frecuencia & Quién & & & \\
\hline Empacado & Físico & $\begin{array}{c}\text { Ausencia } \\
\text { de } \\
\text { elementos } \\
\text { extraños }\end{array}$ & $\begin{array}{l}\text { Contaminantes } \\
\text { físicos: } \\
\text { Pedazos de } \\
\text { concha, } \\
\text { elemento } \\
\text { extraño }\end{array}$ & $\begin{array}{c}\text { Inspección } \\
\text { visual }\end{array}$ & $\begin{array}{c}\text { Cada } \\
\text { empaque } \\
\text { procesado }\end{array}$ & $\begin{array}{c}\text { Operario } \\
\text { de } \\
\text { empacado }\end{array}$ & $\begin{array}{l}\text { Desechar el } \\
\text { empaque }\end{array}$ & $\begin{array}{c}\text { Registro de } \\
\text { incidencias de } \\
\text { contaminantes } \\
\text { físicos en el } \\
\text { proceso de } \\
\text { envasado }\end{array}$ & $\begin{array}{c}\text { Ausencia de } \\
\text { contaminantes }\end{array}$ \\
\hline
\end{tabular}

Elaboración propia. 


\subsection{Impacto ambiental}

Por el lado del impacto ambiental observamos las siguientes matrices causa - efecto:

Tabla 5.6.

Análisis ambiental de procesos

\begin{tabular}{|c|c|}
\hline Proceso & Compresión de aire \\
\hline Aspecto ambiental & Restos en los filtros del compresor \\
\hline Impacto ambiental & Generación de residuos y ruido \\
\hline $\begin{array}{l}\text { Medida de solución } \\
\text { propuesta }\end{array}$ & Entrega de EPP al personal \\
\hline Proceso & Pre enfriamiento de aire \\
\hline Aspecto ambiental & Restos de aceite y ruido \\
\hline Impacto ambiental & Generación de residuos y ruido \\
\hline $\begin{array}{l}\text { Medida de solución } \\
\text { propuesta }\end{array}$ & $\begin{array}{l}\text { Entrega de EPP al personal y tratamiento } \\
\text { del aceite }\end{array}$ \\
\hline Proceso & Purificación de aire \\
\hline Aspecto ambiental & Emisión de ruido y residuos en el tamiz \\
\hline Impacto ambiental & Generación de residuos y ruido \\
\hline $\begin{array}{l}\text { Medida de solución } \\
\text { propuesta }\end{array}$ & $\begin{array}{l}\text { Entrega de EPP al personal y tratamiento } \\
\text { del desecho industrial (filtros) }\end{array}$ \\
\hline Proceso & Intercambio de calor \\
\hline Aspecto ambiental & Uso excesivo de agua \\
\hline Impacto ambiental & Desperdicio de agua usada \\
\hline $\begin{array}{l}\text { Medida de solución } \\
\text { propuesta }\end{array}$ & Riego de cultivos \\
\hline Proceso & Destilación \\
\hline Aspecto ambiental & Emisión de gas \\
\hline \multirow[t]{2}{*}{ Impacto ambiental } & Contaminación de aire \\
\hline & Correcto mantenimiento \\
\hline
\end{tabular}


Medida de solución propuesta

(continuación)

(continúa)

\begin{tabular}{|c|c|}
\hline Proceso & Congelamiento \\
\hline Aspecto ambiental & Emisión de nitrógeno al aire \\
\hline Impacto ambiental & No contaminante \\
\hline $\begin{array}{c}\text { Medida de solución } \\
\text { propuesta }\end{array}$ & - \\
\hline Proceso & Empacado \\
\hline Aspecto ambiental & Restos de bolsas \\
\hline Impacto ambiental & Generación de residuos \\
\hline $\begin{array}{c}\text { Medida de solución } \\
\text { propuesta }\end{array}$ & Reciclaje de plásticos \\
\hline Proceso & Estampado \\
\hline Aspecto ambiental & Restos de etiquetas \\
\hline Impacto ambiental & Generación de residuos \\
\hline $\begin{array}{c}\text { Medida de solución } \\
\text { propuesta }\end{array}$ & Reciclaje de papel \\
\hline
\end{tabular}

Elaboración propia.

Además, al juntar estos procesos en una matriz de aspectos ambientales podemos observar lo siguiente: 
Figura 5.8.

Análisis ambiental utilizando diagrama de flujo.

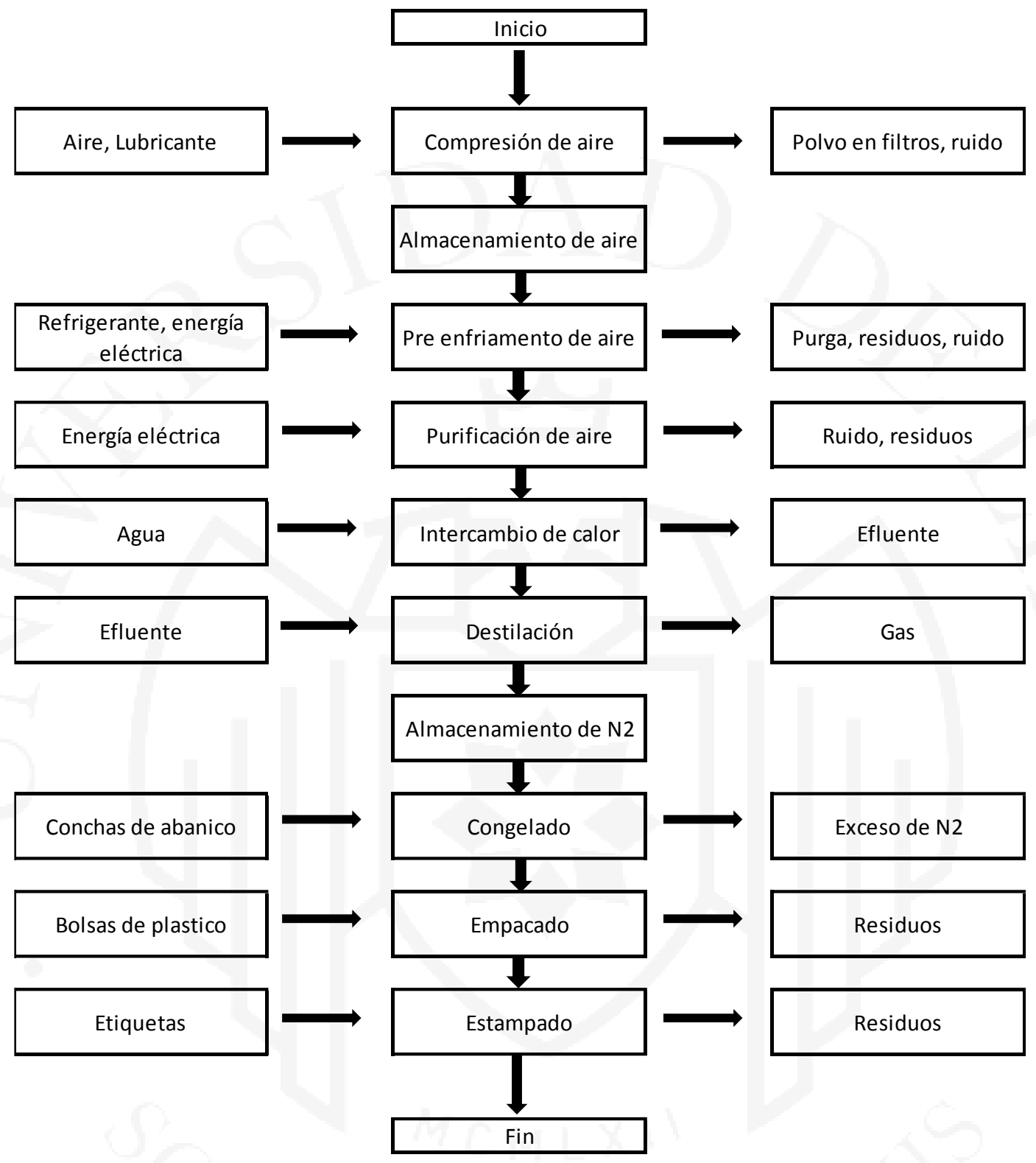

Elaboración propia.

Por otro lado, al analizar cada proceso, podemos encontrar que en la matriz de aspectos ambientales encontramos: 
Tabla 5.7.

Matriz de aspectos ambientales

\begin{tabular}{|c|c|c|c|c|}
\hline Sub proceso & $\begin{array}{c}\text { Aspecto } \\
\text { ambiental }\end{array}$ & $\begin{array}{c}\text { Impacto } \\
\text { ambiental }\end{array}$ & $\begin{array}{l}\text { Recurso } \\
\text { afectado }\end{array}$ & Control operacional \\
\hline $\begin{array}{l}\text { Compresión } \\
\text { de aire }\end{array}$ & $\begin{array}{l}\text { Restos en los } \\
\quad \text { filtros }\end{array}$ & $\begin{array}{c}\text { Contaminación } \\
\text { al suelo }\end{array}$ & Suelo & $\begin{array}{l}\text { Programa de tratamiento } \\
\text { de desechos industriales }\end{array}$ \\
\hline \multirow{2}{*}{$\begin{array}{c}\text { Pre } \\
\text { enfriamiento }\end{array}$} & Restos de aceite & $\begin{array}{l}\text { Contaminación } \\
\text { de ríos y mar }\end{array}$ & Agua & $\begin{array}{l}\text { Programa de tratamiento } \\
\text { de residuos tóxicos }\end{array}$ \\
\hline & $\begin{array}{l}\text { Emisión de } \\
\text { ruido }\end{array}$ & $\begin{array}{l}\text { Contaminación } \\
\text { sonora }\end{array}$ & Aire & $\begin{array}{l}\text { Entrega de EPP a los } \\
\text { trabajadores }\end{array}$ \\
\hline \multirow{2}{*}{ Purificación } & $\begin{array}{l}\text { Emisión de } \\
\text { ruido }\end{array}$ & $\begin{array}{l}\text { Contaminación } \\
\text { sonora }\end{array}$ & Aire & $\begin{array}{c}\text { Entrega de EPP a los } \\
\text { trabajadores }\end{array}$ \\
\hline & Restos en tamiz & $\begin{array}{c}\text { Contaminación } \\
\text { al suelo }\end{array}$ & Suelo & $\begin{array}{l}\text { Programa de tratamiento } \\
\text { de desechos industriales }\end{array}$ \\
\hline $\begin{array}{c}\text { Intercambio } \\
\text { de calor }\end{array}$ & Uso de agua & $\begin{array}{c}\text { Agotamiento de } \\
\text { los RRNN }\end{array}$ & Agua & $\begin{array}{c}\text { Programa de riego de } \\
\text { cultivos }\end{array}$ \\
\hline Destilación & Emisión de gas & $\begin{array}{l}\text { Contaminación } \\
\text { de aire }\end{array}$ & Aire & $\begin{array}{c}\text { Programa de } \\
\text { mantenimiento }\end{array}$ \\
\hline Empacado & $\begin{array}{l}\text { Residuos de } \\
\text { bolsas }\end{array}$ & $\begin{array}{c}\text { Contaminación } \\
\text { al suelo }\end{array}$ & Suelo & Reciclaje de plásticos \\
\hline Estampado & $\begin{array}{l}\text { Residuos de } \\
\text { etiquetas }\end{array}$ & $\begin{array}{c}\text { Contaminación } \\
\text { al suelo }\end{array}$ & Suelo & Reciclaje de papeles \\
\hline
\end{tabular}

Elaboración propia.

Finalmente, haciendo la matriz del medioambiente, basándonos en la ISO 14001, obtenemos: 
Tabla 5.8

Matriz de aspectos ambientales

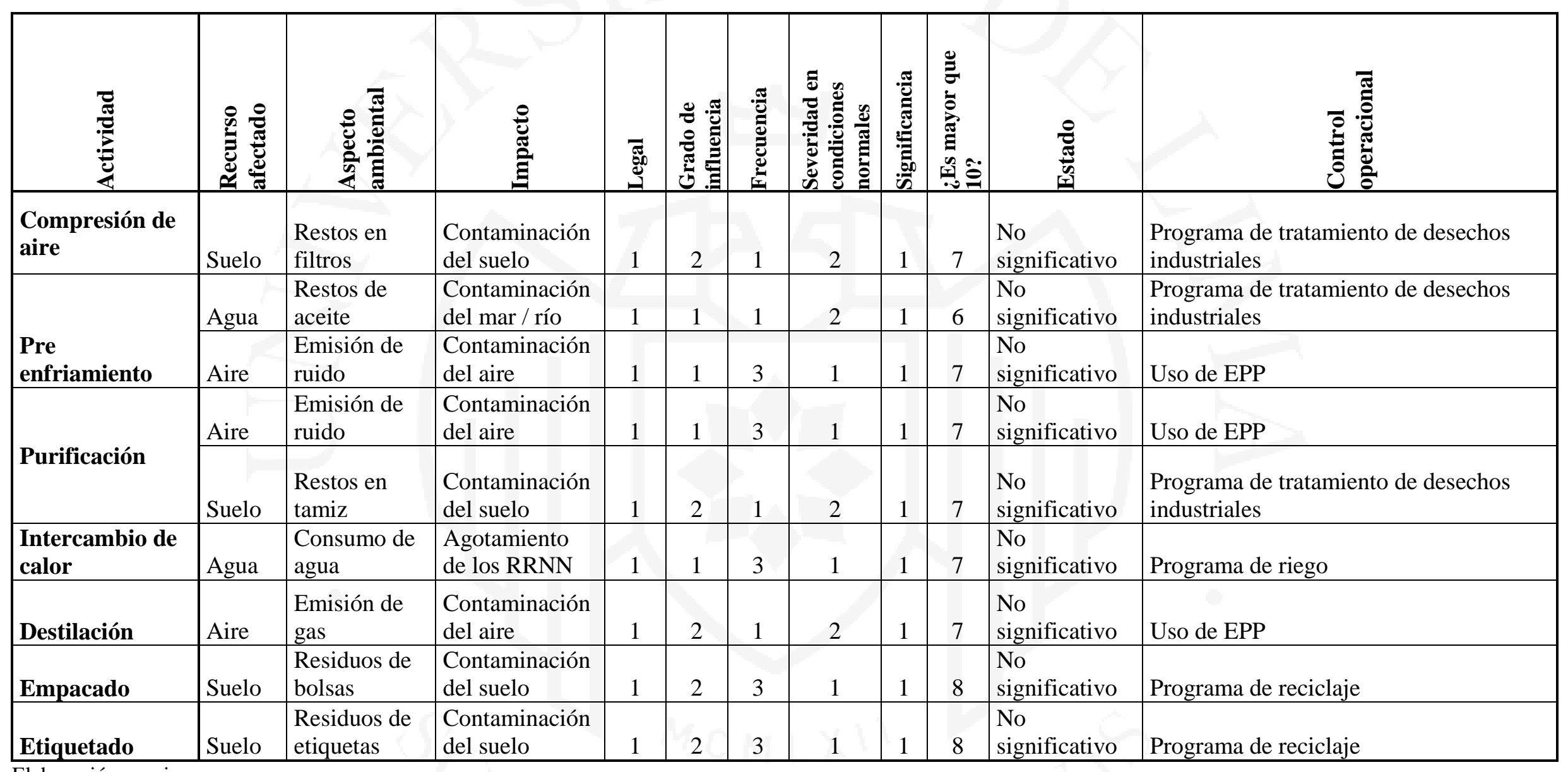


Se concluye que los procesos de la implementación de la planta de nitrógeno, no tenemos actividades que tengan alta significancia y que podemos ofrecer programas para el tratamiento de estos mismos.

\subsection{Seguridad y salud ocupacional}

Para el desarrollo de este capítulo, se comenzará con la elaboración de un mapa de riesgos de la planta. En este cuadro se identificará el factor de riesgo, su ubicación, su fuente y se propondrá una medida preventiva.

Tabla 5.9

Mapa de riesgos

\begin{tabular}{|c|c|c|c|}
\hline \multicolumn{4}{|c|}{ MAPA DE RIESGOS } \\
\hline Factor de riesgo & Ubicación & Fuente & Medida preventiva \\
\hline $\begin{array}{l}\text { Actividad de } \\
\text { mantenimiento }\end{array}$ & $\begin{array}{l}\text { Estación de } \\
\text { mantenimiento }\end{array}$ & Máquinas del proceso & $\begin{array}{c}\text { Capacitación y } \\
\text { utilización de EPP’S }\end{array}$ \\
\hline $\begin{array}{l}\text { Descarga de } \\
\text { bandejas con } \\
\text { concha de abanico }\end{array}$ & Estación de recepción & Bandejas & $\begin{array}{l}\text { Capacitación sobre los } \\
\text { peligros ergonómicos. }\end{array}$ \\
\hline $\begin{array}{l}\text { Llenado con hielo a } \\
\text { las bandejas }\end{array}$ & Estación de pesado & Hielo & $\begin{array}{c}\text { Proporcionar guantes } \\
\text { termoaislantes }\end{array}$ \\
\hline $\begin{array}{l}\text { Congelamiento de } \\
\text { conchas de abanico }\end{array}$ & Estación de congelado & $\begin{array}{l}\text { Ambiente en baja } \\
\text { temperatura }\end{array}$ & $\begin{array}{l}\text { Proporcionar } \\
\text { vestimenta contra } \\
\text { baja temperatura }\end{array}$ \\
\hline $\begin{array}{l}\text { Colocación de } \\
\text { producto congelado } \\
\text { en bolsas }\end{array}$ & Área de envasado & $\begin{array}{l}\text { Conchas de abanico } \\
\text { congeladas }\end{array}$ & $\begin{array}{l}\text { Proporcionar guantes } \\
\text { aislantes }\end{array}$ \\
\hline Descarga eléctrica & $\begin{array}{l}\text { Lugares con } \\
\text { maquinarias }\end{array}$ & Máquinas en general & $\begin{array}{l}\text { Capacitación y colocar } \\
\text { conexiones a tierra }\end{array}$ \\
\hline Piso mojado & Toda la planta & $\begin{array}{l}\text { Hielo y nitrógeno } \\
\text { liquido }\end{array}$ & $\begin{array}{l}\text { Proporcionar botas } \\
\text { contra agua }\end{array}$ \\
\hline
\end{tabular}

Elaboración propia. 
A continuación, se identificará los tipos de fuego que se pueden encontrar en la planta y se propondrán formas de actuar en caso de que estos ocurran.

Tabla 5.10

Tipos de fuegos.

\begin{tabular}{|c|c|c|}
\hline TIPO & $\begin{array}{c}\text { MATERIAL DE } \\
\text { ORIGEN }\end{array}$ & $\begin{array}{c}\text { FORMA DE } \\
\text { ACTUACIÓN }\end{array}$ \\
\hline B (Gases líquidos \\
inflamables) & Combustible & Utilizar dióxido de \\
& & carbono o espuma \\
& & fluoroproteínica \\
\hline C (Materiales & Máquinas, cableado & Utilizar gas carbónico \\
energizados) & & CO2 \\
\hline
\end{tabular}

Elaboración propia.

Dentro de la planta se proporcionará y se capacitará para el uso permanente de equipos de protección personal como:

- Guantes termoaislantes.

- Botas de hule o calzado impermeable.

- Vestimenta térmica.

- Orejeras

-Lentes de seguridad

Finalmente se realizará la matriz de identificación de peligros y riesgos y se propondrán medidas de control para cada peligro identificado. 
Tabla 5.11.

Matriz IPER

\begin{tabular}{|c|c|c|c|c|c|c|c|c|c|c|c|c|}
\hline \multicolumn{13}{|c|}{ PROCESO: CONGELAMIENTO DE CONCHAS DE ABANICO } \\
\hline \multirow[b]{2}{*}{ Actividad } & \multirow[b]{2}{*}{ Peligro } & \multirow[b]{2}{*}{ Riesgo } & \multicolumn{5}{|c|}{ PROBABILIDAD } & \multirow[b]{2}{*}{ 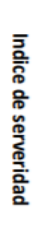 } & \multirow[b]{2}{*}{ 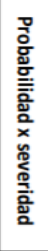 } & \multirow[b]{2}{*}{ 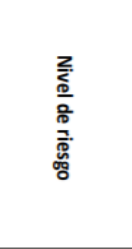 } & \multirow[b]{2}{*}{ 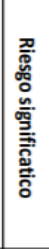 } & \multirow[b]{2}{*}{ Medidas de control } \\
\hline & & & 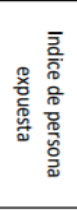 & 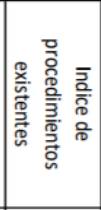 & 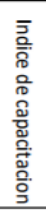 & 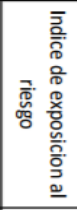 & 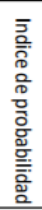 & & & & & \\
\hline $\begin{array}{c}\text { Descargar } \\
\text { bandejas del } \\
\text { camion }\end{array}$ & $\begin{array}{c}\text { Descargar } \\
\text { bandejas de } \\
30 \mathrm{~kg} \text { aprox. }\end{array}$ & $\begin{array}{c}\text { Dolor de espalda } \\
\text { como hernias o } \\
\text { deformacion }\end{array}$ & 1 & 2 & 2 & 3 & 8 & 2 & 16 & Moderado & SI & $\begin{array}{l}\text { Capacitacion sobre } \\
\text { peligros y riesgos } \\
\text { ergonomicos. } \\
\text { Enseñar tecnicas de } \\
\text { levantamiento } \\
\end{array}$ \\
\hline $\begin{array}{c}\text { Traslado de } \\
\text { bandejas al } \\
\text { area de } \\
\text { recepción }\end{array}$ & Piso mojado & Resbalar y caerse & 1 & 2 & 2 & 3 & 8 & 1 & 8 & Tolerable & NO & $\begin{array}{c}\text { Elaborar programa } \\
\text { de limpieza }\end{array}$ \\
\hline $\begin{array}{l}\text { Control de } \\
\text { calidad }\end{array}$ & $\begin{array}{c}\text { Contacto con } \\
\text { conchas de } \\
\text { abanico }\end{array}$ & Alergias, infección & 1 & 2 & 2 & 3 & 8 & 1 & 8 & Tolerable & NO & $\begin{array}{c}\text { Lavado constante de } \\
\text { manos y uso de } \\
\text { guantes }\end{array}$ \\
\hline $\begin{array}{l}\text { Llenado con } \\
\text { hielo a } \\
\text { badejas y } \\
\text { pesado }\end{array}$ & $\begin{array}{c}\text { Contacto con } \\
\text { hielo }\end{array}$ & $\begin{array}{c}\text { Lesiones } \\
\text { musculares en las } \\
\text { manos y dedos }\end{array}$ & 1 & 2 & 2 & 3 & 8 & 2 & 16 & Moderado & SI & $\begin{array}{l}\text { Proporcionar } \\
\text { guantes } \\
\text { termoasilantes }\end{array}$ \\
\hline Congelado & \begin{tabular}{|c} 
Exposicion a \\
bajas \\
temperaturas
\end{tabular} & $\begin{array}{c}\text { Enfermedades } \\
\text { respiratorias y } \\
\text { lesiones de } \\
\text { musculo }\end{array}$ & 1 & 2 & 2 & 3 & 8 & 2 & 16 & Moderado & SI & $\begin{array}{c}\text { Proporcionar } \\
\text { vestimenta termica, } \\
\text { orejeras y lentes }\end{array}$ \\
\hline $\begin{array}{l}\text { Colocacion y } \\
\text { pesado de } \\
\text { bolsas }\end{array}$ & $\begin{array}{c}\text { Manipulacion } \\
\text { de producto } \\
\text { congelado }\end{array}$ & $\begin{array}{c}\text { Enfermedades } \\
\text { respiratorias y } \\
\text { lesiones de } \\
\text { musculo }\end{array}$ & 1 & 2 & 2 & 3 & 8 & 2 & 16 & Moderado & SI & $\begin{array}{c}\text { Proporcionar ropa } \\
\text { termica, orejeras, } \\
\text { lentes }\end{array}$ \\
\hline $\begin{array}{l}\text { Almacenadi } \\
\text { en cámara } \\
\text { frigorifica }\end{array}$ & Apilamiento & $\begin{array}{c}\text { Aplastamiento o } \\
\text { enfermedades } \\
\text { respiratorias }\end{array}$ & 1 & 2 & 2 & 3 & 8 & 3 & 24 & Importante & SI & $\begin{array}{l}\text { Proporcionar ropa } \\
\text { termica y } \\
\text { capacitacion de } \\
\text { tecnicas de } \\
\text { almacenamiento }\end{array}$ \\
\hline
\end{tabular}

Elaboración propia.

\subsection{Sistema de mantenimiento}

Por el lado del sistema de mantenimiento que se aplicará a los equipos que usaremos, al ser maquinaria que estará en constante uso, es necesario que se aplique mantenimientos preventivos programados, en estos mantenimientos se cambiarán los filtros de aire y los lubricantes que se usan. Además, tratar de evitar los mantenimientos correctivos por el alto costo que implica por el paro de las maquinarias. 
Tabla 5.12

Plan de mantenimiento.

\begin{tabular}{l|llc}
\multicolumn{1}{c}{ MÁQUINA } & \multicolumn{1}{c}{ TIPO DE } & & FAREUENCIA \\
MANT. & & Semestral \\
\hline COMPRESOR & Predictivo & Análisis de aceite y temperatura & Semestral \\
& Preventivo & Cambio de aceite y filtros & Semestral \\
TANQUE DE AIRE & Preventivo & Calibración & Semanal \\
CHILLER & Preventivo & Limpieza general & Semanal \\
& Preventivo & Limpieza general & Semestral \\
& Predictivo & Análisis de aceite y temperatura & Semestral \\
TANQUE & Preventivo & Cambio de aceite y filtros & Semestral \\
PURIFICADOR & Preventivo & Calibración & Semanal \\
COLD BOX & Preventivo & Limpieza general & Semanal \\
& Preventivo & Limpieza general & Semanal \\
TANQUE DE & Preventivo & Limpieza general & Anual \\
ALMACENAMIENTO & Preventivo & Calibración de válvulas de & Mensual \\
MÁQUINA & Preventivo & Limpieza general & Semestral \\
GIRATORIA & Preventivo & Cambio de aceite y verificación de & Semanal \\
ESTAMPADORA & Preventivo & Limpieza general & Diario \\
EQUIPOS & Preventivo & Limpieza general & Mensual \\
ELÉCTRICOS & Preventivo & Verificación de aislamiento, & \\
\hline
\end{tabular}

Elaboración propia.

\subsection{Programa de operaciones del servicio}

\subsubsection{Consideraciones sobre la vida útil del proyecto}

El programa de operaciones del servicio se calculará para los años 2018 al 2024, que serán los primeros cinco años del funcionamiento de la planta. Los totales requeridos para cada año variarán de acuerdo a nuestra demanda.

\subsubsection{Programa de operaciones del servicio durante la vida útil del proyecto}

Para elaborar el programa de congelamiento, se considerará la demanda proyectada en toneladas de conchas de abanico a congelar hasta el año 2024. Además, se tendrá en cuenta que la capacidad de la planta para el servicio de congelamiento es de 1,605.03 toneladas/año. 
Tabla 5.13

Programa de congelamiento.

\section{PROGRAMA DE PRODUCCIÓN}

\begin{tabular}{c|ccc}
\hline AÑO & Toneladas & $\begin{array}{c}\text { \%Capacidad } \\
\text { utilizada }\end{array}$ & $\begin{array}{c}\text { \% Capacidad } \\
\text { Ajustada }\end{array}$ \\
$\mathbf{2 0 1 8}$ & 759,53 & $47,32 \%$ & $47 \%$ \\
$\mathbf{2 0 1 9}$ & 763,60 & $47,58 \%$ & $48 \%$ \\
$\mathbf{2 0 2 0}$ & 767,69 & $47,83 \%$ & $48 \%$ \\
$\mathbf{2 0 2 1}$ & 771,78 & $48,09 \%$ & $48 \%$ \\
$\mathbf{2 0 2 2}$ & 775,89 & $48,34 \%$ & $48 \%$ \\
$\mathbf{2 0 2 3}$ & 780,01 & $48,60 \%$ & $49 \%$ \\
$\mathbf{2 0 2 4}$ & 784,15 & $48,86 \%$ & $49 \%$ \\
\hline
\end{tabular}

Elaboración propia.

Como se puede observar en la Tabla 5.13 en todos los años no se logra utilizar toda la capacidad disponible; por lo tanto, se tendría planeado más adelante ofrecer el servicio a otros productos congelados.

\subsection{Requerimiento de materiales, personal y servicio}

\subsubsection{Materiales para el servicio}

Los principales insumos para ofrecer el servicio de congelamiento de conchas de abanico son:

- Aire: Es nuestra fuente para la producción de nitrógeno líquido que será utilizado en el congelamiento de conchas de abanico. Cabe mencionar que en la composición del aire, solo el 78\% es Nitrógeno y la diferencia es oxígeno y otros gases. Además, la proporción que existe entre el nitrógeno utilizado y las conchas de abanico a congelar es de 1:1, como se puede observar en la Figura 5.3. Balance de materia.

- Bolsas: Las conchas de abanico congeladas son almacenadas en bolsas de $2 \mathrm{~kg}$ y posteriormente pasarán a la estación de estampado.

A continuación, se mostrará el requerimiento de los insumos utilizados para cada año de operación de la planta. 
Tabla 5.14

Requerimiento de los principales insumos para el servicio de congelamiento.

\begin{tabular}{|c|c|c|c|}
\hline AÑO & $\begin{array}{c}\text { TONELADAS } \\
\text { A CONGELAR } \\
\text { DE CONCHAS } \\
\text { DE } \\
\text { ABANICO(T) }\end{array}$ & AIRE(T) & $\begin{array}{c}\text { BOLSAS DE } \\
2 \mathrm{KG}\end{array}$ \\
\hline 2018 & 759.53 & $1,011.19$ & $387,515.00$ \\
\hline 2019 & 763.60 & $1,016.61$ & $389,593.00$ \\
\hline 2020 & 767.69 & $1,022.04$ & $391,677.00$ \\
\hline 2021 & 771.78 & $1,027.50$ & $393,767.00$ \\
\hline 2022 & 775.89 & $1,032.97$ & $395,863.00$ \\
\hline 2023 & 780.01 & $1,038.46$ & $397,966.00$ \\
\hline 2024 & 784.15 & $1,043.96$ & $400,074.00$ \\
\hline
\end{tabular}

\subsubsection{Determinación del requerimiento de personal de atención al cliente}

Debido a que se busca la mayor automatización en la planta, todas las operaciones, a excepción del empacado, se trabajarán con máquinas. Se trabajará con 2 supervisores, uno que se encargue de supervisar y operar la planta de nitrógeno y otro que supervisará el congelado, estampado y calidad de las conchas de abanico.

Para el cálculo del número de operarios que se necesitarán en la estación de empacado se utilizará la siguiente fórmula:

Figura 5.9.

Fórmula para el cálculo de número de operarios

$$
\mathrm{N}=\frac{\text { Requerimiento de HH por año }}{\text { Total de horas disponibles al año }}
$$

Requer. HH = Tiempo estándar X Requerimiento de producc.

Fuente: Disposición de planta, segunda edición. (2007)

Se tendrá en cuenta que un operario tarda 30 segundos en embolsar una bolsa de $2 \mathrm{~kg}$ de conchas de abanico congelada y en el año se disponen de 8,736 horas. Los resultados son los siguientes: 
Tabla 5.15

Cálculo del número de operarios necesarios.

\begin{tabular}{|c|c|c|c|c|c|c|c|}
\hline Año & $\begin{array}{c}\text { Demanda } \\
\text { (bolsa) }\end{array}$ & $\begin{array}{c}\text { Tiempo } \\
\text { estándar } \\
\text { HH/ bolsa }\end{array}$ & $\begin{array}{c}\text { Tiempo } \\
\text { disponible } \\
\text { (horas/año) }\end{array}$ & u & e & $\begin{array}{c}\mathbf{N}^{\circ} \text { operarios } \\
\text { calculados }\end{array}$ & $\begin{array}{c}\mathbf{N}^{\circ} \\
\text { operarios } \\
\text { reales }\end{array}$ \\
\hline 2018 & 387515,00 & 0,008 & 8736 & 0,75 & 0,83 & 0,593820643 & 1 \\
\hline 2019 & 389593,00 & 0,008 & 8736 & 0,75 & 0,83 & 0,597004931 & 1 \\
\hline 2020 & 391677,00 & 0,008 & 8736 & 0,75 & 0,83 & 0,600198413 & 1 \\
\hline 2021 & 393767,00 & 0,008 & 8736 & 0,75 & 0,83 & 0,603401089 & 1 \\
\hline 2022 & 395863,00 & 0,008 & 8736 & 0,75 & 0,83 & 0,606612960 & 1 \\
\hline 2023 & 397966,00 & 0,008 & 8736 & 0,75 & 0,83 & 0,609835557 & 1 \\
\hline 2024 & 400074,00 & 0,008 & 8736 & 0,75 & 0,83 & 0,613065816 & 1 \\
\hline
\end{tabular}

Elaboración propia.

A pesar de que la demanda siga aumentando, el número de operarios en la estación de empacado no varía. Estos mismos operarios se encargarán de la carga y la descarga de las conchas de abanico.

\subsubsection{Servicios de terceros}

La planta no contratará servicios de terceros para poder operar.

\subsubsection{Otros: energía eléctrica, agua, transportes, etc.}

Los consumos de cada equipo se detallarán en las siguientes tablas:

Tabla 5.16

Consumo de energía.

\begin{tabular}{|l|c|c|c|}
\hline \multicolumn{1}{|c|}{ Máquina } & $\begin{array}{c}\text { Consumo } \\
\text { (KW/mes) }\end{array}$ & $\begin{array}{c}\text { Tiempo } \\
\text { (meses/año) }\end{array}$ & $\begin{array}{c}\text { Consumo Total } \\
\text { (KW-h/año) }\end{array}$ \\
\hline $\begin{array}{l}\text { Planta de } \\
\text { nitrógeno }\end{array}$ & 497 & 12 & 5962 \\
\hline $\begin{array}{l}\text { Máquina } \\
\text { rotatoria }\end{array}$ & 5112,0 & 12 & 61344 \\
\hline Estampadora & 1080,0 & 12 & 12960 \\
\hline
\end{tabular}

Fuente: Alibaba (2017)

Elaboración propia. 
Tabla 5.17

Consumo de agua.

\begin{tabular}{|l|c|c|c|}
\hline Máquina & Capacidad(m³ $/$ día) & Tiempo & $\begin{array}{l}\text { Consumo } \\
\text { Total }\left(\mathbf{m}^{3} / \mathbf{a n ̃ o}\right)\end{array}$ \\
\hline $\begin{array}{l}\text { Planta de } \\
\text { nitrógeno }\end{array}$ & 0,9 & 260 & 234 \\
\hline $\begin{array}{l}\text { Agua uso } \\
\text { administrativo }\end{array}$ & 0,56 & 260 & 146 \\
\hline
\end{tabular}

Fuente: Alibaba (2017)

Elaboración propia.

\subsection{Soporte físico del servicio}

\subsubsection{Factor edificio}

Tabla 5.18

Análisis del factor edificio.

\begin{tabular}{|c|c|}
\hline Características & Análisis de factor \\
\hline Niveles y pisos & $\begin{array}{l}\text { Debido al área asignada para la planta el edificio tendrá un solo nivel, lo cual nos } \\
\text { da una mayor flexibilidad y control de las áreas de producción y administración, } \\
\text { además, mayor facilidad a la hora de transportar materiales y equipos. Así mismo, } \\
\text { no contaremos con desniveles entre áreas, quitando en su totalidad la necesidad de } \\
\text { instalar rampas para la movilización de nuestros equipos de transportes. }\end{array}$ \\
\hline Suelos & $\begin{array}{l}\text { El área de administración y monitoreo tendrán suelos de madera (parqué) debido a } \\
\text { que son más fáciles de limpiar y le ofrecen una mejor ambientación. Para el área de } \\
\text { producción se usará concreto, de esta forma se evitará que los trabajadores se } \\
\text { resbalen. }\end{array}$ \\
\hline Pasillos & $\begin{array}{l}\text { Presenta pasillos anchos para vehículos como el montacargas que se usará para } \\
\text { descargar y cargar las unidades de nuestros clientes y pasillos lo suficientemente } \\
\text { anchos para poder permitir la circulación de nuestras carretillas hidráulicas. }\end{array}$ \\
\hline Techos & $\begin{array}{l}\text { Todas las áreas de la planta serán techadas con excepción del patio de maniobras y } \\
\text { estacionamiento. La cubierta del techo será tipo inclinada y con producto Ternium } \\
\text { multytecho. }\end{array}$ \\
\hline Almacenamiento & Se tendrán 2 almacenes: de materia prima e insumos y de productos terminados. \\
\hline Iluminación & $\begin{array}{l}\text { Por el lado de la iluminación, se instalará una iluminación general; es decir, } \\
\text { mediante lámparas de techo, asegurando la iluminación mínima de } 300 \text { luxes. }\end{array}$ \\
\hline Ventilación & $\begin{array}{l}\text { Por el lado de las oficinas se contará con una ventilación artificial mediante aire } \\
\text { acondicionado y las demás áreas una ventilación natural, con techos altos para } \\
\text { poder permitir la circulación del aire. }\end{array}$ \\
\hline
\end{tabular}

Elaboración propia. 


\subsubsection{El ambiente del servicio}

- Relativo al hombre.

Tabla 5.19

Servicios relativos al hombre

\begin{tabular}{|l|l|}
\hline \multicolumn{1}{|c|}{ SERVICIO } & \multicolumn{1}{c|}{ ANÁLISIS DE FACTOR } \\
\hline Vías de acceso & $\begin{array}{l}\text { Todas las vías de acceso se mantendrán libres de obstáculos. Además, se } \\
\text { identificará y establecerá las áreas de estacionamiento y las áreas de tránsito de } \\
\text { las máquinas y peatonal. También se tendrá señalizado las salidas de emergencia. }\end{array}$ \\
\hline $\begin{array}{l}\text { Instalaciones para } \\
\text { uso del personal }\end{array}$ & $\begin{array}{l}\text { - Las instalaciones sanitarias se realizarán respetando las especificaciones OSHA } \\
\text { para W.C. y contarán con un programa de limpieza. } \\
\text { - Dentro del área de oficina se contara con herramientas y utilería de primeros } \\
\text { auxilios para atender los accidentes que ocurran. }\end{array}$ \\
\hline $\begin{array}{l}\text { Protección contra } \\
\text { incendios y fugas }\end{array}$ & $\begin{array}{l}\text { Cerca de las zonas de mayor probabilidad de ocurrencia de incendios se ubicarán } \\
\text { extintores. Además, se capacitará al personal para que minimice riesgos y cada } \\
\text { área de trabajo con señales de seguridad. }\end{array}$ \\
\hline Iluminación & $\begin{array}{l}\text { Las paredes serán pintadas de color blanco y las fuentes de luz serán frías para } \\
\text { mantener la temperatura de la planta. Se programará limpieza diaria de las fuentes } \\
\text { de luz para mantener la buena iluminación. }\end{array}$ \\
\hline $\begin{array}{l}\text { Ventilación } \\
\text { calefacción }\end{array}$ & $\begin{array}{l}\text { La planta tendrá sistemas de ventilación y la oficina calefacción. Por lo tanto, se } \\
\text { realizará un programa de control y limpieza de los equipos. En caso que uno de } \\
\text { los equipos se malogre, se priorizara una reparación inmediata. }\end{array}$ \\
\hline
\end{tabular}

Elaboración propia.

- Relativo a la máquina.

Tabla 5.20

Servicios relativos a las máquinas.

\begin{tabular}{|l|l|}
\hline \multicolumn{1}{|c|}{ SERVICIO } & \multicolumn{1}{c|}{ ANÁLISIS DE FACTOR } \\
\hline Mantenimiento & $\begin{array}{l}\text { Los equipos tendrán su programa de } \\
\text { mantenimiento como se detalló en subcapítulo } \\
5.7 \text { " "Sistema de mantenimiento" }\end{array}$ \\
\hline Distribución de líneas de servicios auxiliares & $\begin{array}{l}\text { Se contará con grupos electrógenos para } \\
\text { garantizar el funcionamiento de los equipos. } \\
\text { Además, para no parar la producción de } \\
\text { nitrógeno, se tendrá tanques de agua de reserva. }\end{array}$ \\
\hline
\end{tabular}

Elaboración propia. 
- Relativo al material.

Tabla 5.21

Servicios relativos a las máquinas.

\begin{tabular}{|l|l|}
\hline \multicolumn{1}{|c|}{ SERVICIO } & \multicolumn{1}{c|}{ ANÁLISIS DE FACTOR } \\
\hline Control de calidad & $\begin{array}{l}\text { Se tendrá la actividad de control de calidad después de la actividad de } \\
\text { empacado, donde se realizarán las pruebas mediante muestreo. Se } \\
\text { implementará con todos los instrumentos necesarios para realizar los } \\
\text { controles. }\end{array}$ \\
\hline Control de producción & $\begin{array}{l}\text { Durante la producción de nitrógeno, se buscara reducir demoras y tener } \\
\text { el control de tiempos y movimientos. }\end{array}$ \\
\hline Control de rechazos & $\begin{array}{l}\text { Las mermas se pondrán en contenedores y serán llevados directamente a } \\
\text { una disposición final de residuos sólidos. }\end{array}$ \\
\hline
\end{tabular}

Elaboración propia.

\subsection{Disposición de la instalación del servicio}

\subsubsection{Disposición general}

Para empezar, es necesario calcular los $\mathrm{m}^{2}$ necesarios para la instalación de la planta de congelamiento, para ello se aplica el método de Guerchet, en el que indica que se debe considerar los elementos móviles y los estáticos, para los operarios una altura de 1,65m y una superficie estática de $0,5 \mathrm{~m}^{2}$, además un $\mathrm{K}$ para las fórmulas de 0,1 al tratarse de una industria de alimentación. 
Tabla 5.22

Método de Guerchet

\begin{tabular}{|c|c|c|c|c|c|c|c|}
\hline & \multicolumn{7}{|c|}{ Dimensiones (metros) } \\
\hline Elementos & Largo & Ancho & Altura & N (lados) & $\mathbf{n}$ & Área \\
\hline Estáticos & \multicolumn{7}{|c|}{} \\
\hline Planta productora de N2 & 13,5 & 11 & 10 & 4 & 1 & 148,5 \\
\hline Máquina rotatoria & 9,6 & 1,8 & 1,8 & 4 & 1 & 17,28 \\
\hline Punto de espera: Javas vacías & 1,2 & 1,2 & 0,15 & & 2 & 1,44 \\
\hline Punto de espera: Rollo de bolsas & Diámetro: 0,5 & 1,2 & & 1 & 0,196 \\
\hline Mesa de trabajo del área de empacado & 2,00 & 0,9 & 1,05 & 4 & 1 & 1,8 \\
\hline Balanza & 0,7 & 0,5 & 1 & 3 & 2 & 0,35 \\
\hline Móviles & & & & & & \\
\hline Operarios & & & 1,65 & & 5 & \\
\hline Montacargas & 1,5 & 1,2 & 1,5 & & 1 & 1,8 \\
\hline Contenedor de residuos sólidos & 0,7 & 0,6 & 0,6 & & 1 & 0,42 \\
\hline Contenedor industrial & 2,08 & 1,08 & 1,28 & & 1 & 2,25 \\
\hline
\end{tabular}

Elaboración propia.

Para el cálculo de las superficies, no se incluirá en la evaluación a los puntos de espera identificados en el factor espera, ya que, al estar junto a sus respectivos puestos de trabajo están comprendidas en las superficies de gravitación y evolución. Pues, las superficies de los puntos de espera no son mayor al 30\% del área gravitacional de sus respectivos puestos de trabajo, por ende no se les debería considerar de manera independiente. 
Tabla 5.23

Método de Guerchet, dimensiones

\begin{tabular}{|l|r|r|r|r|}
\hline \multicolumn{1}{|c|}{ Elementos } & \multicolumn{5}{|c|}{ Dimensiones (metros) } \\
\hline \multicolumn{1}{|c|}{ Estáticos } & \multicolumn{1}{c|}{ Ss } & Sg & Se & St \\
\hline Planta productora de N2 & 148,5 & 148,5 & 37,2 & 334,2 \\
\hline Máquina rotatoria & 17,28 & 69,12 & 8,64 & 95,04 \\
\hline Punto de espera: Javas vacías & & & & \\
\hline Punto de espera: Rollo de bolsas & & & & \\
\hline Mesa de trabajo del área de empacado & 1,8 & 7,2 & 0,9 & 9,9 \\
\hline Balanza & 0,35 & 1,05 & 0,14 & 3,08 \\
\hline & & & & \\
\hline Operarios & 0,5 & & & \\
\hline Montacargas & 1,8 & & & \\
\hline Contenedor de residuos solidos & 0,42 & & & \\
\hline Contenedor industrial & 2,25 & & & \\
\hline
\end{tabular}

Elaboración propia.

Es así, que se obtiene que en elementos estáticos es necesario un área de $431,37 \mathrm{~m}^{2}$ en total. Sin embargo, se piensa añadir una pequeña sala de control de $16 \mathrm{~m}^{2}$, donde se ubicarán las computadoras y escritorios para el área administrativa. Respecto a los servicios higiénicos para los operarios, que, en este caso, según la OSHA para W.C es necesario como mínimo 1 instalación por la cantidad de empleados. Su área será de $6 \mathrm{~m}^{2}$.

\subsubsection{Disposición de detalle}

Para poder realizar el bosquejo de nuestro plano es necesario hacer un esquema relacional, en donde nos indica la proximidad que deben tener las áreas de la empresa y los motivos, teniendo en cuenta lo siguiente: 
Tabla 5.24.

Códigos de tabla relacional

\begin{tabular}{c|c} 
CÓDIGO & $\begin{array}{c}\text { VALOR DE } \\
\text { PROXIMIDAD }\end{array}$ \\
\hline $\mathbf{A}$ & Absolutamente necesario \\
$\mathbf{E}$ & Especialmente necesario \\
$\mathbf{I}$ & Importante \\
$\mathbf{O}$ & Normal \\
$\mathbf{U}$ & Sin importancia \\
$\mathbf{X}$ & No recomendable \\
\hline
\end{tabular}

Fuente: Disposición de planta, B. Díaz, B. Jarufe, Noriega (2007)

Figura 5.10.

Áreas para el análisis relacional.

\begin{tabular}{|l|l|}
\hline \multicolumn{1}{|c|}{ Área } & Simbolo \\
\hline Almacén de MP & \\
\hline $\begin{array}{l}\text { Área de } \\
\text { producción }\end{array}$ & \\
\hline $\begin{array}{l}\text { Área de } \\
\text { congelamiento }\end{array}$ & \\
\hline $\begin{array}{l}\text { Área de } \\
\text { empacado }\end{array}$ & \\
\hline $\begin{array}{l}\text { Servicios } \\
\text { higiénicos }\end{array}$ & \\
\hline $\begin{array}{l}\text { Oficina de } \\
\text { monitoreo }\end{array}$ & \\
\hline $\begin{array}{l}\text { Patio de } \\
\text { maniobras }\end{array}$ & \\
\hline Estacionamiento & \\
\hline Almacén de PT & \\
\hline
\end{tabular}

Elaboración propia. 
Tabla 5.25

Motivos de tabla relacional

\begin{tabular}{r|l} 
CÓDIGO & \multicolumn{1}{c}{ MOTIVO } \\
\hline $\mathbf{1}$ & No se desea la manipulación ni la contaminación \\
$\mathbf{2}$ & $\begin{array}{l}\text { Después de su secado va el embolsado al almacén de } \\
\text { productos }\end{array}$ \\
$\mathbf{4}$ & Para no contaminar el producto \\
$\mathbf{5}$ & Por el seguimiento del proceso \\
$\mathbf{6}$ & Para facilitar el control de inventario en el almacén \\
$\mathbf{7}$ & Por las tuberías de agua y desagüe \\
$\mathbf{8}$ & Para el control de entrada y salida \\
$\mathbf{9}$ & Por el polvo o el olor
\end{tabular}

Fuente: Disposición de planta, B. Diaz, B. Jarufe, M. Noriega (2007)

Se obtiene:

Figura 5.11.

Esquema relacional

\begin{tabular}{|l|l|}
\hline 1. Almacén de materias primas \\
\hline 2. Área de producción \\
\hline 3. Área de congelamiento \\
\hline 4. Área de empacado y estampado \\
\hline 6. Oficina de monitoreo \\
\hline 7. Patio de maniobras \\
\hline 8. Estacionamiento & 9ligiénicos \\
\hline 9. Almacén de productos terminados
\end{tabular}

Elaboración propia.

La tabla relacional de actividades de las áreas es la siguiente: 
Tabla 5.26

Tabla relacional de actividades de las áreas

\begin{tabular}{|l|l|l|l|l|}
\hline \multicolumn{1}{|c|}{ Área } & Simbolo & \multicolumn{1}{c|}{ A } & \multicolumn{1}{c|}{ I } & \multicolumn{1}{c|}{ X } \\
\hline Almacén de MP & & $1-2 ; 1-7$ & & $1-4 ; 1-6 ; 1-9$ \\
\hline $\begin{array}{l}\text { Área de } \\
\text { producción }\end{array}$ & & $2-3 ; 2-6$ & $2-5 ; 2-7$ & $2-4 ;$ \\
\hline $\begin{array}{l}\text { Área de } \\
\text { congelamiento }\end{array}$ & & $3-4 ;$ & $3-5 ; 3-6$ & \\
\hline $\begin{array}{l}\text { Área de } \\
\text { empacado }\end{array}$ & & $4-9 ;$ & $4-5 ; 4-6$ & $4-7 ;$ \\
\hline $\begin{array}{l}\text { Servicios } \\
\text { higiénicos }\end{array}$ & & & & \\
\hline $\begin{array}{l}\text { Oficina de } \\
\text { monitoreo }\end{array}$ & & & $6 ; 7$ & \\
\hline $\begin{array}{l}\text { Patio de } \\
\text { maniobras }\end{array}$ & & & $7-8 ; 7-9$ & \\
\hline Estacionamiento & & & & $9-10 ;$ \\
\hline Almacén de PT & & & & \\
\hline
\end{tabular}

Elaboración propia.

A continuación el diagrama relacional de actividades

Figura 5.12.

Diagrama relacional de actividades.

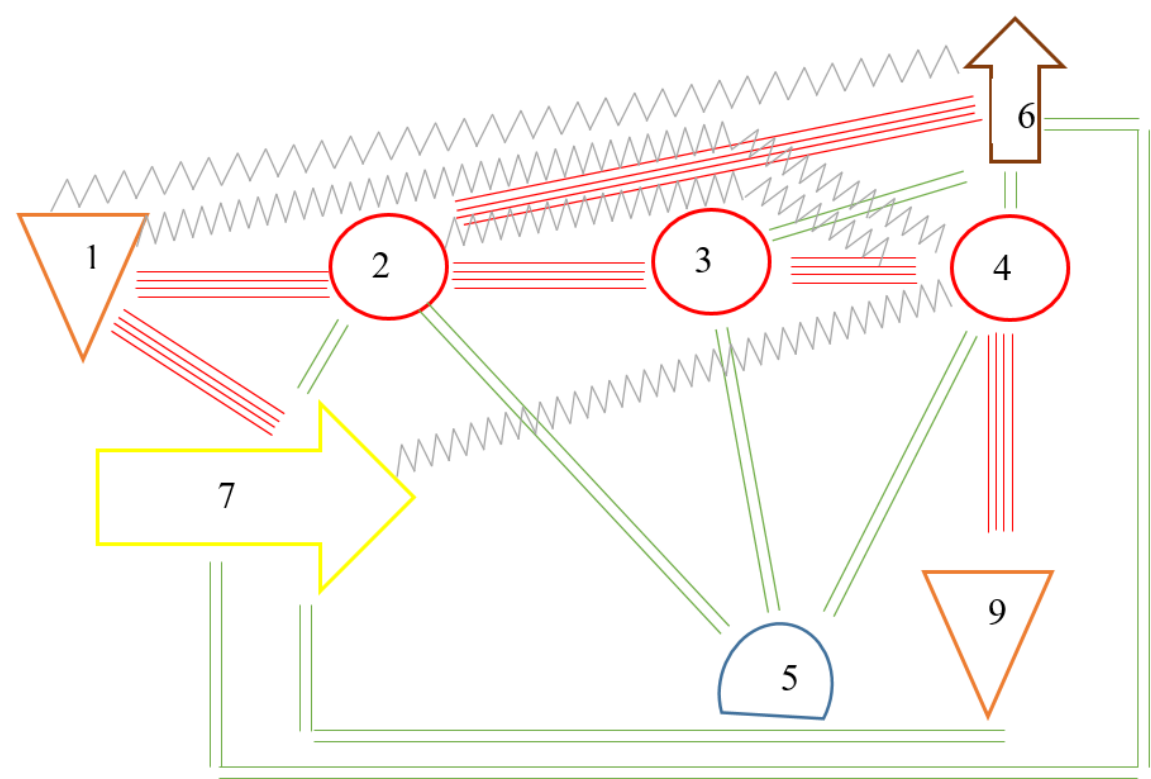

Elaboración propia. 
Entonces, cumpliendo con el esquema relacional se obtiene la siguiente distribución de áreas:

Figura 5.13.

Distribución de áreas.

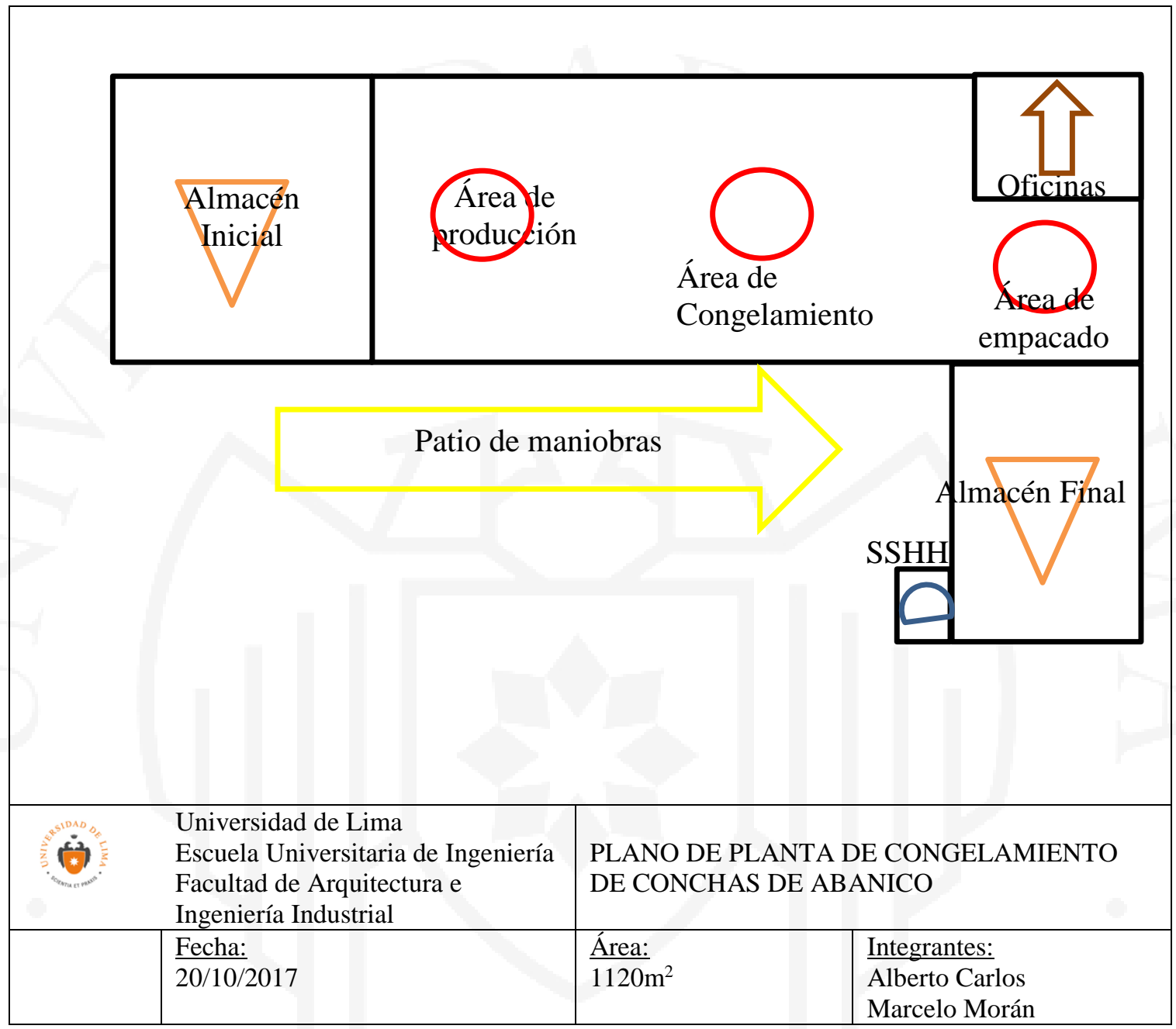

Elaboración propia.

A continuación, se muestra el mapa detallado con las máquinas que se comprarán: 
Figura 5.14.

Mapa general.

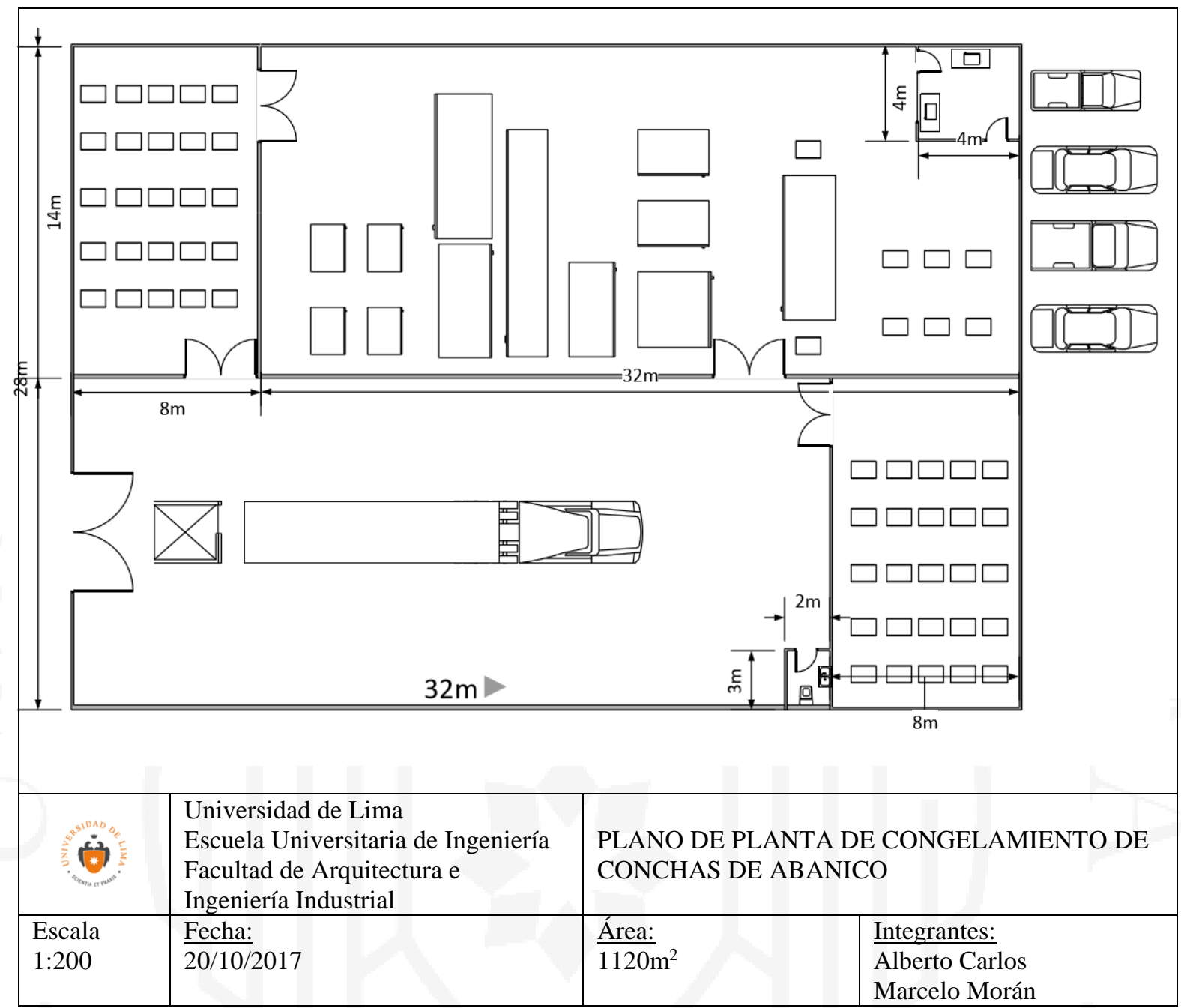

Elaboración propia.

Leyenda:

1 Compresor de aire

2 Sistema de preenfriamiento

3 Sistema de purificación

4 Coldbox

5 Turbinas de expansión

6 Tanque de almacenamiento $\mathrm{O} 2$

7 Tanque de almacenamiento N2

8 Máquina rotatoria 


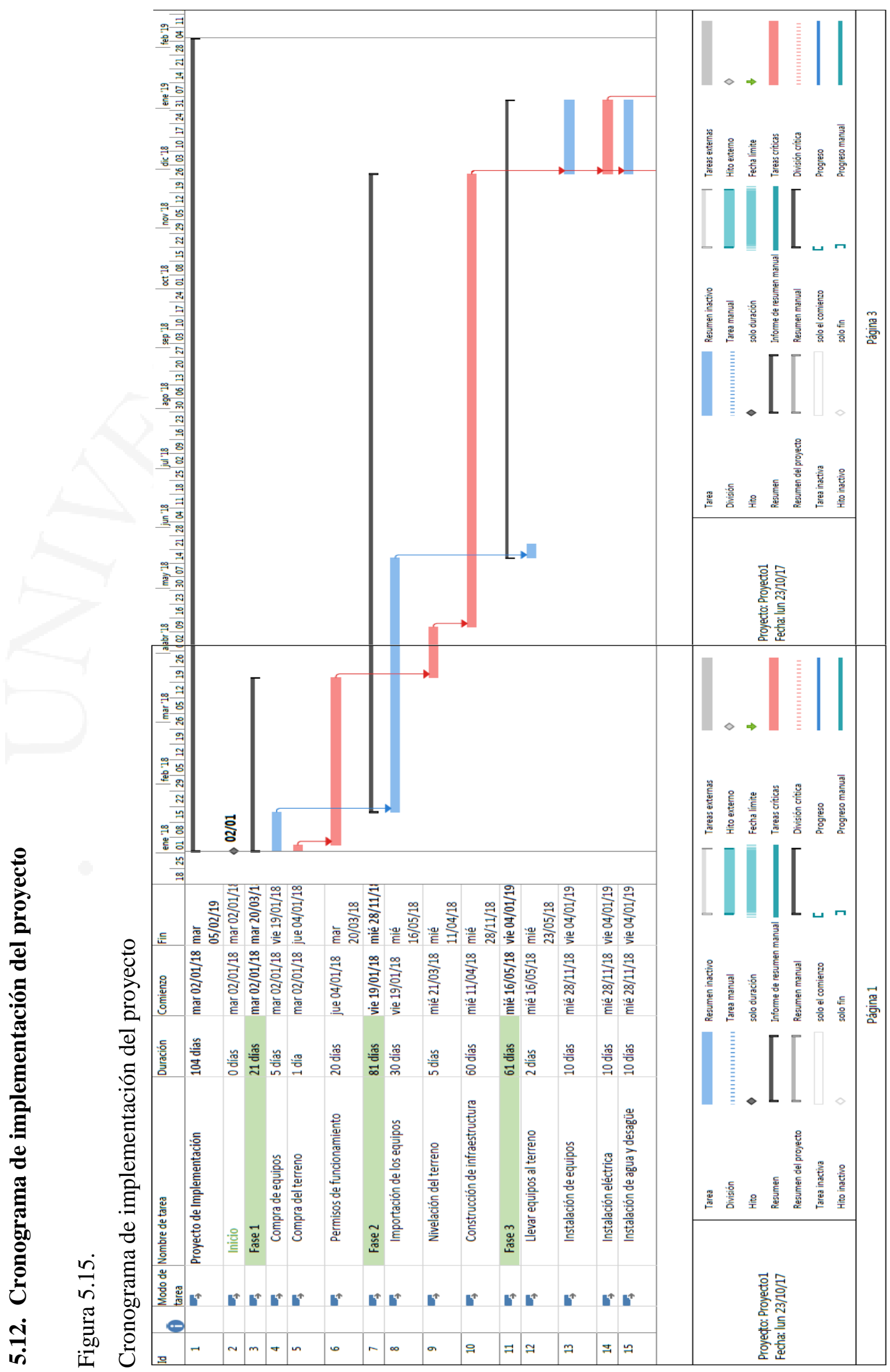

急 


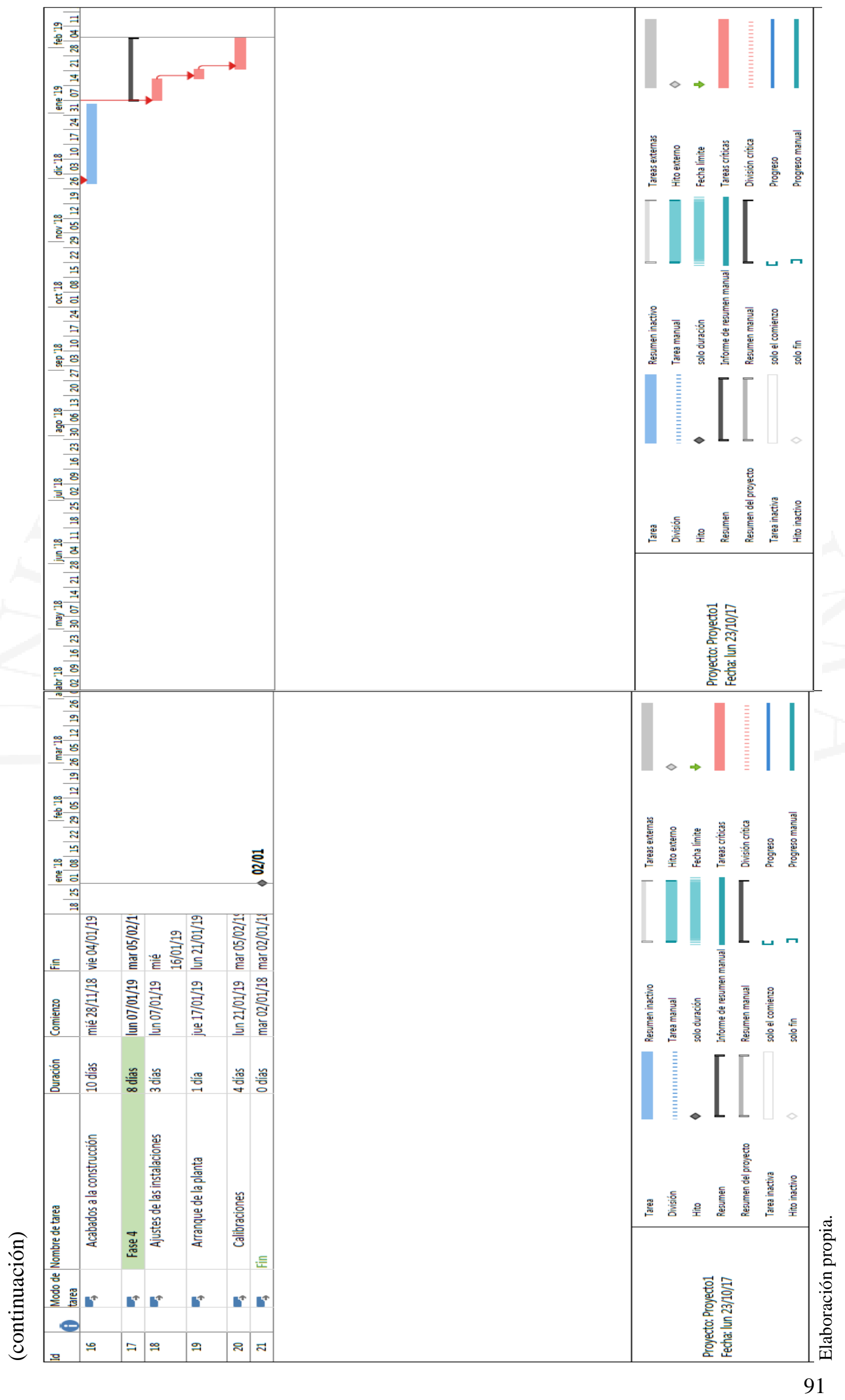




\section{CAPÍTULO VI: ORGANIZACIÓN ADMINISTRATIVA}

\subsection{Formación de la organización empresarial.}

La empresa será una sociedad anónima cerrada (S.A.C), conformada por 2 accionistas, de los cuales no se responderá con el patrimonio personal de los accionistas, se financiará la compra de los equipos. Las decisiones que se tomen en la empresa serán por una junta de accionistas.

Por parte de beneficios, tenemos que no hay un mínimo de capital inicial a concebir, además que no se requiere de tantos accionistas, en este caso solamente 2. Por otro lado, al establecer una S.A.C. no tenemos responsabilidad por las deudas o daños a terceros. Finalmente, las acciones se pueden transferir sin tener que disolver la organización.

Por otro lado, para poder formar la empresa en primer lugar debemos buscar y reservar un nombre con la finalidad de evitar tener una empresa existente con el mismo nombre y perjudicar la inscripción en registros públicos. En segundo lugar debemos elevar el acto constitutivo, en este documento los accionistas declaran su voluntad en constituir la empresa y señalan los acuerdos de esta misma. Seguidamente se debe abonar un capital en el banco de preferencia previamente abriendo una cuenta de los socios suscritos. Posteriormente se procede a inscribir a registros públicos, para poder proceder es necesario obtener la escritura pública en una notaría y llevarlo luego a la SUNARP. Finalmente debemos de crear el RUC este debe ser realizado en la SUNAT. (Gobierno Nacional del Perú, 2019). 


\subsection{Requerimientos de personal directivo, administrativo y de servicios.}

La empresa al tener máquinas automatizadas requerirá de un gerente general, el cual supervisará toda acción que se de en la empresa, tres operarios que se encargarán del embolsado manual y de la carga y descarga del producto terminado, un operario que estará supervisando las computadoras de la planta, dos personales de limpieza y un vigilante.

\subsection{Esquema de la estructura organizacional y funciones generales de los principales puestos.}

El esquema de la empresa, según lo mencionado en el punto 6.2, sería el siguiente:

Figura 6.1.

Esquema estructural de la organización

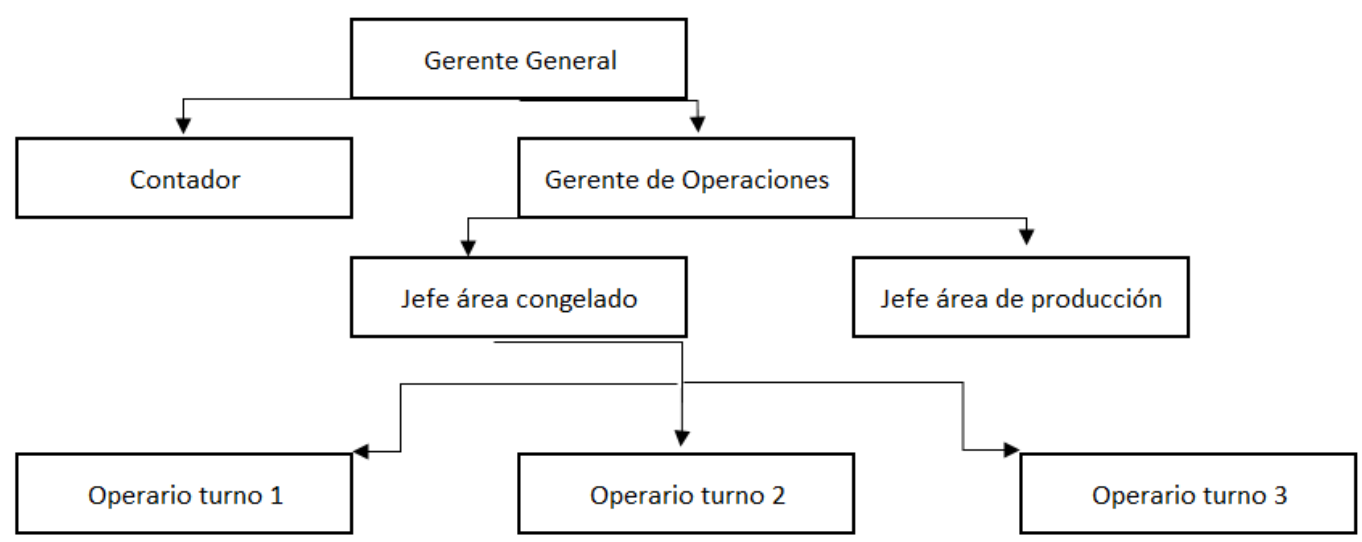

Elaboración propia.

- Gerente General: El gerente general se encargará de negociar y buscar nuevos clientes, tomar las decisiones de la empresa y de representarla ante cualquier suceso. Además de supervisar el trabajo del gerente de operaciones.

- Gerente de operaciones: El gerente de operaciones se encargará de hacer seguimiento a la producción, medir el rendimiento de la planta, responsable del buen funcionamiento de esta misma y de todo el equipo. Además de cotizar las piezas con proveedores para el mantenimiento correspondiente. Finalmente, será el responsable de preservar la calidad del producto final, supervisando el trabajo del equipo que lleva a cargo, este 
mismo tendrá que reportar a la gerencia general la productividad de las máquinas y ventas.

- Jefe de producción: El jefe de producción se encargará de hacer seguimiento a la planta de producción en su perfecto estado, asegurándose que tenga los mantenimientos y las calibraciones adecuadas, finalmente decidir en qué momento se hará el paro de planta para su respectivo mantenimiento preventivo y predictivo.

- Jefe de congelamiento: El jefe de congelamiento se encargará de supervisar a los operarios para que se mantenga la calidad del producto final.

- Operario: Los operarios se encargarán de hacer seguimiento a la planta, medir los indicadores mediante las computadoras e informar cualquier salto de alarma al supervisor, hacer el mantenimiento correspondiente. Además de acomodar el producto final en el almacén de productos terminados.

- Contador: El contador se encargará de hacer el flujo financiero de la empresa, hacer los pagos correspondientes a los trabajadores, además de pagar los impuestos y llevar las facturas correctamente. 


\section{CAPÍTULO VII: PRESUPUESTOS Y EVALUACIÓN DEL PROYECTO}

\subsection{Inversiones}

\subsubsection{Estimación de las inversiones de largo plazo}

Para la estimación de la inversión a largo plazo se determinó todos nuestros activos tangibles e intangibles que se utilizaran durante la vida útil del proyecto. A continuación, detallaremos cada uno de estos y sus respectivas depreciaciones en caso de los activos tangibles y amortizaciones en caso de los activos intangibles, considerando 7 años para cada uno de ellos. Además, se consideró que el valor de mercado sera de 50\% del valor en libros. 
Tabla 7.1.

Costo total de intangibles y amortización

\begin{tabular}{|c|c|c|c|c|c|c|c|c|c|c|c|}
\hline & & & & & & AÑO & & & & AMORT. & VALOR \\
\hline $\begin{array}{l}\text { Gastos pre } \\
\text { operativos }\end{array}$ & $\begin{array}{l}\text { Total en } \\
\text { soles }\end{array}$ & \%Depre & 2018 & 2019 & 2020 & 2021 & 2022 & 2023 & 2024 & TOTAL (S/) & $\begin{array}{l}\text { RESIDUAL } \\
\text { (S/) }\end{array}$ \\
\hline $\begin{array}{l}\text { Licencia de } \\
\text { construcción }\end{array}$ & $1,260.00$ & $100 \%$ & 1260,00 & & - & - & - & - & - & 1260,00 & (NI) \\
\hline Marco legal & 42,00 & $10 \%$ & 4,20 & 4,20 & 4,20 & 4,20 & 4,20 & 4,20 & 4,20 & 29,40 & 12,60 \\
\hline $\begin{array}{l}\text { Capacitación de } \\
\text { personal }\end{array}$ & 880,00 & $10 \%$ & 88,00 & 88,00 & 88,00 & 88,00 & 88,00 & 88,00 & 88,00 & 616,00 & 264,00 \\
\hline $\begin{array}{l}\text { Inscripción en } \\
\text { registros públicos }\end{array}$ & 398,59 & $10 \%$ & 39,86 & 39,86 & 39,86 & 39,86 & 39,86 & 39,86 & 39,86 & 279,01 & 119,58 \\
\hline $\begin{array}{l}\text { Contingencias } \\
\text { ( } 8 \% \text { equipos } \\
\text { directos) }\end{array}$ & 81834,43 & $10 \%$ & 8183,44 & 8183,44 & 8183,44 & 8183,44 & 8183,44 & 8183,44 & 8183,44 & 57284,10 & 24550,33 \\
\hline $\begin{array}{l}\text { Gastos de } \\
\text { remodelación de } \\
\text { terreno }\end{array}$ & 480105,36 & $3 \%$ & 14403,16 & 14403,16 & 14403,16 & 14403,16 & 14403,16 & 14403,16 & 14403,16 & 100822,13 & 379283,23 \\
\hline Total (S/) & 563799,23 & $\begin{array}{c}\text { TOTAL } \\
(\mathrm{S} /)\end{array}$ & 24009,86 & 22749,86 & 22749,86 & 22749,86 & $22,749.86$ & 22749,86 & 22749,86 & 160509,04 & 404323,34 \\
\hline
\end{tabular}

Elaboración propia. 
Tabla 7.2.

Costo total de tangibles y depreciación

\begin{tabular}{|c|c|c|c|c|c|c|c|c|c|c|c|}
\hline \multirow[b]{2}{*}{ Tangible } & \multirow{2}{*}{$\begin{array}{c}\text { Total en } \\
\text { soles }\end{array}$} & & \multicolumn{7}{|c|}{ AÑo } & \multirow{2}{*}{$\begin{array}{c}\text { DEPRECIACIÓN } \\
\text { TOTAL(S/) }\end{array}$} & \multirow{2}{*}{$\begin{array}{c}\text { VALOR } \\
\text { RESIDUAL }\end{array}$} \\
\hline & & \%Depre & 2018 & 2019 & 2020 & 2021 & 2022 & 2023 & 2024 & & \\
\hline $\begin{array}{c}\text { Mobiliario de } \\
\text { oficina y } \\
\text { equipamiento }\end{array}$ & 10000,00 & $25 \%$ & 2500,00 & 2500,00 & 2500,00 & 2500,00 & & & & 10000,00 & - \\
\hline
\end{tabular}

Elaboración propia. 
- Terreno: Costo del lugar donde se instalará la planta ubicada en Sechura, Piura.

- Infraestructura: Costo total de las partidas de construcción de zona de producción y almacenamiento, áreas administrativas, estacionamiento y patio de maniobras y nivelación de terreno.

- Maquinaria y equipos: Costo total de las máquinas como la planta de nitrógeno, tanque de almacén de nitrógeno, maquinaria rotatoria, estampadora y apiladores.

- Mobiliario de oficina y equipamiento: Es el costo total de los muebles como escritorios, estantes y la adquisición de equipos como computadoras, aire acondicionado, etc.

\subsubsection{Estimación de las inversiones de corto plazo}

Para la inversión de corto plazo calcularemos nuestro capital de trabajo, este consiste en identificar todos los egresos necesarios para poder operar, como la compra de materia prima e insumos, sueldos y salarios, servicios de agua y luz, que se detalla en la Tabla 7.3.

Además, se determinó un ciclo de caja de 90 días, donde el periodo promedio de inventario es de 30 días y el periodo promedio de cobro es 60 días.

Ciclo de caja $=$ Periodo prom . de inv. + Periodo prom. de cobro - Periodo prom. de pago Ciclo de caja $=30$ días +60 días -0 días

Tabla 7.3.

Cálculo de egresos anuales.

\begin{tabular}{|c|c|}
\hline Gasto corriente Anual & \multicolumn{1}{|c|}{ TOTAL } \\
\hline Materia Prima e insumos & 15268,09 \\
\hline Sueldos y salarios MO directa e indirecta & 370125,00 \\
\hline Servicios(electricidad, agua) & 87742,12 \\
\hline TOTAL (S/) & S/ 473 135,21 \\
\hline
\end{tabular}

Elaboración propia.

Por lo tanto, nuestro capital es de S/ 118 283,80, resultado de la suma de los egresos anuales por el ciclo de caja entre 360 días al año.

Una vez determinado el capital de trabajo y los activos tangibles e intangibles, calculamos una inversión de S/ 1716 046,50. 


\subsection{Costos de operaciones del servicio}

\subsubsection{Costos de materiales del servicio}

Como se mencionó anteriormente, en el servicio de congelamiento solo se comprará las bolsas de $2 \mathrm{~kg}$ para embolsar las conchas congeladas, mientras que el nitrógeno será fabricado por nuestra planta. El precio de la bolsa es de S/ 0,0394 y se asume que se mantendrá constante los siguientes cinco años.

Tabla 7.4.

Costos de materia prima o insumos para el servicio.

\begin{tabular}{|c|c|c|c|c|c|}
\hline Año & $\mathbf{2 0 1 8}$ & $\mathbf{2 0 1 9}$ & $\mathbf{2 0 2 0}$ & $\mathbf{2 0 2 1}$ & $\mathbf{2 0 2 2}$ \\
\hline Gasto & Cantidad & Cantidad & Cantidad & Cantidad & Cantidad \\
\hline $\begin{array}{c}\text { Bolsas de } \\
2 \mathrm{~kg}\end{array}$ & 387515 & 389593 & 391677 & 393767 & 395863 \\
\hline TOTAL & S/ 15 268,09 & S/ 15 349,96 & S/ 15 432,07 & S/ 15 514,42 & S/ 15 597,00 \\
\hline
\end{tabular}

Elaboración propia.

\subsubsection{Costos de los servicios}

Los principales servicios identificados para el funcionamiento de nuestra planta son los servicios de agua y luz. Donde se recolecto información de las tarifas de EPS GRAU S.A entidad del agua de Piura y OSINERG quien se encarga de las tarifas eléctricas.

Tabla 7.5.

Costo total de los servicios identificados.

\begin{tabular}{|c|c|c|}
\hline Año & \multicolumn{3}{|c|}{ ANUAL } \\
\hline Servicio & Precio & Cantidad \\
\hline Consumo anual de agua & 4,82 & 7254.00 \\
\hline TOTAL & \multicolumn{3}{|c|}{ S/ 35,013.28 } \\
\hline Consumo anual de electricidad & 35,38 & \multicolumn{2}{|c|}{ S/ 2 940,84 } \\
\hline TOTAL & \multicolumn{3}{|c|}{ S/.37 954,12 } \\
\hline TOTAL DE SERVICIOS (S/) & \multicolumn{3}{|c|}{} \\
\hline
\end{tabular}

Elaboración propia.

\subsubsection{Costo de personal}

Para el cálculo del costo de personal se tuvo en cuenta los siguientes factores: Durante el año se considerará dos gratificaciones, una CTS, 9\% de Essalud. 
Tabla 7.6.

Costo total de mano de obra indirecta.

\begin{tabular}{|c|c|c|c|c|c|c|c|}
\hline Personal & $\begin{array}{c}\text { Salario } \\
\text { por } \\
\text { mes } \\
(\mathbf{S} /)\end{array}$ & $\begin{array}{c}\text { Total } \\
\text { anual } \\
\text { sin } \\
\text { benef. }\end{array}$ & $\begin{array}{c}\text { Gratificació } \\
\mathbf{n}(\mathbf{S} /)\end{array}$ & CTS (S/) & $\begin{array}{c}\text { Vacaciones } \\
(\mathbf{S} /)\end{array}$ & $\begin{array}{c}\text { Essalud } \\
(\mathbf{9 \%})\end{array}$ & $\begin{array}{c}\text { Total } \\
\text { anual (S/) }\end{array}$ \\
\hline $\begin{array}{c}\text { Jefe del área } \\
\text { de congelado }\end{array}$ & 2000 & 24000 & 4000 & 1166,67 & 4000,00 & 180,00 & $\mathbf{3 3 ~ 1 6 6 , 6 7}$ \\
\hline $\begin{array}{c}\text { Jefe del área } \\
\text { de producción }\end{array}$ & 2000 & 24000 & 4000 & 1166,67 & 4000,00 & 180,00 & $\mathbf{3 3 ~ 1 6 6 , 6 7}$ \\
\hline $\begin{array}{c}\text { Gerente de } \\
\text { operaciones }\end{array}$ & 7000 & 84000. & 14000 & 4083,33 & 14000,00 & 630,00 & $\mathbf{1 1 6} \mathbf{0 8 3 , 3 3}$ \\
\hline $\begin{array}{c}\text { Gerente } \\
\text { administrativo }\end{array}$ & 7000 & 84000. & 14000 & 4083,33 & 14000,00 & 630,00 & $\mathbf{1 1 6} \mathbf{0 8 3 , 3 3}$ \\
\hline Contador & 1500 & 18000. & 3000 & 875,00 & 3000,00 & 135,00 & $\mathbf{2 4 ~ 8 7 5 , 0 0}$ \\
\hline & \multicolumn{7}{|c|}{ TOTAL (S/) } \\
\hline
\end{tabular}

Elaboración propia.

Tabla 7.7.

Costo total de mano de obra directa.

\begin{tabular}{|c|c|c|c|c|c|c|c|c|}
\hline Personal & Cant. & $\begin{array}{c}\text { Salario } \\
\text { (S/.) }\end{array}$ & $\begin{array}{c}\text { Total } \\
\text { anual sin } \\
\text { benef. }\end{array}$ & Gratific. & CTS & Vacaciones & $\begin{array}{c}\text { Essalud } \\
(\mathbf{9 \%})\end{array}$ & Total anual \\
\hline $\begin{array}{c}\text { Operarios } \\
\text { del área de } \\
\text { embolsado }\end{array}$ & 3,00 & 1000,00 & 12000,00 & 2000,00 & 583,33 & 1000,00 & 90,00 & S/ 46 750,00 \\
\hline
\end{tabular}

Elaboración propia.

\subsection{Presupuesto de ingresos y egresos}

\subsubsection{Presupuesto de ingreso por ventas}

Nuestros ingresos se medirán en soles por tonelada congelada. Por lo tanto, cada tonelada a congelar costará S/ 2600.

Tabla 7.8.

Ingresos totales proyectado.

\begin{tabular}{|c|c|c|c|c|c|c|c|}
\hline \multicolumn{7}{|c|}{ PRESUPUESTO DE INGRESOS } \\
\hline AÑO & $\mathbf{2 0 1 8}$ & $\mathbf{2 0 1 9}$ & $\mathbf{2 0 2 0}$ & $\mathbf{2 0 2 1}$ & $\mathbf{2 0 2 2}$ & $\mathbf{2 0 2 3}$ & $\mathbf{2 0 2 4}$ \\
\hline Cantidad(t) & 759,53 & 763,60 & 767,69 & 771,78 & 775,89 & 780,01 & 784,15 \\
\hline Precio (S/) & 2600,00 & 2600,00 & $2,600,00$ & 2600,00 & 2600,00 & 2600,00 & 2600,00 \\
\hline TOTAL (S/) & $\mathbf{1 9 7 4 ~ 7 8 0 , 6 8}$ & $\mathbf{1 9 8 5 3 6 7 , 8 7}$ & $\mathbf{1 9 9 5 ~ 9 8 6 , 8 1}$ & $\mathbf{2 0 0 6 ~ 6 3 7 , 6 1}$ & $\mathbf{2 ~ 0 1 7 ~ 3 2 0 , 3 6}$ & $\mathbf{2 ~ 0 2 8 ~ 0 3 5 , 1 6}$ & $\mathbf{2 0 3 8 ~ 7 8 2 , 1 1}$ \\
\hline
\end{tabular}

Elaboración propia. 


\subsubsection{Presupuestos de costos del servicio}

Tabla 7.9.

Presupuesto de costos para el servicio de congelamiento

\begin{tabular}{|l|c|c|c|c|c|c|c|}
\hline \multicolumn{7}{|c|}{ PRESUPUESTO DE COSTOS OPERATIVOS } \\
\hline \multicolumn{1}{|c|}{ AÑNO } & $\mathbf{2 0 1 8}$ & $\mathbf{2 0 1 9}$ & $\mathbf{2 0 2 0}$ & $\mathbf{2 0 2 1}$ & $\mathbf{2 0 2 2}$ & $\mathbf{2 0 2 3}$ & $\mathbf{2 0 2 4}$ \\
\hline $\begin{array}{l}\text { COSTOS } \\
\text { FIJOS (S/) }\end{array}$ & 264179,95 & 264179,95 & $264,179,95$ & 264179,95 & 264179,95 & 264179,95 & 264179,95 \\
\hline $\begin{array}{l}\text { COSTOS } \\
\text { VARIABLES } \\
\text { (S/) }\end{array}$ & 15268,09 & 15349,96 & 15432,07 & 15514,42 & 15597,00 & 15679,86 & 15762,92 \\
\hline $\begin{array}{l}\text { Depreciación } \\
\text { fabril (S/) }\end{array}$ & 204586,06 & 204586,06 & 204586,06 & 204586,06 & 204586,06 & - & \\
\hline TOTAL (S/) & $\mathbf{2 7 9 , 4 4 8 , 0 4}$ & $\mathbf{2 7 9 , 5 2 9 . 9 1}$ & $\mathbf{2 7 9 , 6 1 2 . 0 2}$ & $\mathbf{2 7 9 ~ 6 9 4 , 3 7}$ & $\mathbf{2 7 9 7 7 6 , 9 5}$ & $\mathbf{2 7 9} \mathbf{8 5 9 , 8 1}$ & $\mathbf{2 7 9} \mathbf{9 4 2 , 8 6}$ \\
\hline
\end{tabular}

Elaboración propia.

Dentro de los costos fijos consideramos los sueldos de mano de obra directa y mano de obra indirecta, además del valor del servicio de agua que se utiliza para

la producción de nitrógeno. En la depreciación fabril se consideró la depreciación de infraestructura y maquinarias y equipos. 


\subsubsection{Presupuesto operativo de gastos administrativos}

Para el cálculo de los gastos administrativos se consideró los sueldos del contador, que se tendrá en la oficina de la planta, además, se consideró el servicio de luz. Como depreciación no fabril se tomó en cuenta a lo mobiliarios adquiridos para oficina. Finalmente, se adicionó la amortización de intangibles.

Tabla 7.10.

Presupuesto de gastos administrativos.

\begin{tabular}{|c|c|c|c|c|c|c|c|}
\hline \multicolumn{7}{|c|}{ PRESUPUESTO DE GASTOS ADMINISTRATIVOS (S/) } \\
\hline AÑO & $\mathbf{2 0 1 8}$ & $\mathbf{2 0 1 9}$ & $\mathbf{2 0 2 0}$ & $\mathbf{2 0 2 1}$ & $\mathbf{2 0 2 2}$ & $\mathbf{2 0 2 3}$ & $\mathbf{2 0 2 4}$ \\
\hline Personal Administrativo & 140958,33 & 140958,33 & 140958,33 & 140958,33 & 140958,33 & 140958,33 & 140958,33 \\
\hline Servicios y Alquileres & 52728,84 & 52728,84 & 52728,84 & 52728,84 & 52728,84 & 52728,84 & 52728,84 \\
\hline Depreciacion No fabril & 2500,00 & 2500,00 & 2500,00 & 2500,00 & - & - & - \\
\hline Amortizacion de intangibles & 24009,86 & 22749,86 & 22749,86 & 22749,86 & 22749,86 & 22749,86 & 22749,86 \\
\hline TOTAL & 193687,17 & 193687,17 & 193687,17 & 193687,17 & 193687,17 & 193687,17 & 193687,17 \\
\hline
\end{tabular}

Elaboración propia.

\subsubsection{Estado de resultados proyectado}

Para calcular el estado de resultados se considerará de impuesto a la renta de $29.5 \%$, participaciones de $10 \%$, una reserva legal de $10 \%$. Teniendo en cuenta que el monto máximo de la reserva legal es de S/ 638.32 soles. 


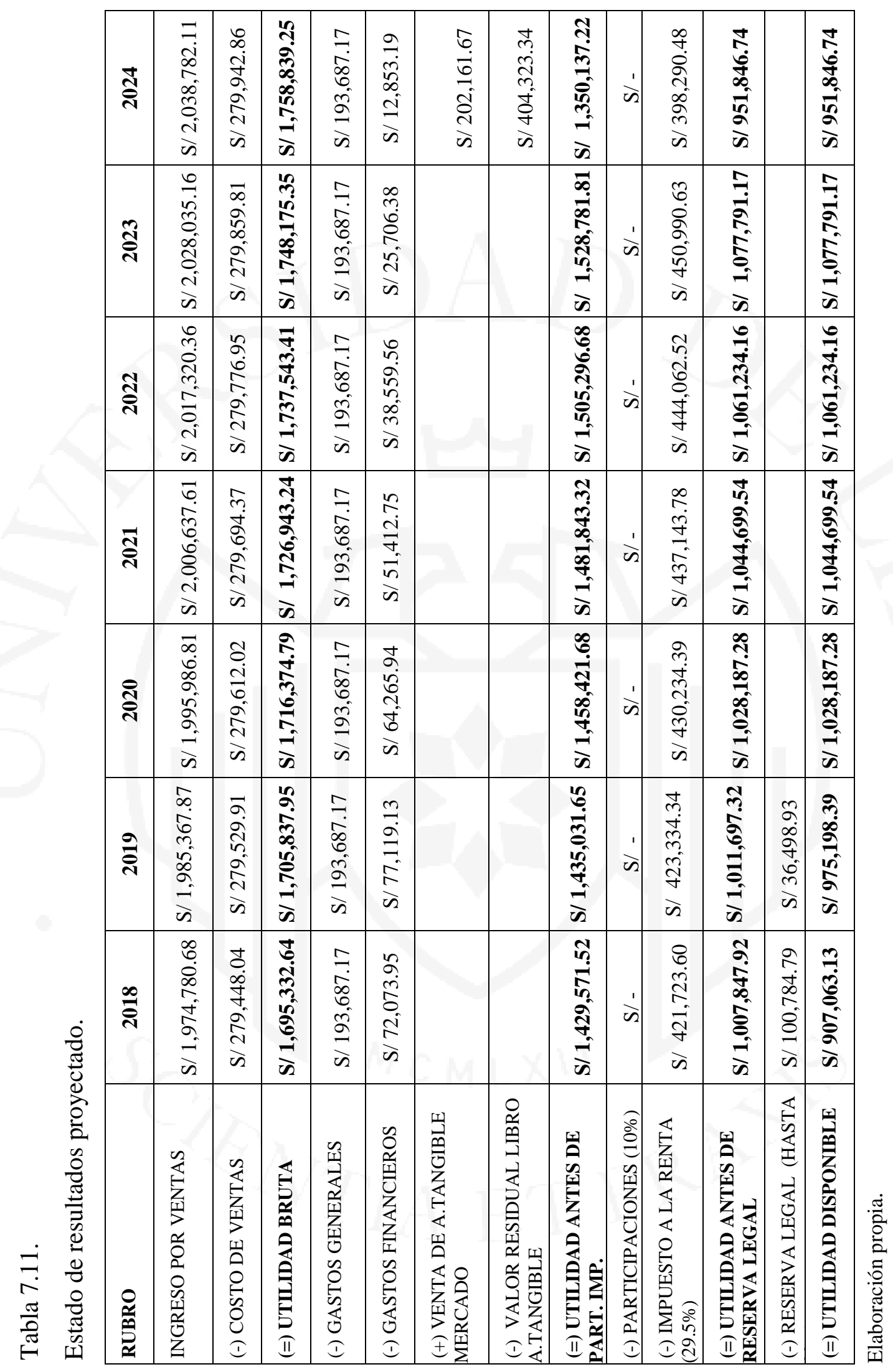


Tabla 7.12

Balance General a inicios del año 2018

\begin{tabular}{|c|c|c|c|}
\hline \multicolumn{4}{|c|}{ BALANCE GENERAL } \\
\hline \multicolumn{4}{|c|}{ Inicio de la Actividad } \\
\hline \multirow[t]{2}{*}{ ACTIVOS } & & PASIVO CORTO PLAZO & 370125,00 \\
\hline & & Sueldos & 370125,00 \\
\hline \multicolumn{4}{|l|}{ ACTIVOS CORRIENTES } \\
\hline CAJA & 473140,71 & PASIVO LARGO PLAZO & 1029627,90 \\
\hline CUENTAS POR COBRAR & - & Devda bancaria & 1029627,90 \\
\hline MATERIALES Y SUMINISTROS & 15268,09 & Prestamo de accionistas & 686418,60 \\
\hline TOTAL ACTIVOS CORRIENTE: & 488408,80 & TOTAL PASIVO & 1399752,90 \\
\hline \multicolumn{4}{|l|}{ ACTIVOS FIJOS } \\
\hline & & $\underline{\text { PATRIMONIO }}$ & \\
\hline & & CAPITAL SOCIAL & 686418,60 \\
\hline MAQUINARLAS & 1022930,32 & UTILIDAD DEL EJERCICIO & - \\
\hline MUEBLES Y ENSERES & 10000,00 & TOTAL PATRIMONIO & 686418,60 \\
\hline INTANGIBLES & 564832,38 & & \\
\hline TOTAL ACTIVO FIJO & 1597762,70 & & \\
\hline TOTAL DE ACTIVOS & 2086171,50 & TOTAL PASIVO + PATRIMONI & 2086171,50 \\
\hline
\end{tabular}

Elaboración propia. 
Tabla 7.13

Balance General a fines del año 2018

\begin{tabular}{|c|c|c|c|}
\hline \multicolumn{4}{|c|}{ BALANCE GENERAL } \\
\hline \multicolumn{4}{|c|}{ Fin del primer año } \\
\hline \multirow[t]{2}{*}{ ACTIVOS } & & PASIVO CORTO PLAZO & 370125,00 \\
\hline & & Sueldos & 370125,00 \\
\hline ACTIVOS CORRIENTES & & Depreciación & \\
\hline CAJA & 536643,26 & PASIVO LARGO PLAZO & 1029627,90 \\
\hline CUENTAS POR COBRAR & 493695,17 & Deuda bancaria & 1029627,90 \\
\hline MATERIALES Y SUMINISTROS & 15349,96 & Prestamo de accionias & - \\
\hline TOTAL ACTIVOS CORRIENTES & 1045688,40 & TOTAL PASIVO & 1399752,90 \\
\hline \multicolumn{4}{|l|}{$\underline{\text { ACTIVOS FLJOS }}$} \\
\hline & & PATRIMONIO & \\
\hline & & CAPITAL SOCIAL & 686418,60 \\
\hline MAQUINARIAS & 818344,26 & UTILIDAD DEL EJERCICIO & 907063,13 \\
\hline MUEBLES Y ENSERES & 7500,00 & TOTAL PATRIMONIO & 1593481,73 \\
\hline INTANGIBLES & 540822,51 & & \\
\hline DEPRECIACIÓN & $-228595,93$ & & \\
\hline AMORTIZACION & $-24009,86$ & & \\
\hline CUENTAS POR COBRAR ACCIONISTAS & 833485,25 & & \\
\hline TOTAL ACTIVO FIJO & 1947546,23 & & \\
\hline TOTAL DE ACTIVOS & 2993234,63 & TOTAL PASIVO + PATRIMONIO & 2993234,63 \\
\hline
\end{tabular}

Elaboración propia.

\subsection{Flujo de fondos}

Antes de comenzar con la elaboración de flujo de fondos, se realizará nuestro cronograma de pagos, donde de una inversión de S/ 1716 046,50, solo el 60\% será financiado mediante una entidad bancaria a una tasa efectiva anual (TEA) de 7\% y la diferencia será el aporte de los accionistas. Para el análisis del flujo de fondo económico se considerará el costo de oportunidad (COK) y este será de $956 \%$.

Para hallar el costo de oportunidad se utilizó el método CAPM y se consideraron los siguientes datos recolectados de Bloomberg:

$\operatorname{Rf}^{2}=5,78 \%$

$\mathrm{B}^{3}=1$

$\mathrm{Rm}^{4}=9,56 \%$

$$
C o k=R f+B(R m-R f)
$$

\footnotetext{
2 Tasa libre de riesgo

${ }^{3}$ Beta del activo

${ }^{4}$ Rentabilidad del mercado
} 


$$
\operatorname{Cok}=5,78 \%+1(9,56 \%-5,78 \%)=9,56 \%{ }^{5}
$$

Para el análisis del flujo de fondos financieros al tratarse de proyecto inicial la tasa de descuento que se utilizará es el COK (Arroyo y Vásquez, 2016, p.206). Y es mayor que la tasa calculada por el metodo WACC o CPPC.

$\mathrm{WACC}=\mathrm{Ws}+\mathrm{Ks}+\mathrm{Wd}[\mathrm{Kd}(1-\mathrm{t})]$

$\mathrm{Kd}^{6}=7 \%$

$\mathrm{Ws}^{7}=40 \%$

$\mathrm{Wd}^{8}=60 \%$

$\mathrm{t}^{9}=29,5 \%$

$\mathrm{Ks}^{10}=9,56 \%$

$$
\mathrm{WACC}=9,56 \% \times 40 \%+60 \%[7 \%(1-29,5 \%)]=6,79 \%
$$

El método de pago será mediante amortizaciones constantes, ya que nos permitirá tener mayor flujo económico en un futuro. El primer año será de gracia total.

Tabla 7.14

Cronograma de pago de deuda en soles (S/).

\begin{tabular}{|c|c|c|c|c|c|c|c|}
\hline AÑO & $\mathbf{2 0 1 8}$ & $\mathbf{2 0 1 8}$ & $\mathbf{2 0 2 0}$ & $\mathbf{2 0 2 1}$ & $\mathbf{2 0 2 2}$ & $\mathbf{2 0 2 3}$ & $\mathbf{2 0 2 4}$ \\
\hline Deuda & $\mathrm{S} / 1029627,90$ & $\mathrm{~S} / 1101701,85$ & $\mathrm{~S} / 918084,88$ & $\mathrm{~S} / 734467,90$ & $\mathrm{~S} / 550850,93$ & $\mathrm{~S} / 367233,95$ & $\mathrm{~S} / 183616,98$ \\
\hline Amort. & & $\mathrm{S} / 183616,98$ & $\mathrm{~S} / 183616,98$ & $\mathrm{~S} / 183616,98$ & $\mathrm{~S} / 183616,98$ & $\mathrm{~S} / 183616,98$ & $\mathrm{~S} / 183616,98$ \\
\hline Intereses & $\mathrm{S} / 72073,95$ & $\mathrm{~S} / 77119,13$ & $\mathrm{~S} / 64265,94$ & $\mathrm{~S} / 51412,75$ & $\mathrm{~S} / 38559,56$ & $\mathrm{~S} / 25706,38$ & $\mathrm{~S} / 12853,19$ \\
\hline Cuotas & & $\mathrm{S} / 260736,10$ & $\mathrm{~S} / 247882,92$ & $\mathrm{~S} / 235029,73$ & $\mathrm{~S} / 222176,54$ & $\mathrm{~S} / 209323,35$ & $\mathrm{~S} / 196470,16$ \\
\hline Saldo & $\mathrm{S} / 1029627,90$ & $\mathrm{~S} / 918084,88$ & $\mathrm{~S} / 734467,90$ & $\mathrm{~S} / 550850,93$ & $\mathrm{~S} / 367233,95$ & $\mathrm{~S} / 183616,98$ & $\mathrm{~S} /-$ \\
\hline
\end{tabular}

Elaboración propia.

\footnotetext{
${ }^{5}$ Anexo N5: Tasa de Riesgo Perú.

${ }^{6}$ Tasa de interés.

${ }^{7}$ Peso de aporte de los accionistas.

${ }^{8}$ Peso de aporte de los acreedores.

${ }^{9}$ Impuesto a la renta.

${ }^{10}$ Rentabilidad exigida por los accionistas.
} 


\subsubsection{Flujo de fondos económicos}

Tabla 7.15.

Flujo económico del proyecto.

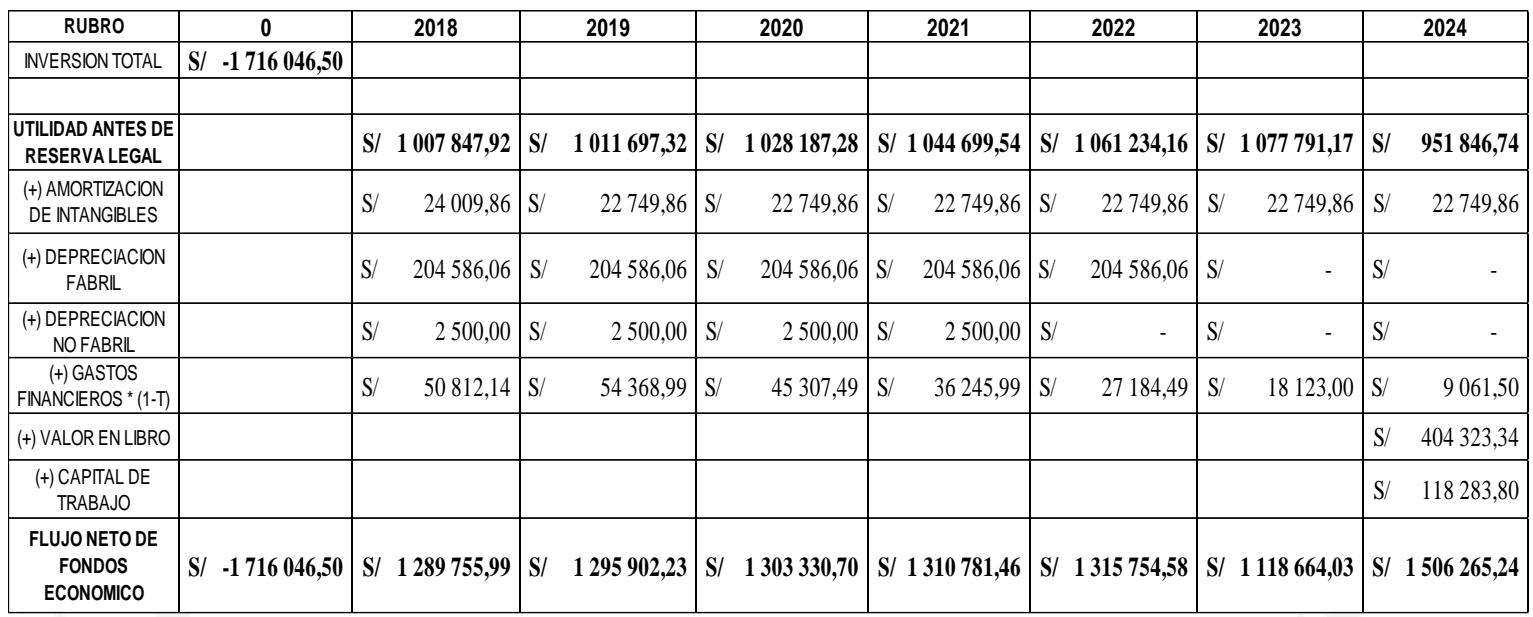

Elaboración propia.

\subsubsection{Flujo de fondos financiero}

Tabla 7.16.

Flujo financiero del proyecto en soles (S/).

\begin{tabular}{|c|c|c|c|c|c|c|c|c|c|c|c|c|c|c|c|}
\hline RUBRO & 2017 & & 2018 & & 2019 & & 2020 & & 2021 & & 2022 & & 2023 & & 2024 \\
\hline $\begin{array}{l}\text { UTILIDAD ANTES DE } \\
\text { RESERVA LEGAL }\end{array}$ & & & 1007847,92 & S/ & 1011697,32 & S/ & 1028187,28 & S/ & 1044699,54 & & 1061234,16 & & 1077791,17 & S/ & 951846,74 \\
\hline $\begin{array}{l}\text { (+) AMORTIZACION DE } \\
\text { INTANGIBLES }\end{array}$ & & S/ & 24009,86 & S/ & 22749,86 & S/ & 22749,86 & S/ & 22749,86 & S/ & 22749,86 & S/ & 22749,86 & S/ & 22749,86 \\
\hline (+) DEPRECIACION FABRIL & & $\mathrm{S} /$ & 204586,06 & $\mathrm{~S} /$ & 204586,06 & $\mathrm{~S} /$ & 204586,06 & $\mathrm{~S} /$ & 204586,06 & S/ & 204586,06 & $\mathrm{~S} /$ & - & $\mathrm{S} /$ & - \\
\hline $\begin{array}{l}\text { (-) AMORTIZACION DE LA } \\
\text { DEUDA }\end{array}$ & & $\mathrm{S} /$ & - & $\mathrm{S} /$ & $-183616,98$ & $\mathrm{~S} /$ & $-183616,98$ & S/ & $-183616,98$ & $\mathrm{~S} /$ & $-183616,98$ & $\mathrm{~S} /$ & $-183616,98$ & $\mathrm{~S} /$ & $-183616,98$ \\
\hline (+) VALOR EN LIBROS & & & & & & & & & & & & & & $\mathrm{S} /$ & 404323,34 \\
\hline (+) CAPITAL DE TRABAJO & & & & & & & & & & & & & & $\mathrm{S} /$ & 118283,80 \\
\hline $\begin{array}{l}\text { FLUJO NETO DE FONDOS } \\
\text { FINANCIERO } \\
\end{array}$ & S/ $\quad-686418,60$ & S/ & 1238943,85 & S/ & 1057916,27 & S/ & 1074406,23 & S/ & 1090918,49 & & 1104953,11 & S/ & 916924,06 & S/ & 1313586,77 \\
\hline
\end{tabular}

Elaboración propia. 


\section{CAPÍTULO VIII: EVALUACIÓN ECONÓMICA Y \\ FINANCIERA DEL PROYECTO}

\subsection{Evaluación económica: VAN, TIR, B/C, PR.}

Tabla 8.1

Evaluación económica.

\begin{tabular}{|l|l|}
\hline VAN ECONOMICO (S/) & 4716877,17 \\
\hline RELACION B / C $=$ & 3,75 \\
\hline TASA INTERNA DE RETORNO ECONOM $=$ & $73,89 \%$ \\
\hline PERIODO DE RECUPERACION (AÑOS) & 1,50 \\
\hline
\end{tabular}

Elaboración propia.

\subsection{Evaluación financiera: VAN, TIR, B/C, PR.}

\section{Tabla 8.2}

Evaluación financiera.

\begin{tabular}{|l|c|}
\hline VAN FINANCIERO $(\mathrm{S} /)=$ & 4823312,77 \\
\hline RELACION B / C = & 8,03 \\
\hline TASA INTERNA DE RETORNO FINAN. = & $171,03 \%$ \\
\hline PERIODO DE RECUPERACION (AÑOS) & 0,61 \\
\hline
\end{tabular}

Elaboración propia.

\subsection{Análisis de los resultados económicos y financieros del proyecto}

Los resultados económicos y financieros obtenidos para este proyecto son viables. En el caso de la evaluación económica nuestro valor actual neto (VAN) es de S/ 4716 877,17 soles que significa que el proyecto es rentable. Además, el valor de la tasa interna de retorno (TIR) es de 73,89\%, es decir, es superior al COK calculado $(9,56 \%)$. Lo que significa que el proyecto es aceptado por inversionistas aun subiendo el costo de oportunidad. Respecto al beneficio-costo, por cada sol invertido se gana S/ 3,75 soles. Considerando que el proyecto tiene 7 años de horizonte, el periodo de recupero es de 1,50 años. Es decir, al segundo año se generaría ganancias.

En el caso de la evaluación financiera, el VAN tiene un valor de S/ 4823 312,77 soles, es decir se generará beneficios. Respecto a la tasa interna de retorno, esta es mucho mayor que la tasa interna de retorno de la evaluación económica con un porcentaje de 
171,03\%. También la relación de beneficio costo aumento, con cada sol invertido se obtiene una ganancia de $\mathrm{S} / \mathrm{8,03}$ y el periodo de recuperación es menor a un año $(0,61$ años).

\subsection{Análisis de sensibilidad del proyecto}

En todo análisis económico y financiero siempre existe incertidumbre asociada a las variables que se manejan en este proyecto.

Mediante el análisis de sensibilidad determinaremos como las variables: precio, cantidad atendida y la tasa del capital del propietario afectan los resultados económicos y financieros.

\section{ESCENARIO 1}

Al modificar el precio, podemos observar lo siguiente:

Tabla 8.3

Análisis de sensibilidad - Precio - Flujo Económico

\begin{tabular}{|c|c|c|c|c|c|}
\hline \multicolumn{7}{|c|}{ Flujo Económico } \\
\hline \% DE VARIACIÓN & VARIABLE & VAN & TIR & B/C & PERIODO DE RECUPERO \\
\hline$-69 \%$ & 802.0 & $-106,435.6$ & $8 \%$ & 0,9 & 7,4 \\
\hline$-68 \%$ & 841.7 & 0.0 & $10 \%$ & 1,0 & 7,0 \\
\hline $0 \%$ & $2,600.0$ & 4716877,1 & $74 \%$ & 3,7 & 1,5 \\
\hline $50 \%$ & $3,900.0$ & 8204339,6 & $116 \%$ & 5,8 & 0,9 \\
\hline $75 \%$ & $4,550.0$ & 9948070,9 & $136 \%$ & 6,8 & 0,8 \\
\hline
\end{tabular}

Elaboración propia. 
Tabla 8.4

Análisis de sensibilidad - Precio - Flujo Financiero

\begin{tabular}{|c|c|c|c|c|c|}
\hline \multicolumn{7}{|c|}{ Flujo Financiero } \\
\hline \% DE VARIACIÓN & VARIABLE & VAN & TIR & B/C & PERIODO DE RECUPERO \\
\hline$-69 \%$ & 802.0 & - & $10 \%$ & 1.0 & 7.0 \\
\hline$-68 \%$ & 841.7 & $106,435.6$ & $15 \%$ & 1.2 & 6.4 \\
\hline $0 \%$ & $2,600.0$ & $4,823,312.7$ & $171 \%$ & 8.0 & 0.6 \\
\hline $50 \%$ & $3,900.0$ & $8,310,775.3$ & $275 \%$ & 13.1 & 0.4 \\
\hline $75 \%$ & $4,550.0$ & $10,054,506.5$ & $327 \%$ & 15.6 & 0.3 \\
\hline
\end{tabular}

Elaboración propia.

Como se puede observar en las tablas anteriores del escenario 1, se puede reducir el precio hasta $68 \%$ para tener un VAN equivalente a 0 en el flujo económico y para el análisis financiero hasta en $-69 \%$. Esto quiere decir que no tendríamos ni ganancias ni perdidas con esta variación negativa. Sin embargo, al subir el precio en un $50 \%$ o $75 \%$ el VAN junto a nuestros demás métricas mejoran sustancialmente; por lo tanto, tendemos a tener unos mejores resultados subiendo los precios si es necesario en el transcurso del proyecto.

\section{ESCENARIO 2}

Al modificar el volumen de toneladas a ser atendidos, podemos observar lo siguiente:

Tabla 8.5

Análisis de sensibilidad - Volumen - Flujo Económico

\begin{tabular}{|c|c|l|c|c|c|}
\hline \multicolumn{7}{|c|}{ Flujo Económico } \\
\hline \% DE VARIACIÓN & VARIABLE & VAN & TIR & B/C & PERIODO DE RECUPERO \\
\hline$-69,7 \%$ & 230.2 & $106,435.6$ & $8 \%$ & 0,9 & 7,4 \\
\hline$-68,2 \%$ & 241.9 & - & $10 \%$ & 1,0 & 7,0 \\
\hline $0,0 \%$ & 759.5 & $4,716,877.1$ & $74 \%$ & 3,7 & 1,5 \\
\hline $50,0 \%$ & $1,139.3$ & $8,177,376.1$ & $115 \%$ & 5,8 & 0,9 \\
\hline $60,0 \%$ & $1,215.2$ & $8,869,475.9$ & $123 \%$ & 6,2 & 0,9 \\
\hline
\end{tabular}

Elaboración propia. 
Tabla 8.6

Análisis de sensibilidad - Volumen - Flujo Financiero

\begin{tabular}{|c|c|c|c|c|c|}
\hline \multicolumn{7}{|c|}{ Flujo Financiero } \\
\hline \% DE VARIACIÓN & VARIABLE & VAN & TIR & B/C & PERIODO DE RECUPERO \\
\hline$-69.7 \%$ & 230.2 & - & $10 \%$ & 1.0 & 7.0 \\
\hline$-68.2 \%$ & 241.9 & $106,435.6$ & $15 \%$ & 1.2 & 6.4 \\
\hline $0.0 \%$ & 759.5 & $4,823,312.7$ & $171 \%$ & 8.0 & 0.6 \\
\hline $50.0 \%$ & $1,139.3$ & $8,283,811.7$ & $274 \%$ & 13.1 & 0.4 \\
\hline $60.0 \%$ & $1,215.2$ & $8,975,911.6$ & $295 \%$ & 14.1 & 0.4 \\
\hline
\end{tabular}

Elaboración propia.

Como se puede observar en las tablas anteriores del escenario 2, se puede reducir el volumen hasta en un $68.2 \%$ para tener un VAN equivalente a 0 en el flujo económico y para el análisis financiero hasta en un $-69.7 \%$. Esto quiere decir que no tendríamos ni ganancias ni perdidas con esta variación negativa. Sin embargo, al subir el volumen en un $50 \%$ o $60 \%$ el VAN junto a nuestros demás métricas mejoran sustancialmente. Además, podemos observar que la variación en volumen no nos daría una mejora notable en cuanto al periodo de recupero de nuestro capital propio.

\section{ESCENARIO 3}

Al modificar la cantidad de aporte al proyecto obtenemos lo siguiente:

\section{Tabla 8.7}

Análisis de sensibilidad - Aporte de deuda / Inversión total - Flujo Económico

\begin{tabular}{|r|r|r|l|r|r|}
\hline \multicolumn{7}{|c|}{ Flujo Económico } \\
\hline \% DE VARIACIÓN & VARIABLE & VAN & \multicolumn{1}{l|}{ TIR } & \multicolumn{1}{l|}{ B/C } & PERIODO DE RECUPERO \\
\hline$-75.0 \%$ & 0.1 & $4,716,877.1$ & $74 \%$ & 3.7 & 1.5 \\
\hline$-50.0 \%$ & 0.2 & $4,716,877.1$ & $74 \%$ & 3.7 & 1.5 \\
\hline $0.0 \%$ & 0.4 & $4,716,877.1$ & $74 \%$ & 3.7 & 1.5 \\
\hline $50.0 \%$ & 0.6 & $4,716,877.1$ & $74 \%$ & 3.7 & 1.5 \\
\hline $100.0 \%$ & 0.8 & $4,716,877.1$ & $74 \%$ & 3.7 & 1.5 \\
\hline
\end{tabular}

Elaboración propia. 
Tabla 8.8

Análisis de sensibilidad - Financiamiento / Inversión total - Flujo Financiero

\begin{tabular}{|r|r|l|l|l|r|}
\hline \multicolumn{7}{|c|}{ Flujo Financiero } \\
\hline \% DE VARIACIÓN & VARIABLE & VAN & TIR & B/C & PERIODO DE RECUPERO \\
\hline$-75.0 \%$ & 0.1 & $4,968,412.5$ & $702 \%$ & 30.0 & 0.2 \\
\hline$-50.0 \%$ & 0.2 & $4,920,045.9$ & $345 \%$ & 15.3 & 0.3 \\
\hline $0.0 \%$ & 0.4 & $4,823,312.7$ & $171 \%$ & 8.0 & 0.6 \\
\hline $50.0 \%$ & 0.6 & $4,726,579.5$ & $115 \%$ & 5.6 & 0.9 \\
\hline $100.0 \%$ & 0.8 & $4,629,846.3$ & $87 \%$ & 4.4 & 1.2 \\
\hline
\end{tabular}

Elaboración propia.

Como se puede observar en las tablas anteriores del escenario 3, en el análisis económico no tenemos variación alguna con la variable de deuda asumida por el accionista; sin embargo, por el lado financiero podemos observar que mientras mayor sea el porcentaje de financiamiento mejor rentabilidad se obtiene proyecto. 


\section{CAPÍTULO IX: EVALUACIÓN SOCIAL DEL PROYECTO}

\subsection{Identificación de las zonas y comunidades de influencia del proyecto}

Para el proyecto es necesario evaluar el impacto social que se tendría; por ello, para empezar identificamos las zonas y comunidades que tendremos influencia directa.

Debido a que nuestra planta se encontrará dando servicio a los acuicultores de conchas de abanico, es necesario que esté localizada en la provincia de Sechura ubicada al sur oeste de Piura.

Figura 9.1

Identificación de las zonas y comunidades de influencia del proyecto
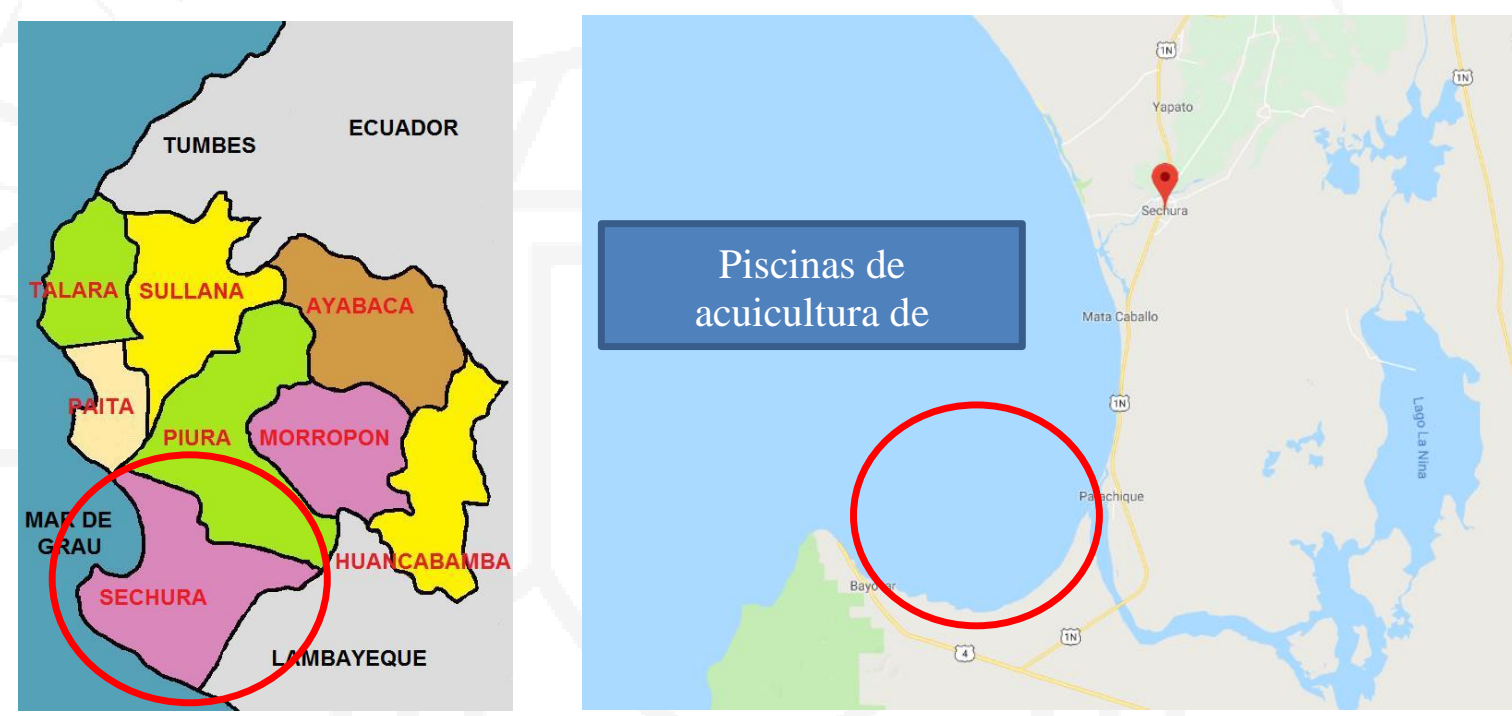

Elaboración propia.

Para poder aportar a la economía de la región, los operarios que se contratarán serán de la misma zona, técnicos especializados en el área de máquinas robotizadas y/o manejo de PLC, para ellos, en la región de Sechura encontramos una escuela de técnicos llamada "Senati", escuela en la cual forman profesionales técnicos para la industria.

Finalmente, como impactos generados en la zona será la generación de ruido, el cual se buscará aislar con paredes y techo. Por otro lado, se generará residuos de agua que se buscará hacer un tratamiento para poder usarlos de riego para los habitantes de la zona. 


\subsection{Impacto en la zona de influencia del proyecto}

Este proyecto busca el desarrollo de todos los eslabones de la cadena de valor, así como la adquisición de la libre competencia en el mercado con proyección internacional.

A través de los dueños de las piscinas conchas de abanico, se fomentará la sostenibilidad de la oferta de congelado IQF usando nitrógeno, principalmente a través de venta del servicio de congelamiento y empacado.

Es así como se buscará elevar la productividad por tonelada exportada, aumentando la calidad del producto y a un precio justo. Además de presentar la posibilidad de poder atender mayor volumen, motivo por el cual el Perú no puede explotar las exportaciones a mayor escala.

\subsection{Impacto social del proyecto}

El impacto social del proyecto que se busca es mejorar la calidad del producto final que se busca exportar, si bien hoy en día se está exportando conchas de abanico congeladas proponemos una nueva tecnología que tiene como principal propiedad mantener las principales propiedades organolépticas al ser descongelados y finalmente consumidas. Además, hoy en día la producción de productos congelados se ve netamente ligada a la producción de los diferentes métodos de congelamiento.

Por otro lado, buscamos ofrecer plazas de trabajo, incrementar los ingresos de los acuicultores de conchas de abanico que a su vez conlleva a un incremento de plazas de trabajo a mayor cantidad de familias indirectamente.

Para poder evaluar nuestro proyecto socialmente consideramos los siguientes indicadores:

1) Valor agregado:

El valor agregado se obtiene de la suma de sueldos y salarios, depreciación de activos tangibles, gastos financieros (intereses de la deuda), utilidad antes de impuesto. Una vez obtenido todo esto se suma obteniendo el valor agregado, posteriormente se trae todo a valor presente y se suma para tenerlo de manera acumulada, utilizando el cok de $9.56 \%$ utilizado en el análisis económico. 
Tabla 9.1

Valor agregado

\begin{tabular}{|c|c|c|c|c|c|c|c|}
\hline Año & $\mathbf{2 0 1 8}$ & $\mathbf{2 0 1 9}$ & $\mathbf{2 0 2 0}$ & $\mathbf{2 0 2 1}$ & $\mathbf{2 0 2 2}$ & $\mathbf{2 0 2 3}$ & $\mathbf{2 0 2 4}$ \\
\hline $\begin{array}{c}\text { Sueldos y } \\
\text { salarios }\end{array}$ & $370,125.00$ & $370,125.00$ & $370,125.00$ & $370,125.00$ & $370,125.00$ & $370,125.00$ & $370,125.00$ \\
\hline Depreciación & $204,586.06$ & $204,586.06$ & $204,586.06$ & $204,586.06$ & $204,586.06$ & 0 & 0 \\
\hline $\begin{array}{c}\text { Gastos } \\
\text { financieros }\end{array}$ & $50,812.14$ & $54,368.99$ & $45,307.49$ & $36,245.99$ & $27,184.49$ & $18,123.00$ & $9,061.50$ \\
\hline UAIR & $1,429,571.49$ & $1,435,031.64$ & $1,458,421.67$ & $1,481,843.31$ & $1,505,296.66$ & $1,528,781.80$ & $1,350,137.18$ \\
\hline $\begin{array}{c}\text { Valor } \\
\text { agregado }\end{array}$ & $\mathbf{1 , 8 7 5 , 7 7 0 . 9 8}$ & $\mathbf{1 , 7 1 9 , 6 0 6 . 7 7}$ & $\mathbf{1 , 5 8 0 , 4 5 2 . 5 7}$ & $\mathbf{1 , 4 5 2 , 5 1 1 . 9 3}$ & $\mathbf{1 , 3 3 4 , 8 8 5 . 5 6}$ & $\mathbf{1 , 1 0 8 , 4 5 1 . 5 7}$ & $\mathbf{9 1 2 , 6 6 6 . 5 3}$ \\
\hline $\begin{array}{c}\text { Valor } \\
\text { agregado } \\
\text { acumulado }\end{array}$ & $\mathbf{1 , 8 7 5 , 7 7 0 . 9 8}$ & $\mathbf{3 , 5 9 5 , 3 7 7 . 7 5}$ & $\mathbf{5 , 1 7 5 , 8 3 0 . 3 2}$ & $\mathbf{6 , 6 2 8 , 3 4 2 . 2 5}$ & $\mathbf{7 , 9 6 3 , 2 2 7 . 8 1}$ & $\mathbf{9 , 0 7 1 , 6 7 9 . 3 8}$ & $\mathbf{9 , 9 8 4 , 3 4 5 . 9 1}$ \\
\hline
\end{tabular}

Elaboración propia.

Relación producto / capital:

La relación producto capital conocido como coeficiente de capital nos permite medir el grado de relación inversa entre valor agregado contra la inversión total con la finalidad de medir si tendremos una relación positiva respecto a la inversión.

\section{$\frac{\text { Valor agregado acumulado }}{\text { Inversión total }}=$ Relación producto capital}

Entonces tomando la data obtenida anteriormente en el Tabla 9.1:

$$
\frac{9984345,91}{1716046,5}=5,81
$$

Esto nos indica que tenemos una relación positiva que a su vez dice que el valor agregado es 5.81 veces más que la inversión.

2) Densidad de capital:

La densidad de capital se calcula de la siguiente manera:

$$
\frac{\text { Inversion total }}{\text { Total de trabajadores }}=\text { Densidad de capital }
$$

Entonces tenemos lo siguiente:

$$
\frac{1716046,5}{8}=214505,8
$$


Esto quiere decir que se ha invertido 214505,8 por cada puesto; sin embargo, debemos de considerar que las máquinas que se comprarán son automatizadas utilizando PLC en su mayoría.

3) Intensidad de capital:

La intensidad de capital se calcula de la siguiente manera:

$$
\frac{\text { Inversion total }}{\text { Valor agregado actual }}=\text { Intensidad de capital }
$$

Utilizando el año 7 para el cálculo obtenemos:

$$
\frac{1716046,5}{9984345,91}=0,17
$$

Esto nos indica que por cada 0,17 sol invertido se generará 1 sol de valor agregado; es decir, se invierte menos y tenemos mayor valor agregado. 


\section{CONCLUSIONES}

- Es factible la instalación de una planta productora de nitrógeno para la congelación criogénica de conchas de abanico, ya que, analizando los flujos económicos y financieros obtenemos un VAN positivo, una tasa interna de retorno (TIR) mayor al costo de oportunidad de capital (COK) y un beneficio costo mayor a 1. De esta forma, concluimos que es un proyecto viable económicamente.

- La instalación de la planta de nitrógeno para el servicio de congelamiento es técnica y medio ambientalmente viable, pues existe la tecnología IQF que es el congelamiento rápido con nitrógeno. Además, se existe una planta capaz de obtener nitrógeno en grandes escalas desde el aire del medio ambiente. Esto nos permite reducir los costos de adquisición de nitrógeno líquido. Es considerado medio ambientalmente viable debido a que durante el proceso solo existe un punto crítico en la producción de nitrógeno.

- La instalación de planta de nitrógeno para el servicio de congelamiento se localizará en el departamento de Piura, Sechura de acuerdo al método de Gibson y Brown. Pues, allí se encuentra el criadero de conchas de abanico más grande a nivel nacional (tiene el $80 \%$ de producción de conchas de abanico), los costos identificados son más económicos lo que significaría una menor inversión para el proyecto. 


\section{RECOMENDACIONES}

- Se recomienda tener contacto directo con empresas productoras de conchas de abanico para tener una demanda más precisa, además tener en cuenta los fenómenos existentes en el país para elaborar plan de contingencias para una posible caída de la producción de conchas de abanico.

- $\quad$ Para poder planear un horizonte con una mira optimista, se recomienda optar por una planta productora de mayor capacidad de la demanda, con la finalidad de poder atender a más porcentaje del mercado, mientras más sea la capacidad de atención, tendremos un margen de ganancia mayor, además de contar con precios altamente atractivos en el mercado.

- Se recomienda además, poder contratar personal de la zona, brindar empleo a los técnicos que estudian en el instituto de Senati, brindándoles capacitaciones para el uso de la maquinaria, así podremos tener personal competente.

- Tener en cuenta que al tener fenómenos como el niño, tendremos años de atención en que la demanda se verá altamente variada, es así que se recomienda tener una extra caja para los años que se verán afectados. 


\section{REFERENCIAS}

Acedo, J. (Diciembre, 2015.). Efecto de la temperatura en respuestas fisiológicas de la concha de abanico Argopecten purpuratus/Effect of temperature on physiological responses of Peruvian scallop Argopecten purpuratus. Recuperado de http://search.proquest.com/docview/1767639288/dec6d5edbf6e4eb1pq/1?accou ntid $=45277$.

Bank, The Wold. (Diciembre de 2013). The Wold Bank. FISH TO 2030 Prospects for Fisheries and Aquaculture, 44-45.

Barrera, A. (2014). Métodos de congelamiento. De Universidad de El Salvador. Recuperado de https://es.scribd.com/doc/37304554/metodos-de-congelamiento.

Chambilla Tuyo, W. (2010). Efecto del método de congelación sobre las características fisicoquímicas y organolépticas de la carne de cuy (Cavia porcellus) (tesis para optar el título profesional de Ingeniero Agroindustrial). Recuperado de http://repositorio.unap.edu.pe/bitstream/handle/unap/3363/chambilla_tuyo_walt er.pdf?sequence $=1 \&$ isallowed $=\mathrm{y}$

Dionicio, J. (2015). Efecto de la temperatura en respuestas fisiológicas de la concha de abanico- Argopecten purpuratus. Revista peruana de biología, 22, 329-334. Recuperado de http://dx.doi.org/10.15381/rpb.v22i3.11439

García, R. (Enero, 2017). Diseño de una estrategia de control difuso aplicada al proceso de ultra congelación de alimentos/Design of fuzzy control strategy applied to food process deep freeze. Recuperado de http://search.proquest.com/docview/1879086954/7C2753EFB21E4125PQ/1?acc ountid $=45277$

INEI. (2012). Sistema de consultas de resultados censales. 2017, de INEI. Recuperado de http://censos.inei.gob.pe/cenagro/tabulados/?id=CensosNacionales.

Loaiza, Karen L; Erazo, Stephanía C; Velez, Carlos P. (2016). Congelación de arveja empleando un sistema de congelación individual, IQF/Freezing peas using an individual freezing system, Iqf. Recuperado de http://search.proquest.com/docview/1783661210/9b1bbefa78c940e0pq/1?accou ntid $=45277$

Mendo, J. (2003). El impacto del niño sobre la producción de concha de abanico en Bahía Independencia, Pisco, Perú. Ecología aplicada, 2(1), 51-57. doi: 10.21704/rea.v2i1-2.247

Ministerio de la Producción. (2015). Anuario estadístico pesquero y acuícola. 2017, de Ministerio de la Producción. Recuperado de http://www.produce.gob.pe/documentos/estadisticas/anuarios/anuarioestadistico-pesca-2015.pdf 
Morales Landeo, R. (1986). Cálculo y diseño de un equipo experimental para la congelación de alimentos mediante nitrógeno líquido (tesis para optar el título profesional de Ingeniero Mecánico). Universidad Nacional de Ingeniería.

Morán, M. (2014). Tecnologías para el Procesamiento de Alimentos para Pescados y Mariscos.

Ortega-Villalba, K J; Vélez-Pasos, C A; Ayala-Aponte, A. (2016). Efecto de las condiciones de operación sobre la calidad de melon (cucumis melo) congelado por Iqf/Effect of operating conditions on quality of frozen melon (cucumis melo) by iqf. Recuperado de http://search.proquest.com/docview/1783661772/9b1bbefa78c940e0pq/4?accou ntid $=45277$

Pesquera exalmar s.a.a. (2016). Superamos nuevos desafios . Memoria anual 2016, 156.

Rudolph Delgado, F. (1989). Análisis tecnológico del congelamiento con nitrógeno de productos marinos de consumo humano (tesis para optar el título profesional de Ingeniero Industrial). Universidad de Lima.

Ramos Gómez, G. (2013). Diseño de un congelador continuo individual iqf on una capacidad de $200 \mathrm{~kg} / \mathrm{hr}$ de espárragos (tesis para optar el título profesional de Ingeniero Mecánico). Pontificia Universidad Católica del Perú.

Sánchez Cuellar, L. (2017). Análisis de la cadena de valor de la concha de abanico en la Bahía de Sechura (tesis para optar el título de Ingeniero Pesquero). Universidad Nacional Agraria La Molina. 


\section{BIBLIOGRAFÍA}

Alvarado, I. (2017). Preocupa contaminación de agua en tres ciudades. Abril 24, 2014, de La opinión. Recuperado de http://search.proquest.com/docview/817302468/f6b21a103de4551pq/1 ?accounti $\mathrm{d}=45277$.

Ballesteros, L. (20/04/2017). Enfriamiento por aire forzado. Mundo HVACR, 1, 1.

Barletta, F., Pereira, M., Robert, V., y Yoguel, G. (2013). Argentina: dinámica reciente del sector de software y servicios informáticos. Revista de la CEPAL(110), 137155 .

Carbosystem. (26 de Agosto de 2017). ¿Cómo funciona un compresor de aire? Recuperado de http://carbosystem.com/funcionamiento-compresor-aire/.

Choy, M., y Chang, G. (2014). Medidas macroprudenciales aplicadas en el Perú. Lima: Banco Central de Reserva del Perú. Recuperado de http://www.bcrp.gob.pe/docs/publicaciones/documentos-detrabajo/2014/documento-de-trabajo-07-2014.pdf.

Diario Gestión. (2014). Empresa de la división pesca del grupo Wong lanzará emisión privada de bonos de titulización. 2017, de Diario Gestión. Recuperado de http://gestion.pe/tu-dinero/empresa-division-pesca-grupo-wong-lanzaraemision-privada-bonos-titulizacion-2090165.

El Comercio. (2015). Sechura podrá seguir enviando conchas de abanico a UE. 2017, de El comercio. Recuperado de http://search.proquest.com/docview/1750375207/117508DD2A3F4126PQ/2?ac countid $=45277$.

García Nieto, J. P. (2013). Consturye tu Web comercial: de la idea al negocio. Madrid: RA-MA.

Imarpe. (2017). Archivo diario de tsm - mar peruano. 2017, de IMARPE. Recuperado de http://satelite.imarpe.gob.pe/uprsig/sst_prov.html.

Junio, Nelio (comunicación personal, 06 de Mayo de 2017).

Morán, M. (2014). Tecnologías para el Procesamiento de Alimentos para Pescados y Mariscos. 20/04/2017

Morán, Miguel (comunicación personal, 15 de Abril de 2017) 
Pérez, E. (2016). Crecimiento, supervivencia e influencia de factores ambientales en tres cohortes de la ostra perla Pinctada imbricata, en cultivo suspendido en el Golfo de Cariaco, Venezuela/Growth, survival and environmental effects on three cohorts of the pearl oyster Pinctada imbricata, under suspended culture at Cariaco Gulf, Venezuela. 2017, de Latin American Journal of Aquatic Research; Valparaiso. Recuperado de http://search.proquest.com/docview/1786822256/b2a43564a8154e9dpq/5?accou ntid $=45277$.

Posada, C. (2017). Niño Costero afecta al 80\% de la producción peruana de conchas de abanico. 2017, de Diario Gestión. Recuperado de: http://gestion.pe/economia/nino-costero-afecta-al-80-produccion-peruanaconchas-abanico-2186016.

Quiminet. (14 de Diciembre de 2006). ¿Qué es un Chiller? Recuperado de https://www.quiminet.com/articulos/que-es-un-chiller-17260.htm.

Ravina Gómez, E., Hung, L., Astete León, R., y Soria, J. (2000). Propuesta de un manual de aseguramiento de la calidad y procedimiento según la norma NTP ISO 9002:1995 para el frigorífico de agropecuaria Esmeralda S.A. Universidad Nacional Agraria La Molina.

Sánchez, L. (2015). Análisis de la cadena de valor de la concha de abanico en la bahía de Sechura. Universidad Nacional Agraria La Molina.

Sanipes. (2015). Plantas de Procesamiento Primario de Moluscos Bivalvos Habilitadas. 2017, de SANIPES. Recuperado de http://www.sanipes.gob.pe/frontend/plantasbivalvos.php.

Tixuz. (2017). Inmuebles y venta de Terrenos. 2017. Recuperado de https://pe.tixuz.com/inmuebles/venta/terreno/oportunidad-de-inversi\%C3\%93nterreno-de-10071-60- $\mathrm{m}^{2}$--ubicado-en-zona-industrial-en-carretera-bayobar-km/2262554?utm_source=casas.mitula.pe\&utm_medium=referra.

UIBB. (6 de Feb de 2017). UIBB. Recuperado de http://uibb.org.ar/acuiculturaactualidad-tendencias-proyecciones/

Urbania. (2017). Venta de terrenos. 2017- Recuperado de http://urbania.pe/.

Vidaurre, Jose (comunicación personal, 22 de Abril de 2017).

Vzyonindustrial. (26 de Agosto de 2017). Torre de enfriamiento. Recuperado de http://vizyonindustrial.com/torre-de-enfriamiento-vs-chiller-de-enfriamiento/.

Wittmann, R. (2006). ¿Hubo una revolución en la lectura a finales del siglo XVIII? En G. Cavallo, y R. Chartier, Historia de la lectura en el mundo occidental (págs. 435-472). México D.F.: Santillan. 
ANEXOS 


\section{Anexo $N^{\circ} 1$ : Resultados De Encuesta}

Pregunta 1:

¿La ubicación de su criadero se encuentra en la bahía de Sechura? (si/no)

\begin{tabular}{|l|l|}
\hline $\mathbf{1}$ & si \\
\hline $\mathbf{2}$ & si \\
\hline & \\
\hline $\mathbf{4}$ & si \\
\hline $\mathbf{5}$ & si \\
\hline $\mathbf{6}$ & si \\
\hline $\mathbf{7}$ & si \\
\hline $\mathbf{8}$ & si \\
\hline $\mathbf{9}$ & si \\
\hline
\end{tabular}

Pregunta 2:

¿Conoce el servicio de congelamiento criogénico que utiliza nitrógeno?

\begin{tabular}{|l|l|}
\hline $\mathbf{1}$ & si \\
\hline $\mathbf{2}$ & si \\
\hline $\mathbf{3}$ & no \\
\hline $\mathbf{4}$ & no \\
\hline $\mathbf{5}$ & no \\
\hline $\mathbf{6}$ & si \\
\hline $\mathbf{7}$ & si \\
\hline $\mathbf{8}$ & no \\
\hline $\mathbf{9}$ & si \\
\hline
\end{tabular}

Pregunta 3:

¿Contrataría el servicio de congelamiento criogénico usando nitrógeno?

\begin{tabular}{|l|l|}
\hline $\mathbf{1}$ & si \\
\hline $\mathbf{2}$ & si \\
\hline $\mathbf{3}$ & no \\
\hline $\mathbf{4}$ & si \\
\hline $\mathbf{5}$ & no \\
\hline $\mathbf{6}$ & si \\
\hline $\mathbf{7}$ & si \\
\hline $\mathbf{8}$ & no \\
\hline $\mathbf{9}$ & si \\
\hline
\end{tabular}


Pregunta 4:

¿Cuál es el grado de intensidad de su posible contratación de este servicio? (escala 1 a 5)

\begin{tabular}{|l|l|l|}
\cline { 2 - 3 } \multicolumn{1}{c|}{} & Empresa & Intensidad \\
\hline si & 1 & 5 \\
\hline si & 2 & 4 \\
\hline no & 3 & 3 \\
\hline si & 4 & 3 \\
\hline no & 5 & 2 \\
\hline si & 6 & 3 \\
\hline si & 7 & 4 \\
\hline no & 8 & 2 \\
\hline si & 9 & 3 \\
\hline
\end{tabular}

Pregunta 5:

¿Cuánto puede producir diariamente? (TON)

\begin{tabular}{|l|l|}
\hline Empresa & Producción diaria (Ton) \\
\hline $\mathbf{1}$ & 15 \\
\hline $\mathbf{2}$ & 12 \\
\hline $\mathbf{4}$ & 15 \\
\hline $\mathbf{6}$ & 13 \\
\hline $\mathbf{7}$ & 18 \\
\hline $\mathbf{9}$ & 13 \\
\hline
\end{tabular}

Pregunta 6:

¿Qué tecnología usa actualmente para este proceso?

\begin{tabular}{|l|l|}
\hline $\mathbf{1}$ & contacto directo con freón \\
\hline $\mathbf{2}$ & $\begin{array}{l}\text { contacto directo con } \\
\text { amoniaco }\end{array}$ \\
\hline $\mathbf{3}$ & contacto directo con freón \\
\hline $\mathbf{4}$ & $\begin{array}{l}\text { contacto directo con } \\
\text { amoniaco }\end{array}$ \\
\hline $\mathbf{5}$ & $\begin{array}{l}\text { contacto directo con } \\
\text { amoniaco }\end{array}$ \\
\hline $\mathbf{6}$ & contacto directo con freón \\
\hline $\mathbf{7}$ & $\begin{array}{l}\text { contacto directo con } \\
\text { amoniaco }\end{array}$ \\
\hline $\mathbf{8}$ & $\begin{array}{l}\text { contacto directo con } \\
\text { amoniaco }\end{array}$ \\
\hline $\mathbf{9}$ & contacto directo con freón \\
\hline
\end{tabular}


Pregunta 7:

¿Cuánto estaría dispuesto a pagar por dicho servicio? (500-1000 dólares x tonelada).

\begin{tabular}{|l|r|}
\hline Empresa & $\begin{array}{l}\text { Precio/ } \\
\text { tonelada }\end{array}$ \\
\hline $\mathbf{1}$ & 950 \\
\hline $\mathbf{2}$ & 880 \\
\hline $\mathbf{3}$ & 860 \\
\hline $\mathbf{4}$ & 900 \\
\hline $\mathbf{5}$ & 1000 \\
\hline $\mathbf{6}$ & 800 \\
\hline Promedio & 898.3 \\
\hline
\end{tabular}

Pregunta 8:

¿Cómo le gustaría que se le entregue el producto congelado?

\begin{tabular}{|l|l|}
\hline $\mathbf{1}$ & embolsado \\
\hline $\mathbf{2}$ & embolsado \\
\hline $\mathbf{3}$ & embolsado \\
\hline $\mathbf{4}$ & javas \\
\hline $\mathbf{5}$ & embolsado \\
\hline $\mathbf{6}$ & javas \\
\hline $\mathbf{7}$ & embolsado \\
\hline $\mathbf{8}$ & javas \\
\hline $\mathbf{9}$ & embolsado \\
\hline
\end{tabular}




\section{Anexo N²: Desembarque De Conchas De Abanico 2007-16}

Abalón

Caracol

Choro

Conchas de Abanico

Macha

Almeja

Calamar

Potd"

Pulpo

Otros moluscos $\begin{array}{llllllllll}2535 & 2757 & 274 & 2237 & 1195 & 1312 & 739 & 1341 & 480 & 573\end{array}$

$\begin{array}{llllllllll}2838 & 4061 & 3308 & 2389 & 2894 & 2821 & 2127 & 3302 & 2799 & 2571\end{array}$

$\begin{array}{llllllllll}8769 & 8894 & 11072 & 9022 & 9171 & 8451 & 6954 & 5866 & 4476 & 3682\end{array}$

$\begin{array}{llllllllll}24768 & 19618 & 26478 & 62827 & 93050 & 39678 & 91474 & 56820 & 30396 & 13343\end{array}$

$\begin{array}{llllllllll}2793 & 1906 & 326 & 765 & 491 & 760 & 1227 & 1207 & 1697 & 610\end{array}$ $\begin{array}{llllllllll}14769 & 4654 & 13178 & 4798 & 2251 & 20483 & 16611 & 10986 & 18330 & 6924\end{array}$

$\begin{array}{llllllllll}427591 & 533414 & 411805 & 369822 & 404730 & 497462 & 451061 & 556156 & 513796 & 323337\end{array}$

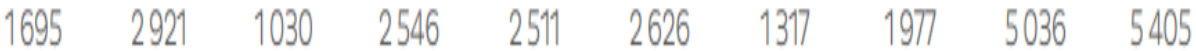
$\begin{array}{llllllllll}4823 & 5465 & 2525 & 3509 & 6046 & 8310 & 2039 & 3314 & 2242 & 845\end{array}$

Fuente: Ministerio de la Producción (2015) 


\section{Anexo N³: Proyección De Población Y Consumo De Pescados}

\subsection{CONSUMPTION}

In all of the simulations presented in this study, the drivers of change on the demand side are specified according to the income and population growth trends as found in table 3.6. According to the World Bank (2012), between 2010 and 2030, China's gross domestic product (GDP) per capita is expected to almost triple. Income levels in IND and SEA are expected to almost double. On the other hand, the UN (2011) projects the highest population growth in AFR. Between 2010 and 2030, the population in AFR is projected to increase by 57.6 percent, or at the annual rate of 2.3 percent.

Currently, about 80 percent of the fish produced globally is consumed by people as food. The model results suggest that this proportion is not expected to change into 2030. Given that the production is expected to grow by 23.6 percent during the $2010-30$ period (table 3.1) and the world population is projected to grow at 20.2 percent over the same period (table 3.6), the world will likely manage to increase the fish consumption level, on average.

As seen in table 3.7, at the global level, annual per capita fish consumption is projected to increase from 17.2 kilograms in 2010 to
18.2 kilograms in 2030. The trend in per capita consumption, however, is diverse across regions. In general, per capita fish consumption is expected to grow fast in the regions with the highest projected income growth (CHN, IND, SEA). However, the highest growth in fish consumption is expected in SAR, where per capita fish consumption is expected to grow at 1.8 percent per year over the 2010-30 period. In all of these regions, however, the growth in per capita fish consumption is expected to slow relative to the $2000-06$ period.

Japan, traditionally the world's largest consumer of seafood, is the only region where per capita fish consumption declined over the 2000-06 period (it declined from 67.7 kilograms to 59.2 kilograms) The model predicts a continued decline, but at a slower rate. A declining trend of fish consumption is also projected for EAP, LAC, and AFR.

Per capita fish consumption is projected to decline in AFR. Starting from a modest level of fish consumption in 2006-7.5 kilograms, which was the second lowest, after IND (5.0 kilograms) - per capita fish consumption in AFR is projected to decline to 5.6 kilograms by 2030.

TABLE 3.6: Income and Population Growth Assumptions

\begin{tabular}{|c|c|c|c|c|c|c|}
\hline & \multicolumn{2}{|c|}{ GDP PER CAPITA } & \multicolumn{4}{|c|}{ POPULATION } \\
\hline & \multirow{2}{*}{$\begin{array}{l}\begin{array}{l}\text { GDP/C } \\
\text { (US\$) }\end{array} \\
2010 \\
\text { (DATA) } \\
\end{array}$} & \multirow{2}{*}{$\begin{array}{c}\% \\
\text { CHANGE } \\
2010-30 \\
\end{array}$} & \multirow{2}{*}{$\begin{array}{c}\begin{array}{c}\text { POPULATION } \\
\text { (MILLIONS) }\end{array} \\
2010 \\
\text { (DATA) }\end{array}$} & \multirow{2}{*}{$\begin{array}{c}\% \\
\text { CHANGE } \\
2010-30 \\
\end{array}$} & \multicolumn{2}{|c|}{$\begin{array}{c}\text { SHARE IN } \\
\text { GLOBAL TOTAL }\end{array}$} \\
\hline & & & & & $\begin{array}{l}2010 \\
\text { (DATA) }\end{array}$ & $\begin{array}{c}2030 \\
\text { (PROJECTION) }\end{array}$ \\
\hline Global total/average & 6,941 & $17.4 \%$ & 6,941 & $20.2 \%$ & $100 \%$ & $100 \%$ \\
\hline ECA & 12,906 & $40.5 \%$ & 891 & $3.3 \%$ & $12.8 \%$ & $11.0 \%$ \\
\hline NAM & 36,764 & $25.2 \%$ & 347 & $16.3 \%$ & $5.0 \%$ & $4.8 \%$ \\
\hline LAC & 4,986 & $32.2 \%$ & 586 & $18.5 \%$ & $8.4 \%$ & $8.3 \%$ \\
\hline EAP & 13,724 & $48.6 \%$ & 110 & $12.8 \%$ & $1.6 \%$ & $1.5 \%$ \\
\hline CHN & 2,797 & $177.0 \%$ & 1,355 & $3.4 \%$ & $19.5 \%$ & $16.8 \%$ \\
\hline JAP & 40,092 & $22.4 \%$ & 126 & $-5.4 \%$ & $1.8 \%$ & $1.4 \%$ \\
\hline SEA & 1,875 & $88.4 \%$ & 550 & $18.7 \%$ & $7.9 \%$ & $7.8 \%$ \\
\hline SAR & 606 & $51.1 \%$ & 460 & $28.8 \%$ & $6.6 \%$ & $7.1 \%$ \\
\hline IND & 828 & $92.6 \%$ & 1,241 & $23.7 \%$ & $17.9 \%$ & $18.4 \%$ \\
\hline MNA & 3,380 & $29.0 \%$ & 382 & $31.8 \%$ & $5.5 \%$ & $6.0 \%$ \\
\hline AFR & 646 & $77.3 \%$ & 874 & $57.6 \%$ & $12.6 \%$ & $16.5 \%$ \\
\hline ROW & 7,103 & $79.0 \%$ & 19 & $13.2 \%$ & $0.3 \%$ & $0.3 \%$ \\
\hline
\end{tabular}

Sources: UN 2011; World Bank 2012.

Note: ECA = Europe and Central Asia; NAM = North America; $\mathrm{LAC}=$ Latin America and Caribbean; $C H N=C$ hina $J A P=$ Japan; EAP = other East Asia and the Pacific; SEA = Southeast Asia; IND = India; SAR = other South Asia; MNA = Middle East and North Africa; AFR = Sub-Saharan Africa; ROW = rest of the world. 
Projections on per capita fish consumption in table 3.7 combined with the population growth projections in table 3.6 determine the aggregate projected trends seen in table 3.8. As with the world population, global fish consumption is also heavily centered in Asia. The Asian regions are also projected to have steady and rapid consumption growth over the period, with IND and SAR expecting

TABLE 3.7: Projected Per Capita Fish Consumption by Region

\begin{tabular}{l|c|c|c|c|c|c|c}
\hline & \multicolumn{2}{|c|}{ DATA (KG/PERSN/YEAR) } & \multicolumn{2}{|c|}{ PROJECTION (KG/PERSON/YEAR) } & \multicolumn{2}{c}{ ANNUAL GROWTH RATE } \\
\hline & $\mathbf{2 0 0 0}$ & $\mathbf{2 0 0 6}$ & $\mathbf{2 0 1 0}$ & $\mathbf{2 0 2 0}$ & $\mathbf{2 0 3 0}$ & $\mathbf{2 0 0 0 - 0 6 ^ { \circ }}$ & $\mathbf{2 0 1 0 - \mathbf { 3 0 }}$ \\
\hline Global average & $\mathbf{1 5 . 7}$ & $\mathbf{1 6 . 8}$ & $\mathbf{1 7 . 2}$ & $\mathbf{1 8 . 0}$ & $\mathbf{1 8 . 2}$ & $\mathbf{1 . 1 \%}$ & $\mathbf{0 . 3 \%}$ \\
\hline ECA & 17.0 & 18.5 & 17.4 & 17.2 & 18.2 & $1.5 \%$ & $0.2 \%$ \\
\hline NAM & 21.8 & 24.3 & 22.9 & 24.5 & 26.4 & $1.8 \%$ & $0.7 \%$ \\
\hline LAC & 8.8 & 9.4 & 8.4 & 8.0 & 7.5 & $1.1 \%$ & $-0.6 \%$ \\
\hline EAP & 32.1 & 36.5 & 27.1 & 26.1 & 23.8 & $2.2 \%$ & $-0.7 \%$ \\
\hline CHN & 24.4 & 26.6 & 32.6 & 37.8 & 41.0 & $1.4 \%$ & $1.2 \%$ \\
\hline JAP & 67.7 & 59.2 & 64.7 & 63.7 & 62.2 & $-2.2 \%$ & $-0.2 \%$ \\
\hline SEA & 24.6 & 27.9 & 25.8 & 28.3 & 29.6 & $2.1 \%$ & $0.7 \%$ \\
\hline SAR & 8.5 & 11.4 & 11.0 & 13.4 & 15.7 & $5.1 \%$ & $1.8 \%$ \\
\hline IND & 4.5 & 5.0 & 5.6 & 6.2 & 6.6 & $1.7 \%$ & $0.8 \%$ \\
\hline MNA & 8.3 & 10.2 & 9.3 & 9.4 & 9.4 & $3.5 \%$ & $0.0 \%$ \\
\hline AFR & 7.1 & 7.5 & 6.8 & 6.1 & 5.6 & $0.8 \%$ & $-1.0 \%$ \\
\hline ROW & 18.4 & 20.1 & 9.4 & 9.6 & 9.6 & $1.5 \%$ & $0.1 \%$ \\
\hline SO & & & & & & \\
\hline
\end{tabular}

Sources: FAO FIPS FBS and IMPACT model projections.

Note: $\mathrm{ECA}=$ Europe and Central Asia; NAM = North America; $\mathrm{LAC}=$ Latin America and Caribbean; $\mathrm{CHN}=\mathrm{China} ; \mathrm{JAP}$

Japan; EAP = other East Asia and the Pacific; SEA = Southeast Asia; IND = India; SAR = other South Asia; MNA = Middle East and North Africa; AFR = Sub-Saharan Africa; ROW = rest of the world.

'Based on data.

bBased on projections.

TABLE 3.8: Projected Total Food Fish Consumption by Region

\begin{tabular}{l|c|r|r|r|c|c|c}
\hline & DATA (000 TONS) & \multicolumn{2}{|c|}{ PROJECTION (O00 TONS) } & \multicolumn{3}{c|}{ SHARE IN GLOBAL TOTAL } & \% CHANGE \\
\hline & $\mathbf{2 0 0 6}$ & $\mathbf{2 0 1 0}$ & $\mathbf{2 0 2 0}$ & $\mathbf{2 0 3 0}$ & $\mathbf{2 0 1 0}$ (PROJECTION) & $\mathbf{2 0 3 0}$ (PROJECTION) & $\mathbf{2 0 1 0 - 3 0}$ \\
\hline Global total & $\mathbf{1 1 1 , 6 9 7}$ & $\mathbf{1 1 9 , 4 8 0}$ & $\mathbf{1 3 8 , 1 2 4}$ & $\mathbf{1 5 1 , 7 7 1}$ & $\mathbf{1 0 0 . 0 \%}$ & $\mathbf{1 0 0 . 0 \%}$ & $\mathbf{2 7 . 0 \%}$ \\
\hline ECA & 16,290 & 15,488 & 15,720 & 16,735 & $13.0 \%$ & $11.0 \%$ & $8.1 \%$ \\
\hline NAM & 8,151 & 7,966 & 9,223 & 10,674 & $6.7 \%$ & $7.0 \%$ & $34.0 \%$ \\
\hline LAC & 5,246 & 4,900 & 5,165 & 5,200 & $4.1 \%$ & $3.4 \%$ & $6.1 \%$ \\
\hline EAP & 3,866 & 2,975 & 3,068 & 2,943 & $2.5 \%$ & $1.9 \%$ & $-1.1 \%$ \\
\hline CHN & 35,291 & 44,094 & 52,867 & 57,361 & $36.9 \%$ & $37.8 \%$ & $30.1 \%$ \\
\hline JAP & 7,485 & 8,180 & 7,926 & 7,447 & $6.8 \%$ & $4.9 \%$ & $-9.0 \%$ \\
\hline SEA & 14,623 & 14,175 & 17,160 & 19,327 & $11.9 \%$ & $12.7 \%$ & $36.3 \%$ \\
\hline SAR & 4,940 & 5,063 & 7,140 & 9,331 & $4.2 \%$ & $6.1 \%$ & $84.3 \%$ \\
\hline IND & 5,887 & 6,909 & 8,688 & 10,054 & $5.8 \%$ & $6.6 \%$ & $45.5 \%$ \\
\hline MNA & 3,604 & 3,571 & 4,212 & 4,730 & $3.0 \%$ & $3.1 \%$ & $32.5 \%$ \\
\hline AFR & 5,947 & 5,980 & 6,758 & 7,759 & $5.0 \%$ & $5.1 \%$ & $29.7 \%$ \\
\hline ROW & 367 & 179 & 198 & 208 & $0.2 \%$ & $0.1 \%$ & $15.7 \%$ \\
\hline SOA & & & & & &
\end{tabular}

Sources: FAO FIPS FBS and IMPACT model projections.

Note: ECA = Europe and Central Asia; NAM = North America; $L A C=$ Latin America and Caribbean; CHN = China; JAP = Japan;

EAP = other East Asia and the Pacific; SEA = Southeast Asia; IND = India; SAR = other South Asia; MNA = Middle East and

North Africa; AFR = Sub-Saharan Africa; ROW = rest of the world 


\section{Anexo N4: Características De La Concha De Abanico}

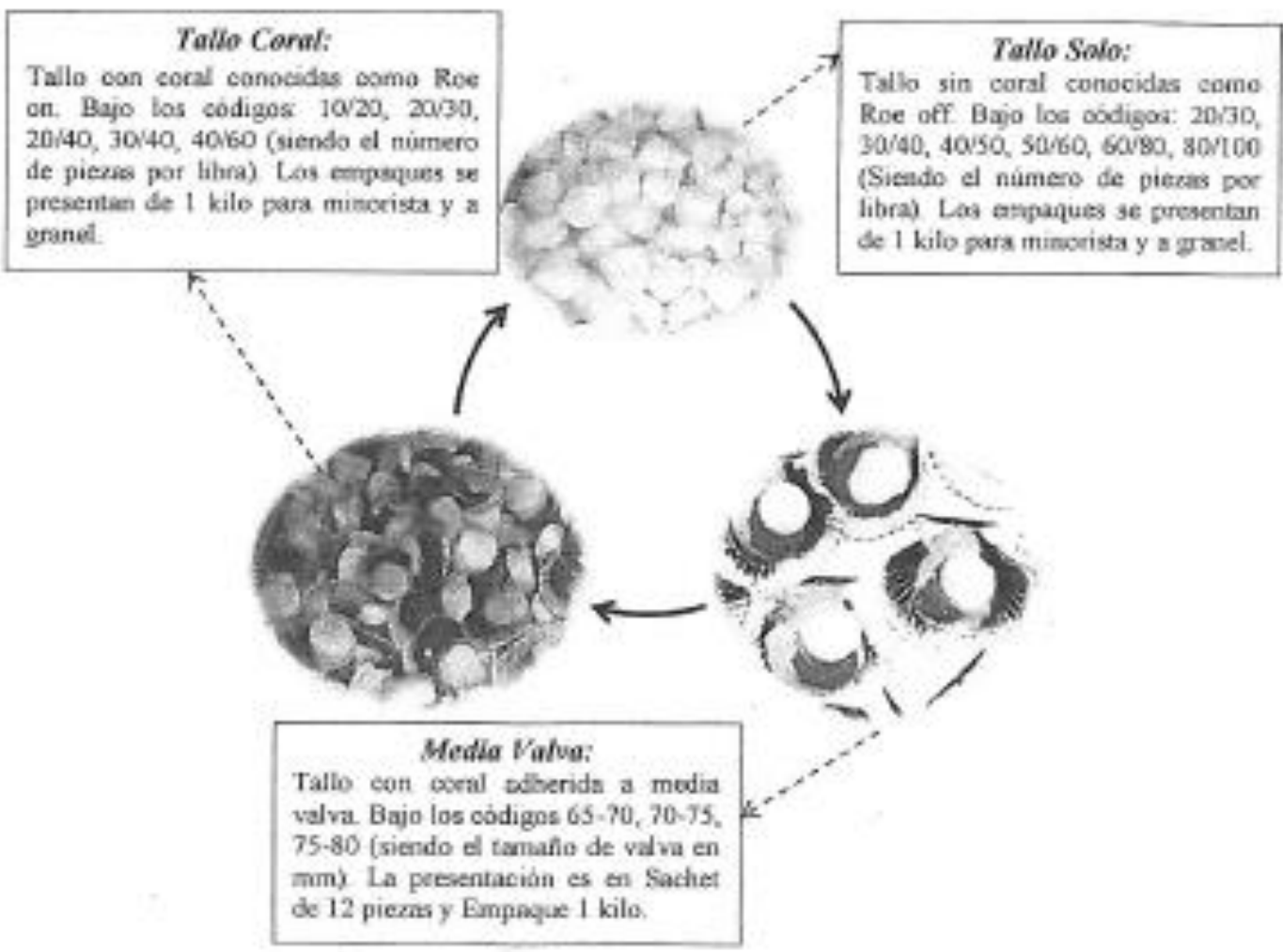

Fuente: Análisis de la cadena de valor de la concha de abanico en la bahía de Sechura (2017) 


\section{Anexo N5: Tasa de Riesgo Perú}

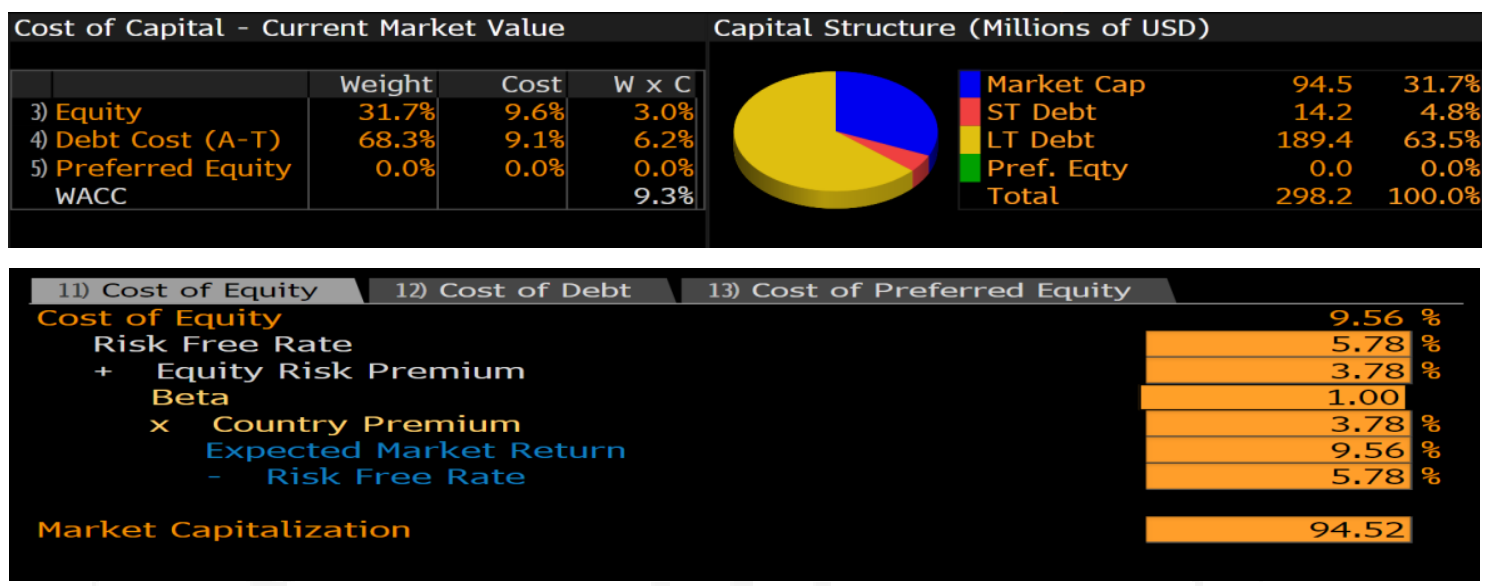

Fuente: Bloomberg (2018) 